\title{
WestVirginiaUniversity
}

THE RESEARCH REPOSITORY @ WVU

Graduate Theses, Dissertations, and Problem Reports

2006

\section{Pitch foam production by use of physical blowing agents}

Mark E. Heavner

West Virginia University

Follow this and additional works at: https://researchrepository.wvu.edu/etd

\section{Recommended Citation}

Heavner, Mark E., "Pitch foam production by use of physical blowing agents" (2006). Graduate Theses,

Dissertations, and Problem Reports. 1732.

https://researchrepository.wvu.edu/etd/1732

This Thesis is protected by copyright and/or related rights. It has been brought to you by the The Research Repository @ WVU with permission from the rights-holder(s). You are free to use this Thesis in any way that is permitted by the copyright and related rights legislation that applies to your use. For other uses you must obtain permission from the rights-holder(s) directly, unless additional rights are indicated by a Creative Commons license in the record and/ or on the work itself. This Thesis has been accepted for inclusion in WVU Graduate Theses, Dissertations, and Problem Reports collection by an authorized administrator of The Research Repository @ WVU. For more information, please contact researchrepository@mail.wvu.edu. 


\title{
Pitch Foam Production by Use of Physical Blowing Agents
}

\author{
Mark E. Heavner \\ Thesis submitted to the \\ College of Engineering and Mineral Resources \\ at West Virginia University \\ in partial fulfillment of the requirements \\ for the degree of \\ Master of Science \\ in \\ Chemical Engineering \\ John W. Zondlo, Ph.D., Chair \\ Rakesh K. Gupta, Ph.D. \\ Alfred H. Stiller, Ph.D. \\ Department of Chemical Engineering \\ Morgantown, West Virginia \\ 2006 \\ Keywords: \\ Pitch, Carbon Foam, Physical Blowing Agents
}




\section{Abstract \\ Pitch Foam Production by Uses of Physical Blowing Agents \\ Mark Heavner}

Carbon foam is a material with many unique characteristics and proposed applications. Demanding processing requirements make many of the applications uneconomical. In this study, the possibility of impressing external physical blowing agents (PBA) into pitch is investigated to form pitch foam, a precursor to carbon foam. This would reduce processing pressure and temperature requirements and decrease the cost of manufacturing. Two pitches have been characterized and have thermoplastic character similar to organic polymers. Several physical properties were measured for $110^{\circ} \mathrm{C}$ and $180^{\circ} \mathrm{C}$ softening point pitch which were supplied by Koppers Inc. and compared to select common polymers. PBAs are frequently used in industrial polymeric foam to produce cells within the melt. Introduction of PBAs into pitch melts, coupled with an induced thermodynamic instability, successfully yielded foams.

Variations of three polymeric foam process parameters, temperature, saturation pressure, and pressure release rate, in a batch process were examined to determine if the parameters qualitatively yield similar trends for pitch foam as for polymer foam. Results showed parallel trends of the variables with pressure release rate being the prominent variable. It is believed that ambient moisture present in the pitch coupled with $\mathrm{CO}_{2}$ and $\mathrm{N}_{2}$ PBAs may have a significant factor in cell formation. A simple extrusion setup was constructed in which pitch foam was successfully extruded. This investigation could lead to a novel and inexpensive route for the production of carbon foam. 


\section{Acknowledgements}

The author would like to thank his research advisor, Dr. John W. Zondlo for his continuous friendship and much patience in writing revisions. The author would like to extend his appreciation to the committee members, Dr. Alfred H. Stiller and Rakesh K. Gupta for guidance. Additionally, the author extends his thanks to Dr. Peter G. Stansberry, Mr. Elliot Kennel, Mr. David Statler, and Mr. Stephen Carpenter for their assistance.

Funding for this research was provided by Development of Continuous Solvent Extraction Processes for Coal Derived Carbon Products sponsored by US DOE, National Energy Technology Laboratory grant/contract No: DE-FC26-03NT41873.

The author expresses a special thanks to his parents for their encouragement, insight, and constant support without which this would not have been possible. 


\section{Table of Contents}

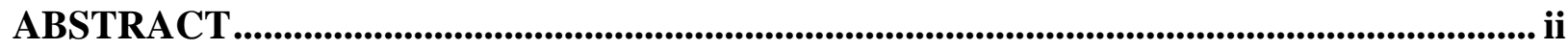

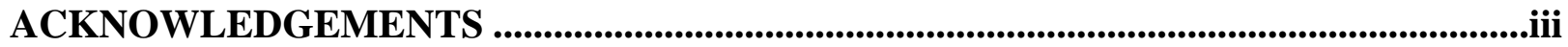

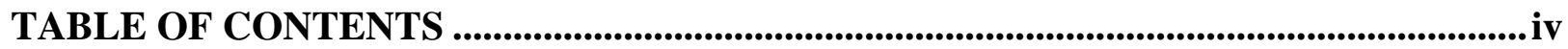

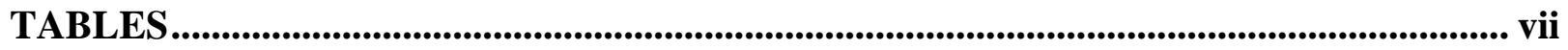

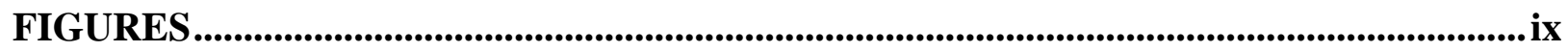

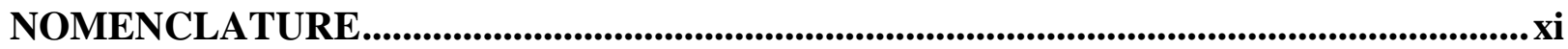

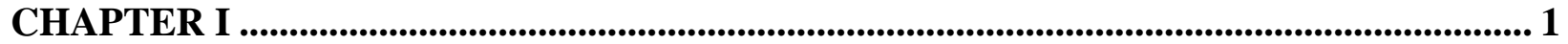

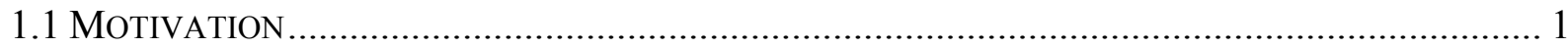

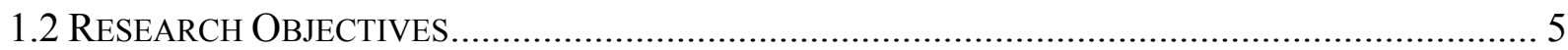

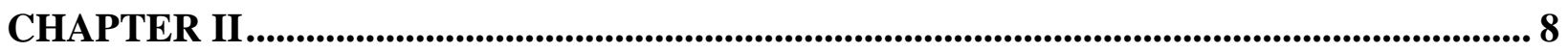

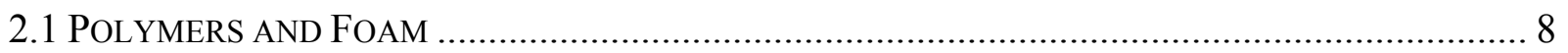

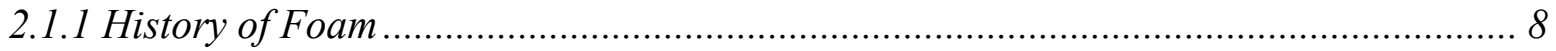

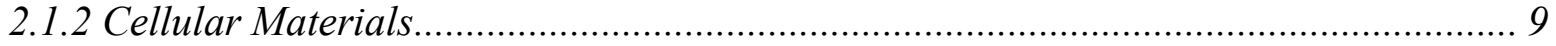

2.1.3 Polymer Foam Production ................................................................................... 13

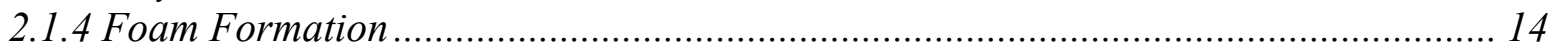

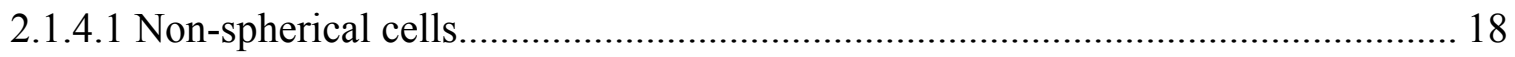

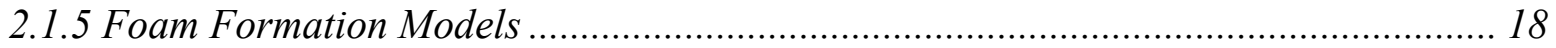

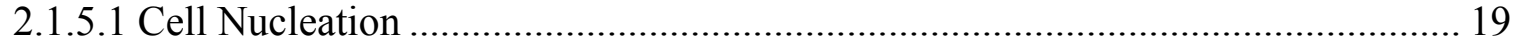

2.1.5.2 Foam Growth ......................................................................................... 21

2.1.5.3 Cell Coalescence and Coarsening .................................................................. 23

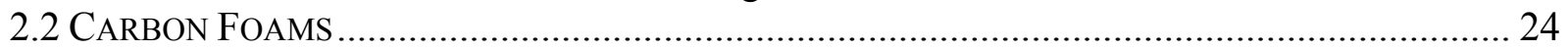

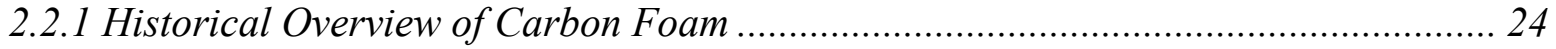

2.2.2 Carbon Foam Production Methods ....................................................................... 24

2.2.3 Taylorable Properties of Carbon Foam .................................................................. 25

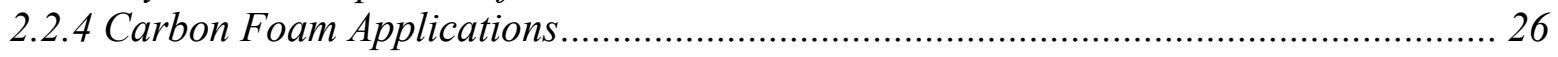

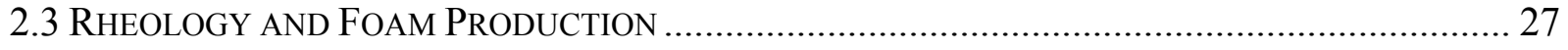

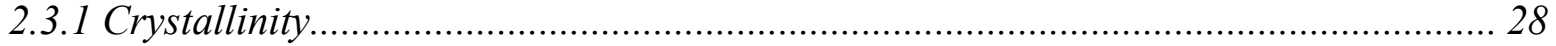

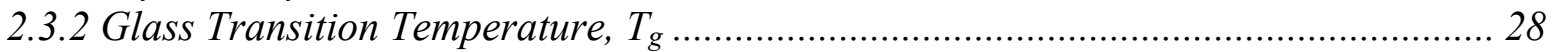

2.3.3 Metler Softening Point Correlation .................................................................... 30

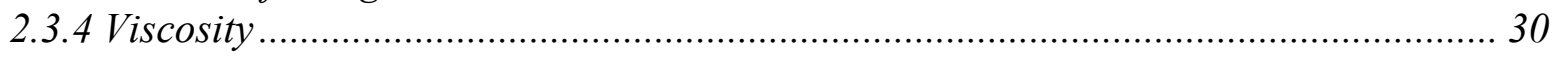

2.3.5 Plasticizing Effects of Dissolved Gases ....................................................... 31

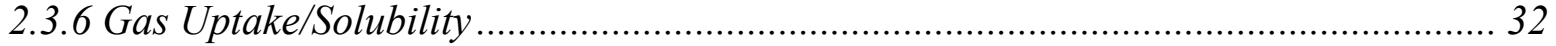

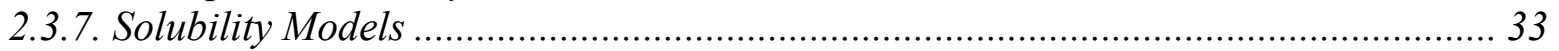

2.3.7.1 Sanchez-Lacombe Equation of State .......................................................... 34

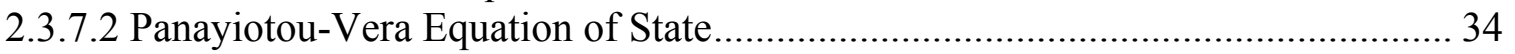

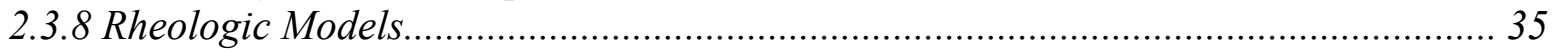

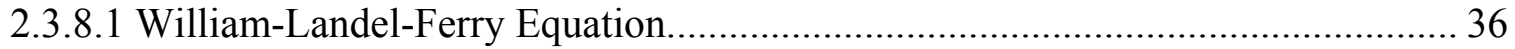

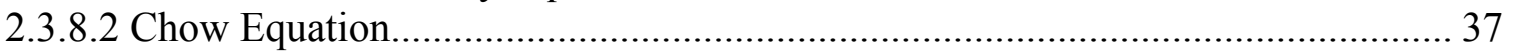

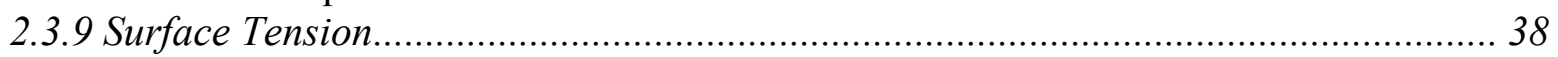

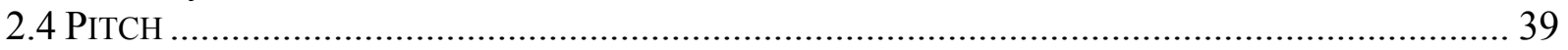




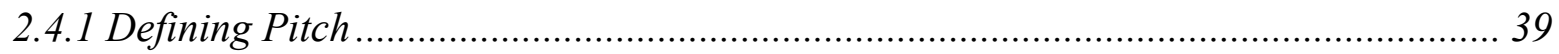

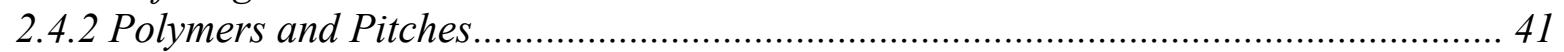

2.4.3 Pitch Thermoplastic Processing: Pitch Fibers .......................................................... 42

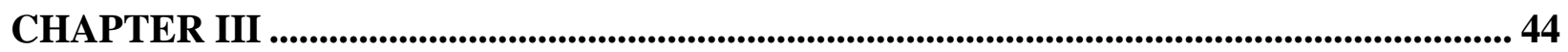

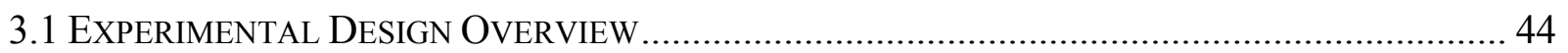

3.2 PROOF OF CONCEPT EXPERIMENT ……………………............................................... 44

3.3 Pitch Preparation AND Properties Tests ............................................................... 45

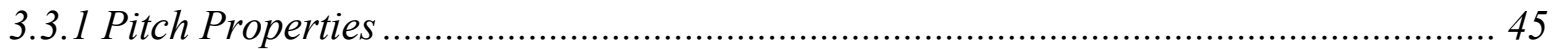

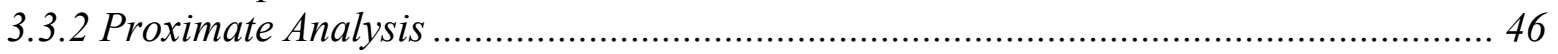

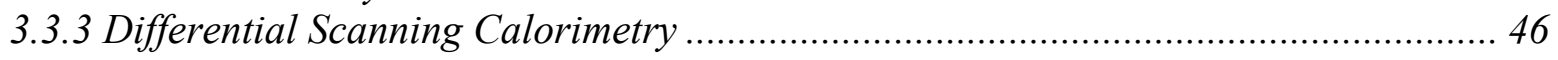

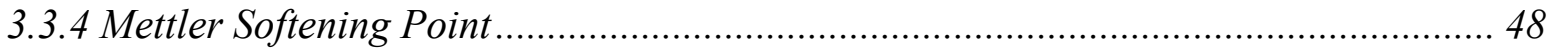

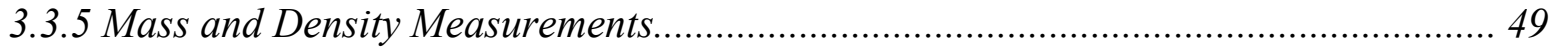

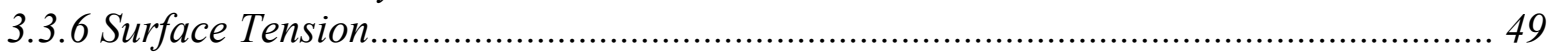

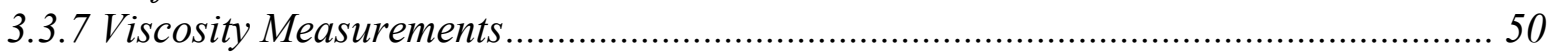

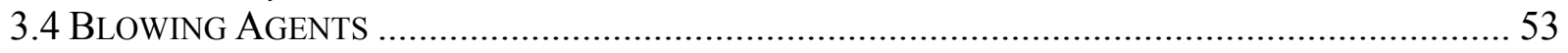

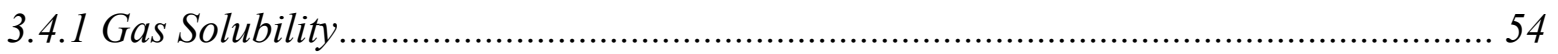

3.4.2 Reduction of Glass Transition by Blowing Agent ................................................. 55

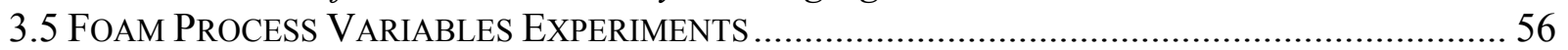

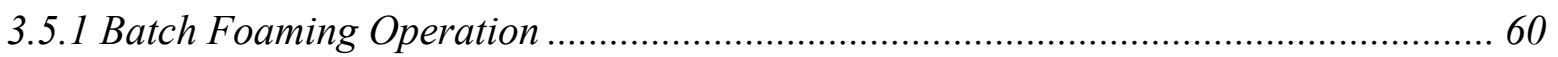

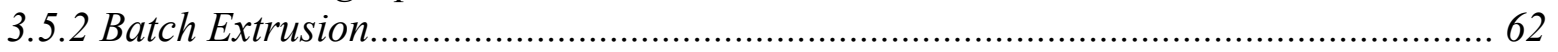

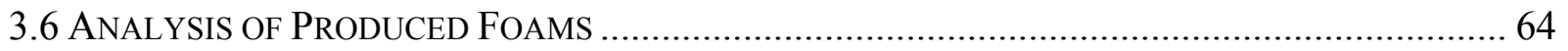

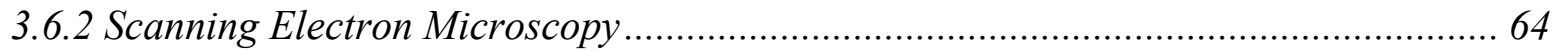

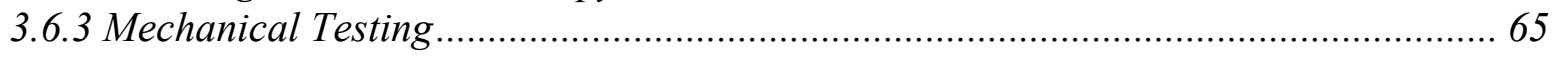

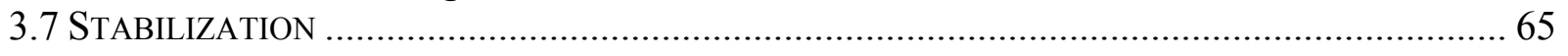

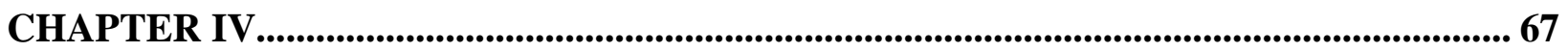

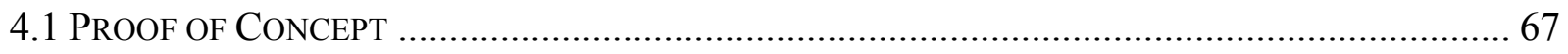

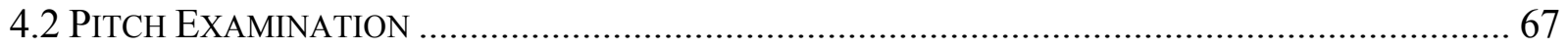

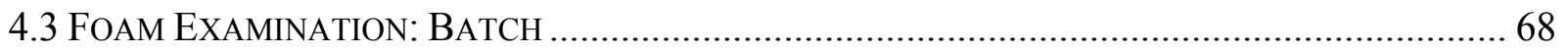

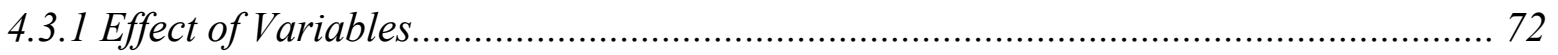

4.3.1.1 Nucleating Agents...................................................................................... 73

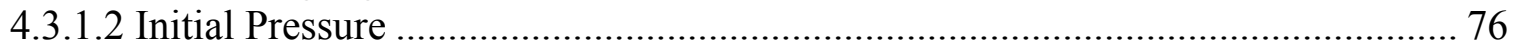

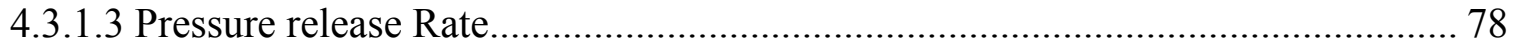

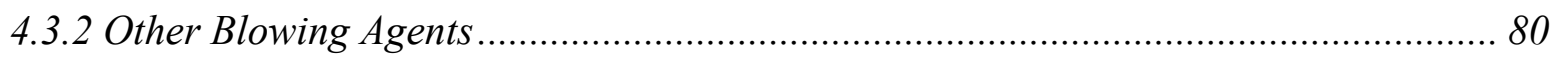

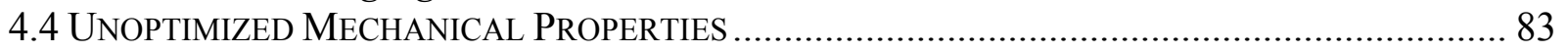

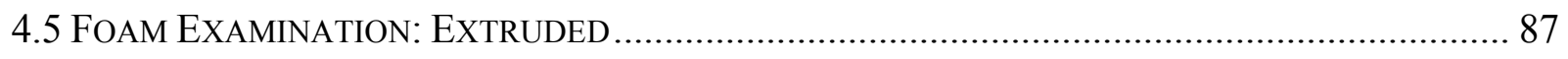

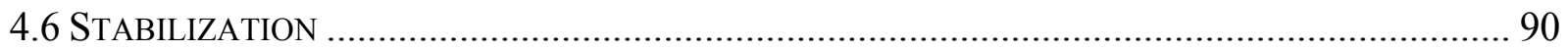

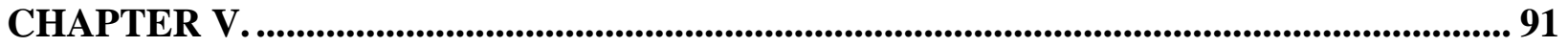

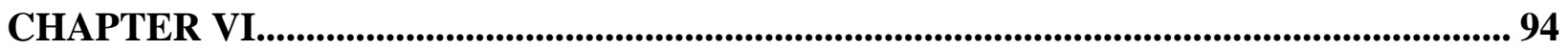

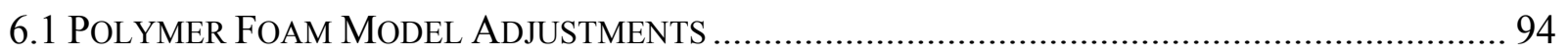

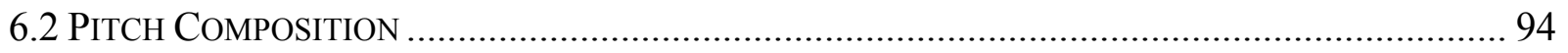

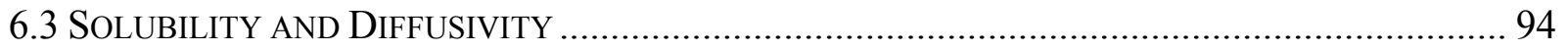

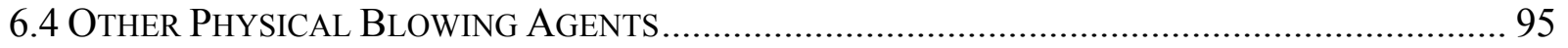

6.5 ADDITIVES TO PITCH FOAM ………………………………......................................... 95 


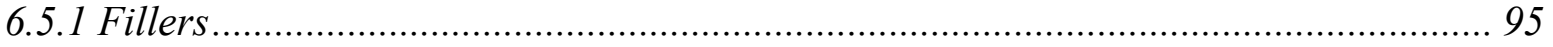

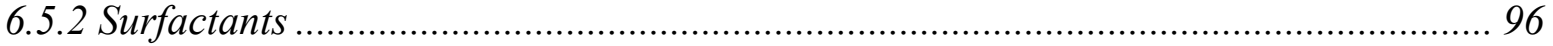

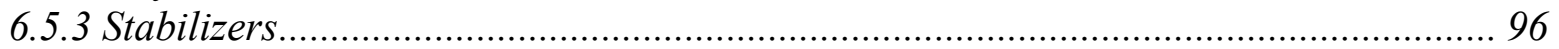

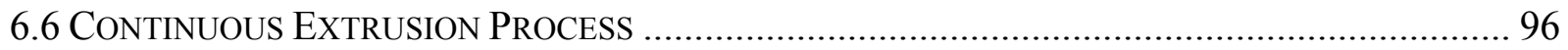

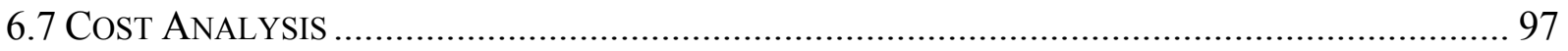

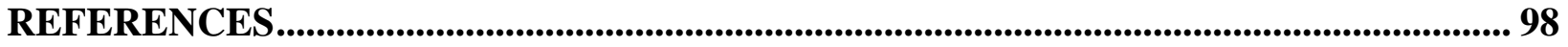

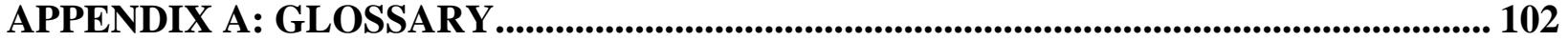

APPENDIX B: SAMPLE CALCULATIONS ............................................................... 104

APPENDIX C: RAW VISCOSITY DATA................................................................................. 105

APPENDIX D: PROXIMATE ANALYSIS RAW DATA ................................................... 107 


\section{Tables}

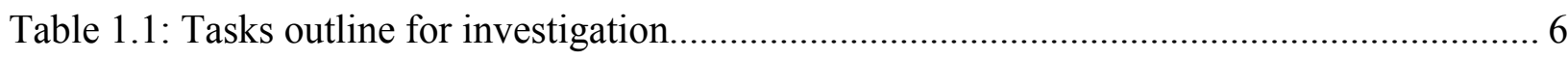

Table 2.1: Foam production in the United States (in Millions)............................................ 13

Table 2.2: Common foaming technologies and applicable polymers.................................... 14

Table 3.1: Planed sets of experiments................................................................................... 44

Table 3.2: Mean average proximate analysis of pitches used in experimentation expressed as

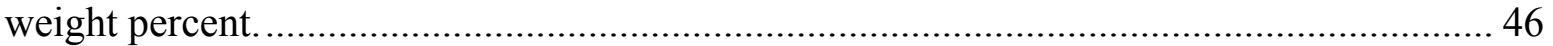

Table 3.3: Properties of Koppers Industries Inc. Coal Tar Pitch used in work. ........................ 47

Table 3.4: William-Ferry-Landel Equation constants and error............................................ 52

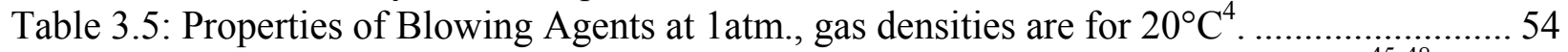

Table 3.6: Mass percentage of $\mathrm{CO}_{2}$ in select heavy petroleum fractions and bitumens ${ }^{45-48} \ldots \ldots . . .55$

Table 3.7: Reduction of glass transition temperature due to diluent predicted by Chow

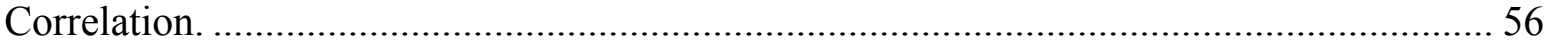

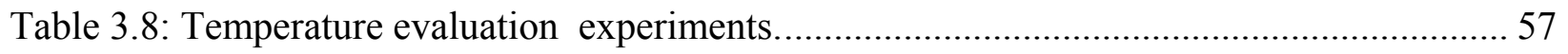

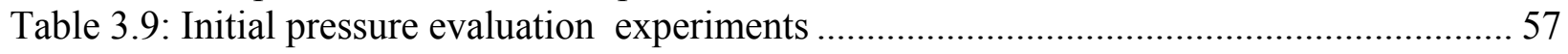

Table 3.10: Pressure release rate evaluation experiments. ......................................................... 58

Table 3.11: Evaluation of other blowing agents experiments...............................................5

Table 3.12: Evaluation sample runs for mechanical testing. ................................................... 59

Table 3.13: Sample Talc weight percent example ............................................................... 59

Table 3.14: Complete experimental variable matrix. A specific matrix is given for each variable

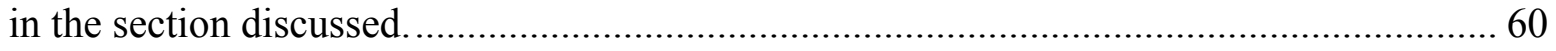

Table 4.1: Comparison of the two coal tar pitches with some common polymers ${ }^{10} . M_{p}$ is the molecular weight of the repeat unit of the molecule........................................................ 68

Table 4.2: Common boiling, fusion points, and vapor pressure (from Antoine equation) at $155^{\circ} \mathrm{C}$

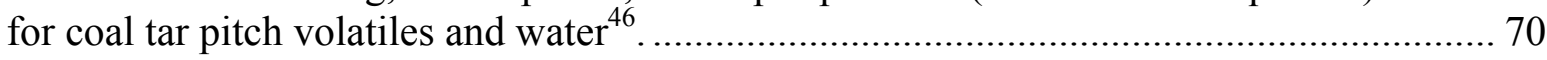

Table 4.3: Change in volume per gram of blowing agent at $155^{\circ} \mathrm{C}$ from a pressure release from 215 psia to 15 psia from NIST phase data ${ }^{46}$ and mass of blowing agent needed per mass of pitch to reduce bulk density from $1.3 \mathrm{~g} / \mathrm{ml}$ to $0.66 \mathrm{~g} / \mathrm{cm}^{3}$ assuming isothermal conditions and

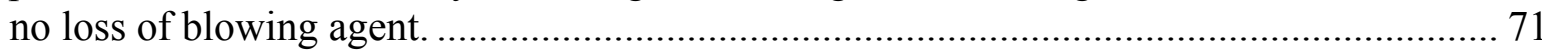

Table 4.4: Bulk density variation of samples at increasing temperature (decreasing viscosity) and cell size range of a $110^{\circ} \mathrm{C}$ softening point pitch foamed under 200 psig of $\mathrm{CO}_{2}$.............. 76

Table 4.5: Bulk density of samples and cell size range with increasing overpressure of $\mathrm{CO}_{2}$ for foam from the $180^{\circ} \mathrm{C}$ softening point pitch produced at $155^{\circ} \mathrm{C}$ and $\sim 16 \mathrm{psi} / \mathrm{sec}$ pressure release rate. ............................................................................................. 78

Table 4.6: Bulk density variation with pressure release rate for a $180^{\circ} \mathrm{C}$ softening point pitch

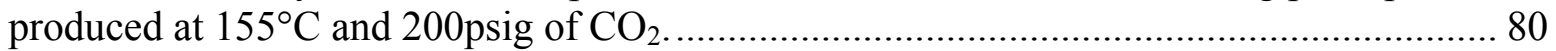

Table 4.7: Pitch foam process conditions and mechanical properties for samples produced for mechanical testing using $\mathrm{CO}_{2}$ as the blowing agent. ........................................... 83

Table 4.8 Comparison of sample pitch foams from Table 4.7 with carbon foam from Touchstone Research Laboratories and Poco Graphite Incorporated and graphite foam from Materials and Electrochemical Research using test method developed by Carpenter. 
Table 4.9: Comparison of properties of pitch foam samples from Table 4.7 to carbon foam properties reported by Koppers Inc. and Touchstone Research Laboratories using unspecified compression tests for commercially available carbon foams sorted by bulk density

Table 5.1: Qualitative relationships between experimental variables and how each effects foam

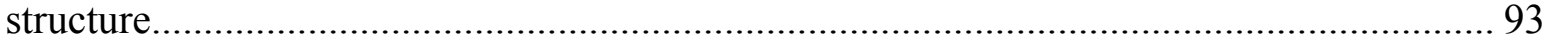




\section{Figures}

Figure 1.1:Composite consisting of carbon foam, balsa wood, fiberglass, and epoxy ${ }^{2}$.............. 1 Figure 1.2: Machineability of carbon foam ${ }^{2}$.................................................................... 2

Figure 2.1: Relative comparison of cellular solid (left) and solids with isolated pores (right)... 10 Figure 2.2: Comparative view of open celled and closed celled foam. Left: open cell alumina foam $^{12}$, right: closed cell pitch foam produced at West Virginia University...................... 11

Figure 2.3: Range of properties available to engineers through foaming ${ }^{5}$. ............................. 12

Figure 2.4: Relationships between parameters in a continuous extrusion foaming process using $\mathrm{CO}_{2}$ as the blowing agent ${ }^{10}$.

Figure 2.5: Electrical resistivity versus heat treatment temperature for carbon foam produced in reference ${ }^{18}$

Figure 2.6: Estimated specific modulus/property chart of pitch-based carbon foam and competing materials ${ }^{14}$. 26

Figure 2.7: Comparison of viscosity profiles for Bingham plastic, Newtonian, and power law fluids (shear thickening \& thinning). 31

Figure 2.8: $\mathrm{CO} 2$ solubility in polystyrene at different pressures and temperatures (the thick line on the surface is the $\left.\mathrm{T}_{\mathrm{g}}\right)$.

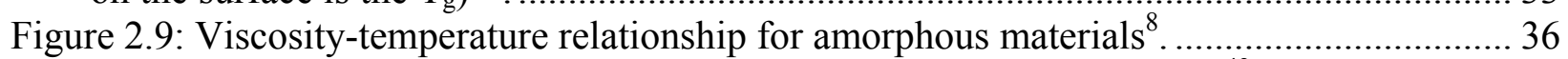

Figure 2.10: Manufacturing process schematic for pitch-based carbon fibers ${ }^{43}$, for oxidation and graphitization processes, $\mathrm{N}$ stands for inert atmosphere (nitrogen)............................... 43

Figure 3.1: DSC of $110^{\circ} \mathrm{C}$ softening point pitch displaying the glass transition....................... 47

Figure 3.2: DSC of $110^{\circ} \mathrm{C}$ softening point pitch displaying the melting point. ....................... 48 Figure 3.3: Viscosity curves for $180^{\circ} \mathrm{C}$ Softening Point Coal Tar Pitch at $170^{\circ} \mathrm{C}, 180^{\circ} \mathrm{C}$, and $190^{\circ} \mathrm{C}$.

Figure 3.4: William-Landel-Ferry fit of a $110^{\circ} \mathrm{C}$ softening point coal tar pitch at a shear rate of $10 \mathrm{sec}^{-1}$ fitted by Oakdale Engineering's DataFit version 6.1.10 software.

Figure 3.5: William-Landel-Ferry fit of a $180^{\circ} \mathrm{C}$ softening point coal tar pitch at a shear rate of $10 \mathrm{sec}^{-1}$ fitted by Oakdale Engineering's DataFit version 6.1.10 software. ....................... 53

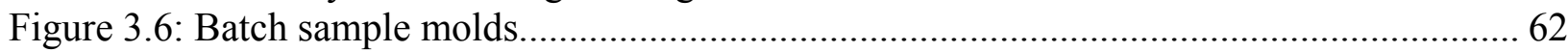

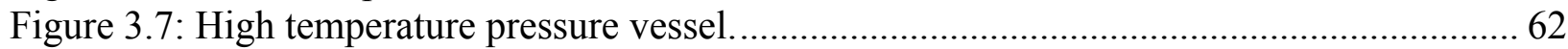

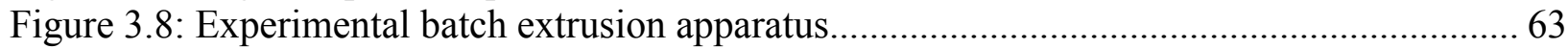

Figure 4.1: Voids present in some of pitch foam samples, possibly due to shock during removal from kiln..... 72

Figure 4.2: No distinguishable difference between pitch with and without talc for a talc concentration of the same order of magnitude as ash present in the pitch. $110^{\circ} \mathrm{C}$ softening point pitch foam at $90^{\circ} \mathrm{C}$ and $200 \mathrm{psig}$, Left: no talc, Right: $1.9 \mathrm{wt} \%$ talc. 74

Figure 4.3: SEM of sample $1\left(110^{\circ} \mathrm{C} \mathrm{SP}\right.$ pitch foam prepared at $95^{\circ} \mathrm{C}$ and 200 psig of $\left.\mathrm{CO}_{2}\right) \ldots . . .75$ Figure 4.4: SEM of sample $2\left(110^{\circ} \mathrm{C} \mathrm{SP}\right.$ pitch foam prepared at $100^{\circ} \mathrm{C}$ and 200 psig of $\left.\mathrm{CO}_{2}\right) \ldots 75$ Figure 4.5: SEM of sample $3\left(110^{\circ} \mathrm{C} \mathrm{SP}\right.$ pitch foam prepared at $105^{\circ} \mathrm{C}$ and 200 psig of $\left.\mathrm{CO}_{2}\right) \ldots 76$ Figure 4.6: SEM of sample $5\left(180^{\circ} \mathrm{C} \mathrm{SP}\right.$ pitch foam prepared at $155^{\circ} \mathrm{C}$ and 80 psig of $\left.\mathrm{CO}_{2}\right) \ldots . . .77$ Figure 4.7: SEM of sample $6\left(180^{\circ} \mathrm{C} \mathrm{SP}\right.$ pitch foam prepared at $155^{\circ} \mathrm{C}$ and 150 psig of $\left.\mathrm{CO}_{2}\right) \ldots .77$ Figure 4.8: SEM of sample $8\left(180^{\circ} \mathrm{C} \mathrm{SP}\right.$ pitch foam prepared at $155^{\circ} \mathrm{C}$ and $220 \mathrm{psig}$ of $\left.\mathrm{CO}_{2}\right) \ldots .78$ 
Figure 4.9: SEM of sample $7\left(180^{\circ} \mathrm{C}\right.$ SP pitch foam prepared at $155^{\circ} \mathrm{C}, 220 \mathrm{psig}$ of $\mathrm{CO}_{2}$ and

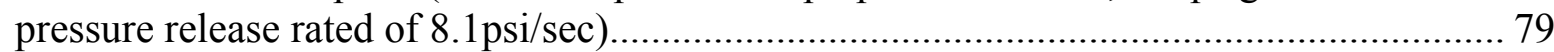

Figure 4.10: SEM of sample $8\left(180^{\circ} \mathrm{C}\right.$ SP pitch foam prepared at $155^{\circ} \mathrm{C}, 220 \mathrm{psig}$ of $\mathrm{CO}_{2}$ and

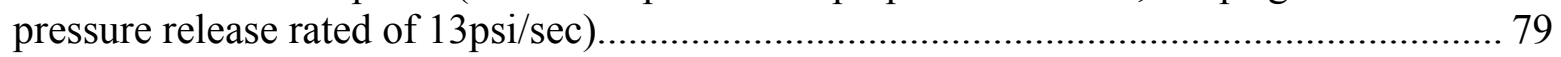

Figure 4.11: SEM of sample $9\left(180^{\circ} \mathrm{C} \mathrm{SP}\right.$ pitch foam prepared at $155^{\circ} \mathrm{C}, 200 \mathrm{psig}$ of $\mathrm{CO}_{2}$ and

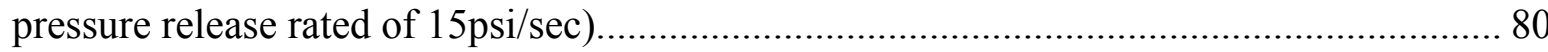

Figure 4.12: SEM of sample $4\left(110^{\circ} \mathrm{C}\right.$ softening point pitch foam produced at $90^{\circ} \mathrm{C}, \mathrm{dP} / \mathrm{dt}$ of $20 \mathrm{psi} / \mathrm{sec}$, and 200psig of $\mathrm{N}_{2}$ ).

Figure 4.13: SEM of sample $1\left(110^{\circ} \mathrm{C}\right.$ softening point pitch foam produced at $95^{\circ} \mathrm{C}, \mathrm{dP} / \mathrm{dt}$ of 22psi/sec, and 200psig of $\left.\mathrm{CO}_{2}\right)$..... 81

Figure 4.14: SEM of sample $10\left(180^{\circ} \mathrm{C}\right.$ softening point pitch produced at $150^{\circ} \mathrm{C}, \mathrm{dP} / \mathrm{dt}$ of

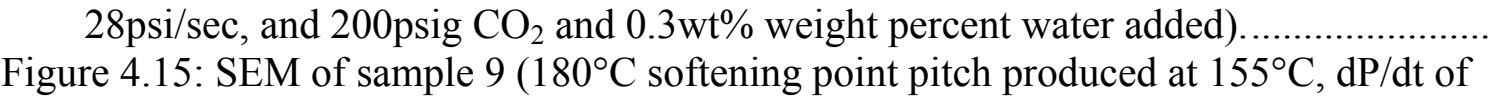
82

$15 \mathrm{psi} / \mathrm{sec}$ and $\left.180 \mathrm{psig} \mathrm{CO}_{2}\right) \ldots$
Figure 4.16: Compressive Stress St 82 sample 11. Figure 4.17: Compressive Stress Strain Curves for two $0.52 \mathrm{~g} / \mathrm{cm} 3$ pitch foam samples from

\section{sample 12 .}

Figure 4.18: Compressive Stress Strain Curves for two $0.77 \mathrm{~g} / \mathrm{cm}^{3}$ pitch foam samples from

Figure 4.19: Compressive Stress Strain Cures for two $0.80 \mathrm{~g} / \mathrm{cm}^{3}$ pitch foam samples from

Figure 4.20: Extrusion test with a $110^{\circ} \mathrm{C}$ softening point pitch extruded at approximately $106^{\circ} \mathrm{C}$ 86

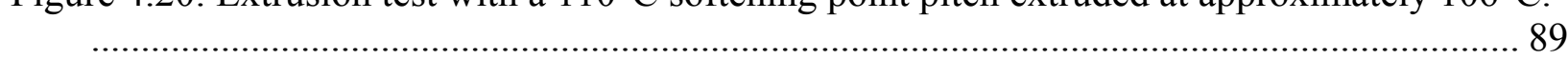

Figure 4.21: Foam expansion upon exiting the experimental extrusion apparatus at 106C and 540 psig of $\mathrm{N}_{2}$ on a $110^{\circ} \mathrm{C}$ softening point pitch. 


\section{Nomenclature}

\begin{tabular}{|c|c|}
\hline A & Area \\
\hline $\mathrm{b}$ & Affinity respectively \\
\hline $\mathrm{c}$ & Blowing agent concentration \\
\hline $\mathrm{c}_{1}, \mathrm{c}_{2}$ & Constants \\
\hline CBA & Chemical blowing agents \\
\hline $\mathrm{C}_{\mathrm{L}}$ & Langmuir capacity \\
\hline $\mathrm{D}$ & Diffusion coefficient \\
\hline DCFC & Direct carbon conversion fuel cell \\
\hline DSC & Differential Scanning Calorimetry \\
\hline $\mathrm{E}$ & Elastic modulus \\
\hline EOS & Equation of state \\
\hline $\mathrm{E}_{\mathrm{v}}$ & $\begin{array}{l}\text { Activation energy for viscosity } \\
\text { equation }\end{array}$ \\
\hline $\mathrm{f}$ & Frequency factor \\
\hline $\mathrm{F}$ & Surface energy \\
\hline $\mathrm{G}$ & Gibbs free energy \\
\hline $\mathrm{k}$ & Boltzmann constant \\
\hline $\mathrm{m}$ & Mass of a gas molecule \\
\hline $\mathrm{N}$ & Nucleation rate \\
\hline $\mathrm{N}$ & $\begin{array}{l}\text { Number of external contacts present } \\
\text { in the system }\end{array}$ \\
\hline $\mathrm{P}$ & Pressure \\
\hline $\mathrm{k}_{\mathrm{H}}$ & Henry's law constant \\
\hline $\mathrm{P}^{*}$ & Critical point characteristic pressure \\
\hline $\mathrm{P}_{1}$ & Pressure within the melt \\
\hline $\mathrm{P}_{\infty}$ & Bulk pressure \\
\hline PAN & Polyarcrylonitrile \\
\hline $\mathrm{P}_{\mathrm{b}}$ & Pressure in the cell \\
\hline PBA & Physical blowing agent \\
\hline PEM & Proton exchange membrane \\
\hline $\mathrm{P}_{\mathrm{g}}$ & Initial pressure in a cell \\
\hline $\mathrm{P}-\mathrm{V}$ & Panayiotou-Vera EOS \\
\hline q & Effective chain length \\
\hline $\mathrm{R}$ & Gas-polymer interface radius \\
\hline$r$ & Radial coordinate \\
\hline $\mathrm{R}_{\mathrm{f}}$ & Cell outer radius, \\
\hline $\mathrm{R}_{\mathrm{g}}$ & Ideal gas constant \\
\hline SEM & Scanning Electron Micrograph \\
\hline SH & Superheat \\
\hline S-L & Sanchez-Lacombe EOS \\
\hline SP & Metler softening point \\
\hline$t$ & Foam growth time \\
\hline
\end{tabular}

$\mathrm{T}^{*} \quad$ Critical point characteristic temperature

$\mathrm{T}_{\mathrm{c}} \quad$ Crystallization temperature

$\mathrm{T}_{\text {foam }}$ Temperature foamed

$\mathrm{T}_{\mathrm{g}} \quad$ Glass transition temperature

$\mathrm{T}_{\mathrm{g} 0} \quad$ Glass transition temperature without diluent

$\mathrm{T}_{\mathrm{m}} \quad$ Melting temperature

$\mathrm{T}_{\mathrm{MS}} \quad$ Mettler Softening Point Temperature

$\mathrm{T}_{\mathrm{s}} \quad$ Reference temperature

$\mathrm{v}^{*} \quad$ Critical point characteristic volume

of a lattice site

$\mathrm{V}_{\mathrm{r}} \quad$ Radial component of velocity

WFL William-Ferry-Landel Equation

$\mathrm{Z} \quad$ Finite coordination number

$\mathrm{z} \quad$ Lattice constant

$\gamma \quad$ Surface tension

$\Delta \mathrm{C}_{\mathrm{p}} \quad$ Heat capacity

$\Delta \mathrm{G}^{*} \quad$ Activation energy to sustain a bubble

$\eta \quad$ Viscosity

$\eta_{0} \quad$ Viscosity

$\eta_{\mathrm{s}} \quad$ Reference viscosity

$\theta \quad$ Fraction of total external contacts in the system that are mer-mer contacts in a random array of molecules and holes

$\rho^{*} \quad$ Critical point characteristic density

$\rho_{\mathrm{f}} \quad$ Density of foam

$\rho_{g} \quad$ Density of the blowing agent

$\rho_{p} \quad$ Density of the polymer

$\rho_{\mathrm{s}} \quad$ Density of original material

$\sigma \quad$ Rate of strain tensor

$\varsigma$ Shear rate

$\sigma \quad$ Shear stress

$\tau_{(1)}$ Convected time derivative of the stress tensor

$\tau_{\gamma \gamma} \quad$ Stress in the radial direction

$\tau_{\theta \theta} \quad$ Stress in the circumferential direction

$\varphi \quad$ Relative density

$\omega \quad$ Mass fraction 


\section{Chapter I \\ Introduction}

\subsection{Motivation}

Carbon foam is a relatively new material that has a broad range of tailorable properties, such as density, thermal and electrical conductivity, and heat and fire resistance ${ }^{1}$. In addition it can be bonded with a wide range of common adhesives (Figure 1.1). It is easily machineable (Figure 1.2) and has a Young's modulus comparable to wood at $1 / 3$ rd to $1 / 5$ th the density of wood. Some of the proposed applications include fire-proof ship decking and bulkheads, impact mitigation for aircraft and automobiles, structural panels and firewalls, low radar signature parts, good EMI shielding panels, high-performance electrodes in fuel cells, abrasion resistant panels, composite tooled parts, and in aerospace thermal management systems ${ }^{2,3}$.

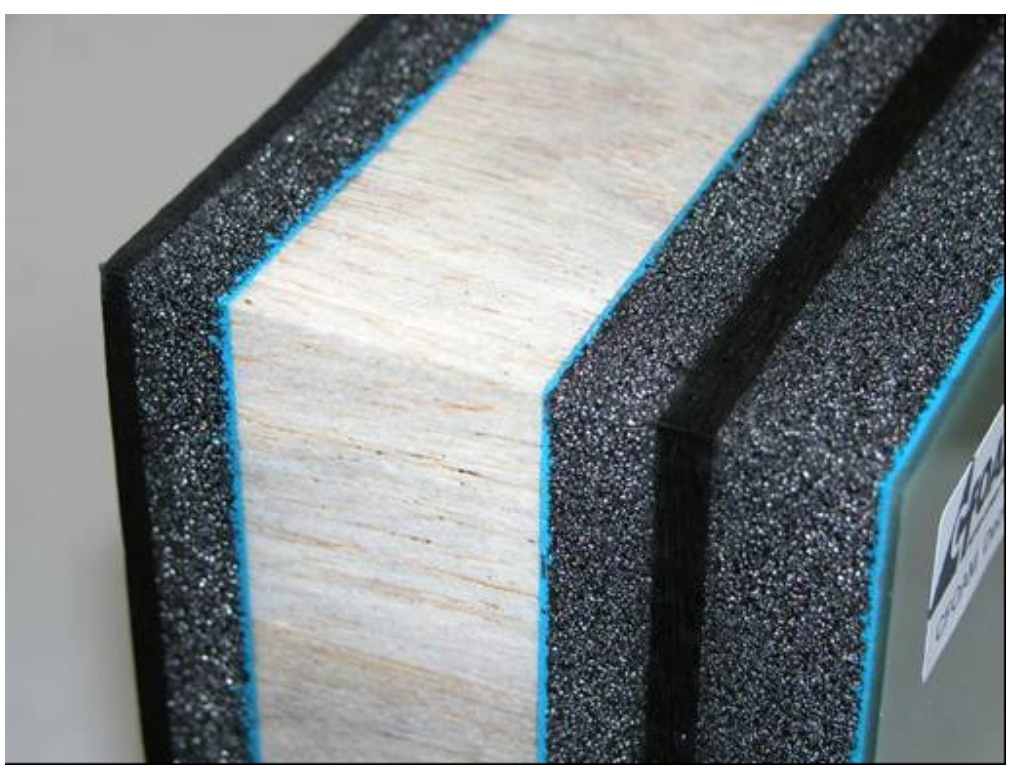

Figure 1.1:Composite consisting of carbon foam, balsa wood, fiberglass, and epoxy ${ }^{2}$. 


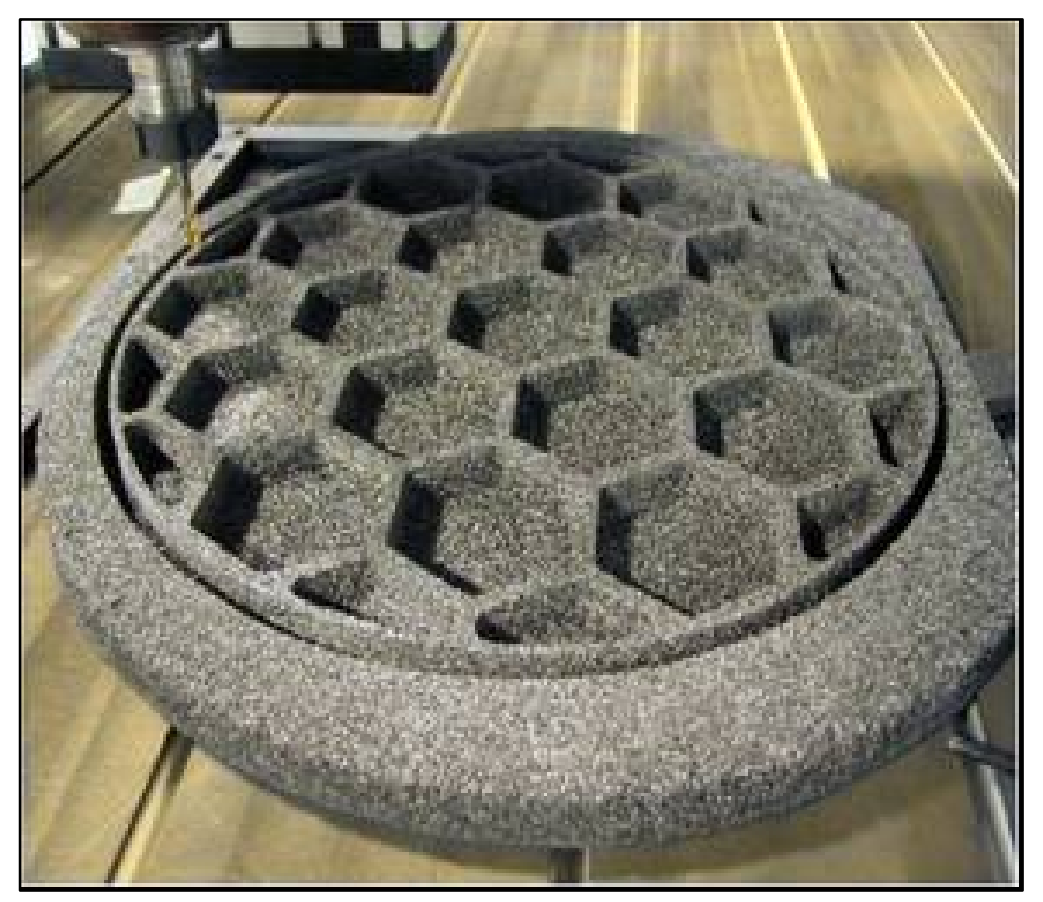

Figure 1.2: Machineability of carbon foam².

Currently, the primary disadvantage of carbon foam is cost. A large percentage of that cost is due to the manufacturing processes and equipment. The cost of carbon foam currently starts at approximately $\$ 10 / \mathrm{in}^{3}$ and increases depending on properties and processing. A number of the proposed applications may be commercially viable if carbon foam were available at lower cost. The production of pitch foam, a potential precursor of carbon foam, could be an alternative that yields less expensive carbon foam. Pitch foam and carbon foam are made from the same precursor. Through further processing, similar to that of converting pitch fibers to carbon fibers, pitch foam can be converted into carbon or graphite foams.

The motivation of this project is two fold: (1) to explore a possible alternative production method of carbon foam by use of pitch foam as a precursor and (2) to develop possible novel production methods for pitch foam by borrowing techniques for foaming thermoplastic polymers to reduce equipment requirements. 
One of the developments in material science during the 1930's was the production of synthetic urethane and vinyl polymeric foam ${ }^{8}$. Since that time, many other polymers have been successfully converted into foams and the processing steps have been further refined. Using polymeric foaming developments, other materials were produced in foam form. Some of theses materials include metals and metal alloys, silicon oxide, carbon and graphite. Carbon and graphite foams are of much interest due to their good mechanical performance and tailorable properties ${ }^{1}$. This has spawned a myriad of proposed applications that range from impact adsorptive panels to high performance heat sinks and nonconductive thermal insulation.

The production of carbon foam is fairly specialized and capital intensive. This is manly due to the high thermal and pressure requirements in the manufacturing process. Currently, carbon foam is produced by two different methods. The first uses a suitable polymeric foam which is subsequently pyrolysized. The pyrolysis often requires significant amount of time at elevated temperatures. The second method involves heating coal, coal tar or petroleum pitch under pressure. The heating process softens the starting material, causes vaporization of volatile content in the starting material and decomposition of some of the side chains to form gases. These volatiles act as an imbedded blowing agent. High pressure prevents the volatiles from escaping, resulting in cell formation in the solid matrix. This results in significant increase in bulk volume. In this way, the volatile matter acts similarly to a chemical blowing agent in polymeric foam. While vaporization is occurring, the remaining higher molecular weight molecules cross-link (carbonize) to solidify and stabilize the bulk structure. Again, this process requires significant lengths of time at elevated temperature, and, depending upon the process conditions, elevated pressure to retain the volatile components in the matrix material. 
The addition of additives known as blowing agents is common for several foaming processes in the production of polymeric foams ${ }^{4}$. Blowing agents are commonly gases that are soluble in the polymer melt or compounds that undergo thermal decomposition to produce gas during process conditions. The blowing agents are used to produce a supersaturated solution upon the reduction of pressure and/or increase in temperature. Because of the thermodynamic instability, bubbles, termed cells for foam materials, are formed in the melt. If the cells remain upon solidification of the material, the resulting material is a cellular solid, and is commonly referred to as foam. From a technical standpoint, a foam is $1 / 3^{\text {rd }}$ or less the bulk density of the parent material ${ }^{5}$.

The use of $\mathrm{CO}_{2}, \mathrm{~N}_{2}$, and water as physical blowing agents (PBA) has gathered much interest as alternatives to chlorofluorocarbons (CFC) and hydrochlorofluorocarbons (HCFC). CFCs and HCFCs, which were the choice physical blowing for many years, have come under increasing environmental regulation due to their ozone depleting chemistry in the atmosphere. $\mathrm{CO}_{2}$ and $\mathrm{N}_{2}$ have also received interest due to plasticizing effects (i.e. lowering of the glass transition temperature, softening point, and viscosity) seen during processing. This plasticization effect can reduce processing expenses. The plasticization effect was seen with CFCs but, is more prominent with lower molecular-weight blowing agents and diluents. These effects are due to the influence that blowing agents have on the free volume of the polymer and real dilution effect on the polymer.

There are many similarities between molten pitches and polymer melts. Some of the characteristics that both have in common include: macro-organic molecules, molecular weight distributions, and amorphous to semi-crystalline morphologies. Due to the molecular weight range, polymers and pitches both have comparable rheologic profiles with a majority showing 
shear thinning character. Additionally, process temperature of several polymers falls in the same temperature range as that of several grades of pitch.

One of the primary differences between pitches and polymers is in the molecular skeleton. Most polymers consist of long chains of molecules, with varying degrees of branching and/or side groups, which are often characterized as strings or lines, whereas pitches are primarily composed of napthene aromatics, polar aromatics, and asphaltenes. The molecules in pitches tend to be more planar or globular in structure. In polymer theory, polymers are often modeled as spherical or globular wrapping forms, particularly for amorphous morphology and in certain solvents. Thus it may be that these polymer models may are suited to modeling pitches as well.

\subsection{Research Objectives}

This work will investigate if pitch foam can be produced in a fashion similar to that of thermoplastic polymeric foam. This would require that pitch, the blowing agents in the pitch, and the thermodynamic process be similar to that of thermoplastic polymers. Prior to this work, no use of an external blowing agent to produce pitch foam has been reported. The introduction of an external blowing agent is usually less thermally intensive than that of vaporizing internal volatile mater. Successful foam manufacture by blowing agents could reduce the cost of manufacturing carbon foam.

The main objectives of this research are given below with details:

1. Verify if pitch foam can be produced with physical blowing agents

2. Examine current polymer foaming theory and practice

3. Compare properties of select polymers and pitches

4. Test applicability of pitch foaming by subjecting pitch to foaming process variables 
5. Evaluate pitch foam samples

6. Suggest further refinement in theoretical understanding of foaming pitch with physical blowing agents

7. Recommend methods for further applicability to foaming pitch

The research objectives will be carried out in five rounds of experimentation and literature review with the findings reported (Table 1.1).

Table 1.1: Tasks outline for investigation.

\begin{tabular}{|c|l|l|}
\hline Step & \multicolumn{1}{|c|}{ Activities } & \multicolumn{1}{|c|}{ Anticipated Results } \\
\hline 1 & $\begin{array}{l}\text { Verify if pitch foam can be produced } \\
\text { with PBA, Objective 1 }\end{array}$ & Proceed to steps 2 and 3 if successful \\
\hline 2 & Evaluate pitch properties, Objective 2 & $\begin{array}{l}\text { Compare to literature values of select } \\
\text { polymers }\end{array}$ \\
\hline 3 & $\begin{array}{l}\text { Literature review and comparison of } \\
\text { polymers, polymeric foaming and } \\
\text { pitch, Objectives 2, 3, and 4 }\end{array}$ & $\begin{array}{l}\text { Compare select polymers and pitch, } \\
\text { and identify key foam control } \\
\text { variables, proceed to step 4 }\end{array}$ \\
\hline 4 & $\begin{array}{l}\text { Test and compare effects of key } \\
\text { variables of foaming, Attempt pitch } \\
\text { foam extrusion, Objectives 5 and 6 }\end{array}$ & $\begin{array}{l}\text { Observe if trends are similar for } \\
\text { polymer and pitch foaming, Verify if } \\
\text { similar processing possible, Proceed to } \\
\text { Step 5 }\end{array}$ \\
\hline 5 & Compile report, Objectives 5 and 6 & Report findings \\
\hline
\end{tabular}

The first round of experimentation is to examine if pitch foam production is possible. If production is not possible, further investigation would be fruitless. With positive results, research would progress to the next objective.

The second objective of the present study is to examine current polymer foaming theory and production practices, specifically the use of physical blowing agents (gaseous and liquid), the blowing agent solubility and equilibrium fraction and how the physical blowing agents affect the rheology of the melt. Key polymeric foam production variables will also be identified.

The third objective is to evaluate properties of pitch identified as key properties for polymers foaming. Some of the evaluated properties of selected pitch include viscosity, heat capacity, proximate analysis, and glass transition. From the examination of polymer theory and 
practices, an assessment of their applicability to foam pitch will be made. This will include a comparison of melt rheology, surface tension, and effects of physical blowing agents on the melt. In objective four, samples will be produced by a batch method to qualitatively compare the effect of select process variables (temperature, pressure, pressure-drop rate, and nucleating agent) on pitch foam. A test apparatus will be constructed for extrusion to observe if pitch foam can be produced in a manner similar to that of polymer extrusion. The experiments will utilize $\mathrm{CO}_{2}, \mathrm{~N}_{2}$, and $\mathrm{H}_{2} \mathrm{O}$ as physical blowing agents. Talc, a common polymer nucleating agent, will be used at various mass fractions.

In objective five, the pitch and foam samples will be examined under optical and scanning electron microscopes (SEM) to quantify the morphology and cell structure. The size, size range, shape of the cells, and whether the cells are open or closed in nature will be examined in that manner. Parallel trends of the variables will be looked for between polymer foaming trends listed in literature and that of the produced pitch foam. Mechanical properties of the pitch foam will also be examined, but not optimized in this work. The focus of the project is on the production and quantification of cells formed within pitch foam rather than on the evaluation and optimization of their mechanical properties. Gibson and Ashby and others ${ }^{5-7}$ have quantified the mechanical properties of foam from structure and these resources could be used for a theoretical evaluation of the mechanical properties. Objectives seven and eight will be addressed once the findings of this work are determined. 


\section{Chapter II}

\section{Literature Review}

The literature review is focused on the three major areas. The first is an examination of current polymer foaming practices, particularly with respect to physical blowing agents. The second is a review of the physical properties of pitch and how temperature, pressure and soluble blowing agents affect its properties. The third is a review of polymer foaming theory with a focus on parameters that are quantifiable and are shared by both pitches and polymers.

\subsection{Polymers and Foam}

With the increased availability and application of polymers, various techniques are employed to enhance their properties and thereby reduce quantities needed for equivalent performance. By adding inexpensive fillers (glass, minerals, etc.), polymer producers are able to partially attain both goals. The use of gas as a filler was a natural progression to increase performance to weight ratio in polymers.

\subsubsection{History of Foam}

Some of the earliest documented foams were naturally occuring foams, such as corkwood and sea sponges which, from Horace's Odes were in use as early as $27 \mathrm{BC}$. The first reports of synthetic foams were studies by Dr. Baekeland (early 1900's) in which he was actually trying to produce nonporous resins of phenol and formaldehyde ${ }^{8}$ but instead made cellular solids. In the late 1920's, production began on natural latex foam and it was soon being employed as cushioning on London buses ${ }^{8}$. Urethane and vinyl foams came under much development in Germany during the mid-1930s, though their production was hampered by the lack of suitable blowing agents. By the end of World War II, vinyl foam had come into common use for a variety of applications in Germany. The production of urethane and vinyl foams was quickly followed by that of polystyrene (PS) ${ }^{9}$. During the later $40 \mathrm{~s}$ and into the $50 \mathrm{~s}$, researchers interested in 
phenol and silicone resins found that they were foamable, and commercial production of both began soon thereafter. In the $60 \mathrm{~s}$ and $70 \mathrm{~s}$, the processes were further refined, new plastics were developed and additional blowing and molding techniques were introduced. During this time chlorofluorocarbons (CFC's) became a common physical blowing agent in the industry. Today, the list of foamable polymers includes those already listed along with polypropylene (PP), polyethylene (PE), polyvinyl chloride (PVC), polyphenylene (PPE), polyesters, polycarbonate (PC), and Teflon ${ }^{10}$.

In the mid-70s, investigations of CFC's, a major class of physical blowing agents, were shown to cause severe detrimental affects to the earth's ozone layer. Phase-out initiatives were soon introduced to reduce the amount of CFCs released. In 1987 the Montreal Protocol called for reduction of CFCs by 50\% from 1987 production-day values by the year 2000 . The Montreal Protocol was amended five years later and called for the end of CFC production in industrial countries by $1996^{4}$. This led to major investigations into alternative blowing agents for foam manufacture. Some of the alternatives were inert gases, new chemical blowing agents, low molecular weight hydrocarbons and hydrochloroflurocarbons (HCFC's), though HCFC's are currently being phased-out also. Each of them presented technical difficulties to production methods at that time, but many of the difficulties have since been overcome.

\subsubsection{Cellular Materials}

The dispersion of voids or bubbles, known as cells, in solid materials results in the formation of a two-phase system and has lead to the development of a class of materials called cellular solids ${ }^{5}$, commonly known as foams. The gas phase can be considered as a filler or extender of the solid phase ${ }^{8}$. The gas filler markedly extends the solid properties toward a lower solid property limit ${ }^{11}$. The majority of the mechanical properties for cellular materials are derived 
from the solid material while the gas phase plays a significant part in the thermal properties. It has been proposed that the presence of micron and smaller sized cells do not seriously disrupt the continuity of the solid matrix and thus mechanical properties vary only slightly with reduced weight till a critical point is reached ${ }^{11}$.

Cellular materials can be made from numerous feedstocks, including polymers, metals, and ceramics. True cellular solids are usually considered to be materials that are less than $1 / 3$ of the bulk density of the original solid material ${ }^{5}, \rho_{\mathrm{s}}$. Equation 2.1 quantifies this effect where, $\varphi$ is the relative density and $\rho_{\mathrm{f}}$ is the bulk density of the foamed material. Materials above the $30 \%$ relative density, but still below that of the solid material are properly termed solids containing isolated pores (Figure 2.1 for relative comparison).

$$
\varphi=\frac{\rho_{f}}{\rho_{s}}
$$
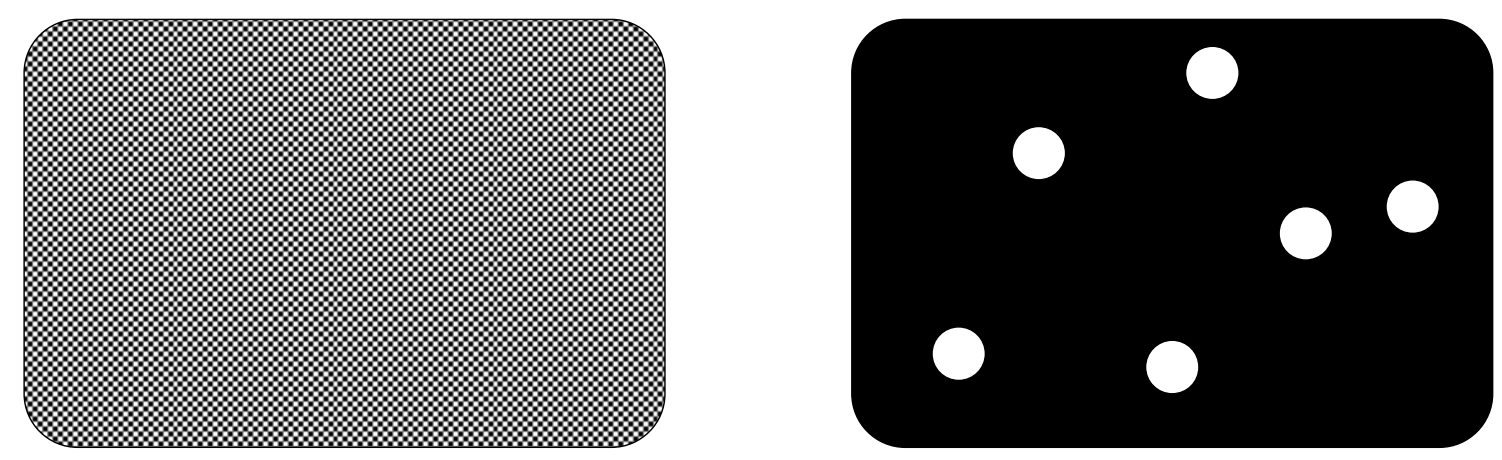

Figure 2.1: Relative comparison of cellular solid (left) and solids with isolated pores (right).

Cellular solids can be ideally organized into two basic groups. The first consisting of a two-dimensional matrix of polygons, often called a honeycomb matrix. The other consists of a three-dimensional matrix, and is known as foam. In the literature, foams are often represented as idealized pentagonal dodecahedrons, though this is rarely true in reality. Foam can be further divided into two subgroups: closed cell and open cell (Figure 2.2) depending upon cell wall 
structure. The cell walls or membranes between the cells in closed cell foams remain intact and do not allow flow through the foam. In open cell foam, the membranes between cells have ruptured leaving a basic skeleton or strut type structure. The cell structure in real world foam is often some combination of open and closed cells which is characterized as percent open or closed cells.
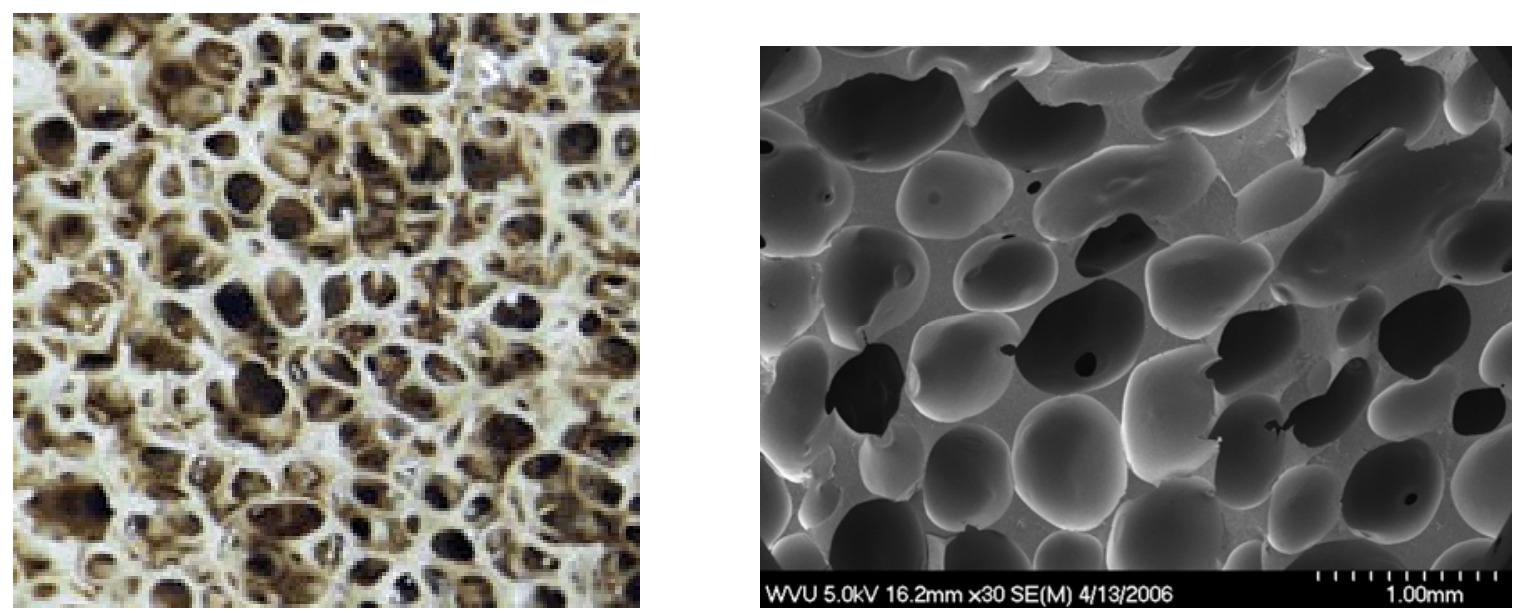

Figure 2.2: Comparative view of open celled and closed celled foam. Left: open cell alumina foam ${ }^{12}$, right: closed cell pitch foam produced at West Virginia University.

Both rigid and flexible cellular solids can be produced. The degree of rigidity or flexibility of the cellular solid depends on the solid material's glass transition temperature, chemical composition, polymer backbone, degree of crystallinity, and degree of cross linking ${ }^{8}$. The glass transition temperature, $T_{g}$, is the temperature at which some molecules achieve partial mobility within the material, (further detail is given in Section 2.3.2 Glass Transition Temperature, $\mathrm{Tg}$ ). The $\mathrm{T}_{\mathrm{g}}$ of polymers needs to be below room temperature to produce a flexible foam. For polymers that have $\mathrm{T}_{\mathrm{g}}$ above room temperature, it may be possible to produce flexible foam if the proper plasticizers are used to reduce the $T_{g}$ below room temperature.

Cellular materials are an area of much interest due to their extension of the material properties of the solid. A majority of interest comes from the density reduction and material 
savings in comparison with marginally diminished strength, Young's Modulus, conductivity

(Figure 2.3) and improved energy absorption.
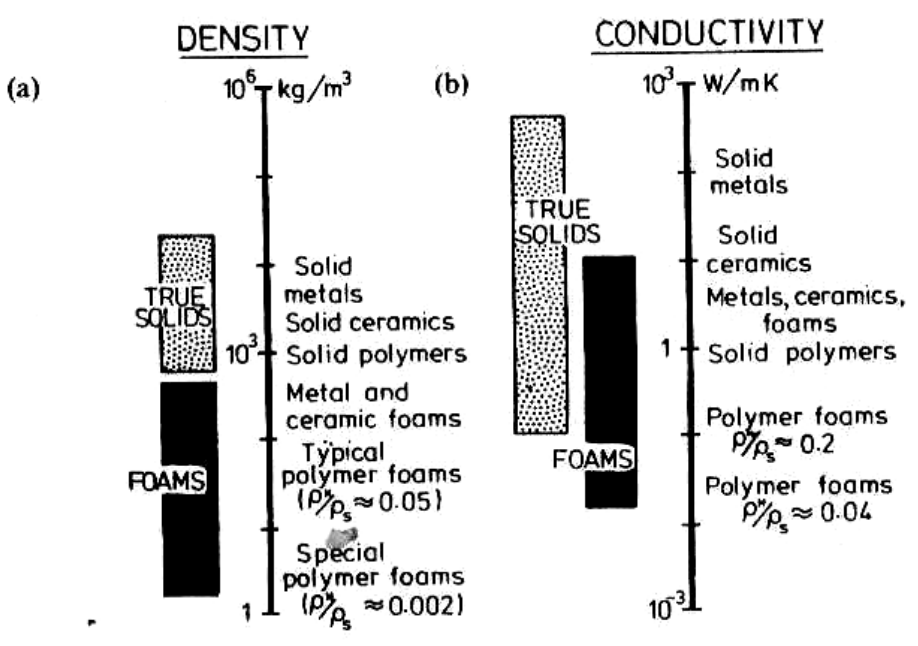

\section{YOUNGS MODULUS}

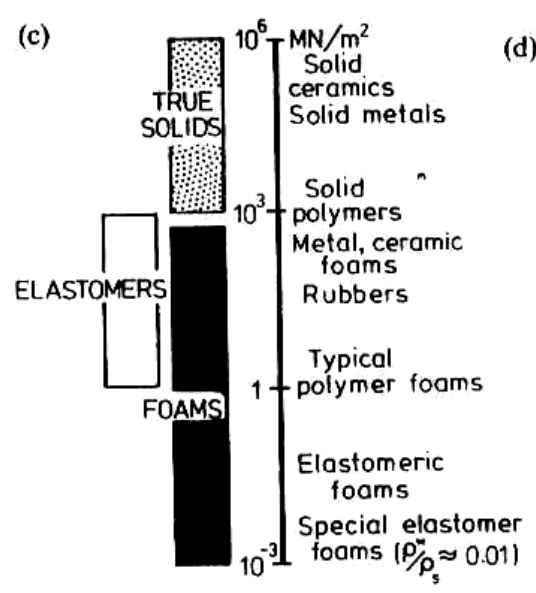

\section{STRENGTH}

(d)

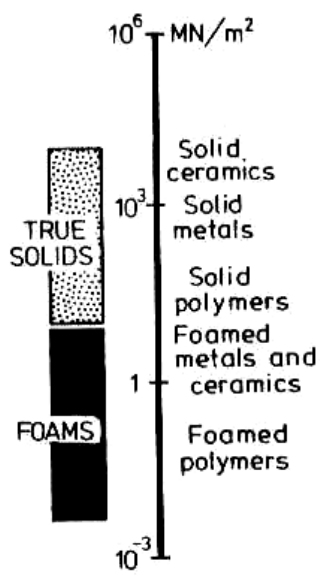

Figure 2.3: Range of properties available to engineers through foaming 5

The increased surface area afforded by foam is also of interest for both catalysis and thermal management. Major areas where these enhanced properties have found application are in thermal insulation, packaging, structural components, and flotation devices. Gibson and Ashby in their text Cellular Solids ${ }^{5}$, go into much detail in describing the theoretical basis for understanding and predicting properties of cellular solids and is an excellent reference on the subject. 
It is interesting to note that the size, shape, flexibility, and amount of interconnecting cells directly determine the physical properties of the foam, but the application for the foam directs which type of cell structure is desired. For example, a closed cell structure is desirable for thermal insulation while an open cell is desired for acoustic insulation.

\subsubsection{Polymer Foam Production}

Since the advent of producing polymeric foams by means of batch processes, many continuous processes have been developed to increase production rate and reduce cost. Foam has made inroads into a diverse variety of applications. Due to continued development of foam properties, total demand has steadily increased (Table 2.1) to over 3.7 million tons per year in the United States in 2001 and this number is expected to continue to increase for the near future. In 1993, foam accounted for $31 \%$ of total polystyrene and $7.7 \%$ of all plastic consumed in Japan.

Table 2.1: Foam production in the United States (in Millions).

\begin{tabular}{|l|cccc|}
\hline \multicolumn{1}{|c}{ Item } & $\mathbf{1 9 7 5}^{\mathbf{8}}$ & $\mathbf{1 9 8 7}^{\mathbf{1 1}}$ & $\mathbf{1 9 9 6}^{\mathbf{1 1}}$ & $\mathbf{2 0 0 1}^{\mathbf{1 1}}$ \\
\hline Total Foamed Plastics Demand (millions of lbs.) & 2,633 & 4,558 & 6,325 & 7,420 \\
Urethanes & 1,330 & 2,363 & 3,325 & 3,910 \\
Polystyrene & 600 & 1,316 & 1,676 & 1,900 \\
Other Polymers & 703 & 879 & 1,324 & 1,620 \\
Total Foamed Plastics Demand (millions \$) & N/A & 6,850 & 12,100 & 16,200 \\
\hline
\end{tabular}

There are several production methods in use today (Table 2.2) to manufacture foam from a myriad of polymers and polymer/additive mixtures. Continuous extrusion is a method of producing large quantities of foam quickly, usually in slab stock or rod form. This method can mix both physical and chemical blowing agents and other additives into the melt during the processing phase. Injection molding couples the continuous extrusion method with a mold to produce complex foam shapes. 
Table 2.2: Common foaming technologies and applicable polymers.

\begin{tabular}{|l|l|}
\hline Production Method & Applicable Thermoplastics \\
\hline Extrusion & PS, PVC, PE, PP, PVOH \\
\hline Molded Beads & PS, PP, PE \\
\hline Injection Molding & ABS, PC, PPO \\
\hline Reactive Injection & PU, UF \\
\hline Mechanical Blending & PU, UF, Elastomers \\
\hline
\end{tabular}

\subsubsection{Foam Formation}

In forming foam, two events must take place sequentially, independent of the solid matrix material. The first is the formation of large numbers of bubbles in the melt. This involves increasing the surface free energy of the foaming material system. The second is stabilization of the melt before the bubbles collapse or escape (i.e. reach the surface free energy minimum of the foaming material system).

The progression from a homogeneous uniform material into one containing voids with controlled dimensions can be daunting. Naturally produced foams such as sea sponges and cork grow with the voids present, while sea foam is mechanically churned or frothed by wind and wave motion. While natural foams can be interesting and of some use, they often are not available in quantities or qualities that are economically viable. For this reason several industrial production techniques have been developed to introduce bubbles into the precursor materials. The developed techniques include: mechanical whipping or frothing of a liquid, expansion of dissolved gas(es) in a melt, flash vaporization of low-boiling liquids in a melt, volatilization of gas-producing compounds within a melt, incorporation of insoluble salts into a melt which are later removed, and the incorporation of hollow beads (microspheres) ${ }^{8}$ which remain in the final product. 
The mechanical frothing techniques are usually used with low viscosity liquids that have low energy requirements to stir at high rates. An example of frothing to produce a foam is beating egg whites to form meringue for pies. Incorporating hollow beads or insoluble salts is a sure way of producing solids containing voids. Once the melt is stabilized, the beads or salt remain and can result in additional concerns for each. For the beads, the foam matrix instead of being a single solid phase is now a two-phase solid in which surface interactions of the two materials need to be considered. For salts, the difficulty comes in the removal of the salts without damaging the foam matrix. Salts have been used successfully in the production metal foams. Both the frothing technique and the incorporation of microspheres are of limited usefulness for polymer melts due to processing and cost constraints.

A majority of polymeric foam is produced by incorporating soluble gases, low-boiling point liquids, or compounds that decompose to form gases during heating. Theses additives are usually referred to as blowing agents. The purpose of the blowing agent is to saturate the melt with gas at low temperature or elevated pressure. Gases produced by decomposition of molecules in the processing temperature range, are known as a chemical blowing agents, while gas or liquids added directly to the melt and dispersed by diffusion or mechanical agitation of the melt are known as physical blowing agents. The purpose of these additives is to cause a thermodynamic instability, specifically a supersaturated gas state, within the melt upon temperature rise or pressure release. Bubbles are formed to bring the system back into a metastable thermodynamic state.

Chemical blowing agents usually decompose to produce $\mathrm{CO}_{2}, \mathrm{~N}_{2}, \mathrm{CO}, \mathrm{H}_{2} \mathrm{O}, \mathrm{NH}_{3}$, $\mathrm{HCHO}, \mathrm{SO}_{2}$, or some combination thereof. Some common chemical blowing agents are azodicarbonamide (ADC), zinc carbonate, and citric acid derivatives ${ }^{4}$, but just about any 
compound that has a well-defined decomposition temperature and produces a soluble gas in the processing range can be used.

Physical blowing agents are usually introduced in a continuous process at some predetermined point and mechanically mixed to form a single-phase mixture. At elevated pressures, melts sustain higher equilibrium concentrations of soluble gas. Through an extrusion process, the pressure is reduced to near ambient conditions, which results in a thermodynamic instability (supersaturation) in the melt. If the instability is produced rapidly, bubbles will be spontaneously generated following classical homogeneous and heterogeneous nucleation models as in batch liquid processes. The supersaturated gas in the melt expands forming voids, and results in both pressure and temperature reductions to regain thermodynamic equilibrium. The most common currently used physical blowing agents in the polymer foam industry are $\mathrm{CO}_{2}, \mathrm{~N}_{2}$, water, and low molecular weight hydrocarbons. Liquid blowing agents (e.g. water and low molecular weight hydrocarbons) are usually added with the polymer pellets. During processing, both the temperature and pressure are raised. The pressure is raised in order to maintain the blowing agents in a liquid state. For water, this results in the formation of an emulsion. Upon release of pressure, the blowing agents vaporize, and diffuse out of the melt. By controlling the viscosity, blowing agent concentration, and pressure release rate, the cell structure can be optimized $^{13}$.

It has been shown that the presence of fine, dispersed solid particles, known as nucleating agents, greatly aid in increasing bubble formation by reducing the level of supersaturation needed before bubbles form ${ }^{14}$. This phenomenon has been likened to the addition of boiling chips to aqueous solutions, in that it provides an irregular surface on which bubbles can nucleate. The use of nucleating agents has led to the production of more and smaller cells in foam. 
In extrusion processes, in addition to the above nucleation phenomenon, shear nucleation of bubbles can also occur. The shear nucleation can be caused by cavitation of the screw in the melt and cavities along the barrel of the extruder. Shear nucleation has been studied and modeled, but is very much dependent upon the operation and condition of the equipment.

Once a bubble is formed it must satisfy the stability equation (Equation 2.2), otherwise the gas in the bubble will be reabsorbed into the melt. In Equation 2.2, $\Delta \mathrm{P}$ is the vapor pressure gradient from the bubble to the melt, $\gamma$ is the surface tension of the melt, and $\mathrm{R}$ is the radius of the bubble. Nucleation of new bubbles will continue till the supersaturation is sufficiently reduced to favor bubble growth over new bubble formation. At this point, diffusion becomes the dominant means of reducing the remaining supersaturated gas.

$$
\Delta \boldsymbol{P} \geq \frac{2 \gamma}{R}
$$

Once diffusion becomes dominant, the nucleated bubbles begin to expand till $\Delta \mathrm{P}=2 \gamma / \mathrm{r}$. When the gas concentration reaches equilibrium, bubbles can only grow by diffusion of gas from smaller bubbles, where the pressure gradient is greater than in larger bubbles, coalescence of adjacent bubbles, or by the exothermic expansion of the gas in the bubble. These growth mechanisms act to further reduce the free surface energy of the melt system by following Equation 2.3 where $\Delta \mathrm{F}$ is the surface energy, $\gamma$ is the surface tension, and $\mathrm{A}$ is the total surface area the bubbles.

$$
\Delta \boldsymbol{F}=\gamma \boldsymbol{A}
$$

As can clearly be seen from Equations 2.2 and 2.3, the surface tension is a significant factor in both the formation of bubbles and the free energy needed for foam systems. By reducing the surface tension of the material melt, the pressure gradient (i.e. the concentration of 
gas) and the free energy input requirements are reduced resulting in bubble formation sooner and greater transient stability for smaller bubble formation.

\subsubsection{Non-spherical cells}

Frequently, cells are not spherical in nature. In highly-expanded, open or closed cell foams, the cells exhibit polyhedron structure due to the interaction with adjacent cells. The cell structure is often idealized as pentagonal dodecahedrons for modeling the mechanical properties. Foams formed in a mold or in pressure gradient fields often exhibit ellipsoid-shaped cells. In this case, the ellipsoidal behavior is due to pressure interactions on either side of the cell during growth. The ellipsoidal growth was seen to be retarded through increasing both initial pressure of cell formation and viscosity of the bulk melt ${ }^{14}$.

\subsubsection{Foam Formation Models}

Several researchers have modeled foam formation and growth to give quantitative insight into production. The foaming process has been simplified into three major events: (1) cell nucleation, (2) cell growth, and (3) cell coalescence with temperature, pressure, surface tension, heat and momentum transfer, diffusion, gas solubility and viscosity as variables. Tomasko et al. in their literature review outline the finding for many of the variables and their relationship to one another for a $\mathrm{CO}_{2}$ based blowing of polymeric foam (Figure 2.4) ${ }^{10}$. They identified three major variables that influenced the polymer properties, nucleation and growth mechanisms. These were: temperature, pressure drop rate, and blowing agent concentration. 


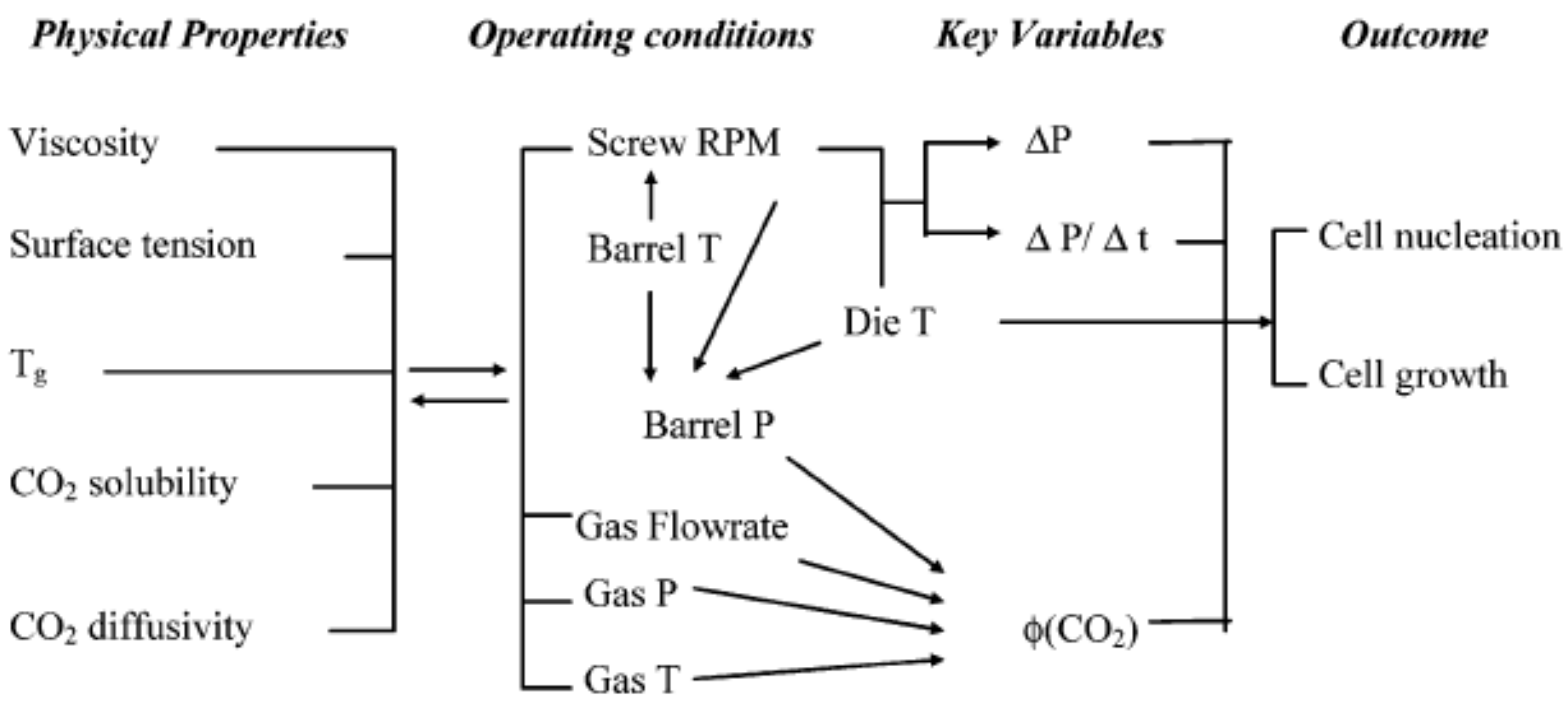

Figure 2.4: Relationships between parameters in a continuous extrusion foaming process using $\mathrm{CO}_{2}$ as the blowing agent ${ }^{10}$.

\subsubsection{Cell Nucleation}

From classical homogeneous nucleation theory, the rate at which invisible gas clusters are energized by effective diffusion governs the nucleation rate ${ }^{11}$. From work by Gibbs, the rate of nucleation can be expressed as:

$$
N=f c \exp (-\Delta G * / k T)
$$

where $N$ is the nucleation rate, $f$ is a frequency factor, $c$ is the gas concentration, $\Delta G^{*}$ is the activation energy to sustain a bubble, and $k$ and $T$ are the Boltzmann constant and the absolute temperature respectively. Further work by Blander and Katz defined the minimum work term, $\Delta G^{*}$, and frequency factor, $f$, into measurable parameters (Equation 2.5) resulting in Equation 2.6 for homogeneous nucleation:

$$
\begin{aligned}
& \Delta G_{\text {hom }}^{*}=\frac{16 \pi \gamma^{3}}{3\left(P_{b}-P_{\infty}\right)^{2}} \\
& f=\left(\frac{2 \gamma}{\pi m}\right)^{0.5}
\end{aligned}
$$




$$
N=c\left(\frac{2 \gamma}{\pi m}\right)^{0.5} \exp ^{\left(\frac{-16 \pi \gamma^{3}}{3 k T\left(P_{b}-P_{\infty}\right)^{2}}\right)}
$$

where $\gamma, P_{b}, P_{l}$, and $\mathrm{m}$ are the surface tension, pressure in the bubble, pressure in the melt, and mass of a gas molecule respectively. Often $P_{\infty}$ is assumed equal to atmospheric pressure.

S. T. Lee collected and presented a detailed development of nucleation theory ${ }^{11}$. Tomasko et al. in their review presented simplified models in terms of an activation energy, $\Delta G^{*}$, for heterogeneous nucleation (Equation 2.7), though they did not define the frequency factor, $f$, for the equation ${ }^{10}$.

$$
\begin{gathered}
N_{1}=c_{1} f_{1} e^{\left(\frac{-\Delta G^{*}{ }_{h e t}}{k T}\right)} \\
\Delta G^{*}{ }_{h e t}=\frac{16 \pi \gamma^{3}}{3 \Delta P^{2}} \frac{(2+\cos \theta)(1-\cos \theta)^{2}}{4}
\end{gathered}
$$

For Equations 2.7, $c_{1}$ is the concentration of gas, $f$ is the frequency factor of gas adding to the nucleation site, $k$ is the Boltzman constant, $T$ is the absolute temperature, $\gamma$ is the surface tension, $\Delta P$ is the gas pressure difference, and $\theta$ is the contact angle of the melt-particle/gasphase interface. For single phase polymer melts, only homogeneous nucleation occurs. In melts containing solid particles or two-phase systems, both the homogeneous and heterogeneous equations need to be solved simultaneously.

From the pressure difference, $\Delta P$, Blander and Katz developed the concept of superheat, $\mathrm{SH}$, (Equation 2.8). For low superheat, diffusion is able to reestablish equilibrium before the critical bubble radius is reached thereby limiting nucleation.

$$
S H=P_{b}-P_{1 \infty}
$$


In actuality, polymer melt bubble nucleation has been seen to deviate from what is predicted. This is believed to be due to the polymer being of non-homogeneous character, and the thermodynamic-based model's inability to handle the simultaneous pressure and temperature changes on the gas activity and polymer chain mobility. However, when pressure gradients and surface tension dominate, bubble nucleation is in close agreement with homogeneous theory ${ }^{11}$. Some researchers have modified nucleation theory to better predict nucleation rate and added or modified several terms resulting in more complex homogeneous and heterogeneous nucleation equations.

\subsubsection{Foam Growth}

Early models focused on the growth of a single bubble (i.e. a single bubble in an infinite fluid with infinite gas available). This is clearly not the case for foam formation where there are many bubbles with a finite amount of gas. Newer models sought to correct for this problem by using cell or "swarm" bubble growth models. These cell models assume an interaction between the cells in the foam.

Older foaming models usually involve simultaneous solution of the momentum, heat, and mass balances, with a specific rheologic model. The incorporation of gas loss from the foam, blowing agent plasticization, concentration-dependent diffusion, and transient cooling have further improved the models. The models shown below in Equations 2.9-2.12 need to be solved simultaneously with appropriate boundary conditions to yield cell number and density predictions $^{11}$.

Momentum Equation:

$$
P_{g}-P_{\infty}-\frac{2 \gamma}{R}+\int_{R}^{R_{f}}\left(\tau_{\gamma \gamma}-\tau_{\theta \theta}\right) \frac{d r}{r}=0
$$

Rheological Equations: 


$$
\begin{gathered}
\tau+\frac{\eta_{0} *}{E} \tau_{(1)}=-\eta_{0} * \sigma \\
\eta_{0}^{*}=\eta_{0} \exp ^{\left[\frac{E_{v}}{R_{g}}\left(\frac{1}{T}-\frac{1}{T_{0}}\right)\right]} f(c)
\end{gathered}
$$

where $\mathrm{f}(\mathrm{c})=$ viscosity reduction factor

Growth of Radius Equation:

$$
\frac{d}{d t}\left(\rho_{g} R^{3}\right)=3 \rho_{p} D R^{2}\left[\frac{\partial c}{\partial r}\right]_{r=R}
$$

Concentration-Dependent Diffusion Equation:

$$
\begin{aligned}
& \frac{\partial c}{\partial t}+V_{r} \frac{\partial c}{\partial r}=\frac{1}{r^{2}} \frac{\partial}{\partial r}\left(D r^{2} \frac{\partial c}{\partial r}\right) \\
& \text { where } D=(1+A c) 10^{-7} e^{\left(B-\frac{c}{T}\right)}
\end{aligned}
$$

In the above equations, $P_{g}$ is initial pressure in a cell, $P_{\infty}$ is the bulk pressure, $\gamma$ is the surface tension, $\tau_{\gamma \gamma}$ and $\tau_{\theta \theta}$ are the normal stress elements in the radial and circumferential directions respectively, $\eta_{0}$ is the viscosity, $R_{f}$ is the cell outer radius, $R$ is the gas-polymer interface radius, $\mathrm{r}$ is the radial coordinate, $\tau_{(1)}$ is the convected time derivative of stress tensor, $E$ is the elastic modulus, $\sigma$ is the rate of strain tensor, $E_{v}$ is the activation energy for the viscosity equation, $R_{g}$ is the ideal gas constant, $\mathrm{T}$ is the foaming temperature, $\mathrm{T}_{0}$ is the initial temperature, $\rho_{g}$ is the density of the blowing agent, $\rho$ is the density of the polymer, $D$ is the diffusion coefficient, $c$ is the blowing agent concentration, $\mathrm{t}$ is foam growth time, and lastly $V_{r}$ is the radial component of velocity.

From inspection, general trends expected are an increase in cell size with increased blowing agent concentration, time dependent concentration (decreasing pressure-drop rate) and reduced viscosity. It is important to remember that the above equations are for growth of a cell from the instant of formation. It is therefore necessary to make some assumptions to solve the 
equations as cells continue to form until the supersaturation of blowing agent is reduced to favor diffusional growth instead of nucleation.

S.T. Lee et al. have developed a model that approximates experimental results for low density polyethylene with butane as a blowing agent in a continuous extrusion process based on the above equations ${ }^{11}$. It is expected that the general trends captured by their models will be suitable for other systems and that is what the present study will investigate for pitch melts.

\subsubsection{Cell Coalescence and Coarsening}

As long as the pressure is sufficient to overcome the critical radius, there is the possibility that as new cells form, and that they will do so adjacent to existing cells. Due to pressure difference within the adjacent cell, diffusion occurs from smaller (high pressure) cells to larger (low pressure) cells, causing the larger cell to grow while the smaller cell shrinks till it is reabsorbed into the matrix material. This process is known as cell coarsening ${ }^{15}$.

As new cells continue to form and grow, the possibility increases that two or more cells of approximately the same size will come in contact with one another. As a result, a wall or membrane will form between the adjacent cells. As cell growth continues, the separating membrane is stretched thinner and becomes less stable. Eventually, the membrane ruptures resulting in the merger of the two cells into one larger cell as a way for the matrix material to minimize surface free energy. The net result is a reduction in cell number density which is usually undesirable since it adversely affects the thermal and mechanical properties of the foam $^{15}$.

Coalescence and coarsening of cells are difficult to model and this continues to be an area of research. Much of the research focuses on improving melt strength or reducing surface tension thereby increasing the likelihood of adjacent cells surviving until the matrix material stabilizes ${ }^{15}$. 


\subsection{Carbon Foams}

Carbon foam, as the name implies, is composed of carbonaceous material which frequently contains cyclic and aromatic molecular structures. Some of the earlier reported carbon foams were produced in the mid 1970's by a French research group ${ }^{16}$. Since that time many other research groups have investigated varying aspects from raw materials, to processing conditions and proposed diverse applications for carbon foam.

\subsubsection{Historical Overview of Carbon Foam}

Carbon is one of the latest materials to be processed into foams. The first patented carbon foam was by Bonzom, Crepaux, and Moutard in $1977^{16}$. Their starting material was pitch from the steam-cracked residue of asphalt and coal. Since that time, carbon foam has been produced from pyrolitic polymeric materials, coal, and coal extract precursors.

West Virginia University became interested in producing carbon foam in the early 1990's. The carbon foam program was an outgrowth from previous investigations into coal and coal pitches which produced some porous carbonaceous materials during experimentation. Since the goal of the carbon products research group was researching value-added products from coal and coal derivatives, carbon foam was easily added to the group's research interests. To date, several techniques for processing carbon foam from several raw materials have been developed.

\subsubsection{Carbon Foam Production Methods}

Currently, carbon form is produced two ways. The first is to use a pyrolitic polymeric foam and subject it to high temperatures to cause char and cross-linking of the polymer matrix. The second way is to subject coal or pitch to high temperature and pressure, usually between $300-500^{\circ} \mathrm{C}$ and $14.7-1500 \mathrm{psia}^{17}$. The second process takes advantage of naturally-present, lower molecular-weight molecules that volatilize during the heating process to create cells in the bulk phase. The resulting material is a cellular carbon which is sometimes referred to as "green" 
carbon foam. The foam can be further processed by carbonization, graphitization, or subjected to acid or base washes to alter the surface characteristics and compounds. Green carbon foams have been treated under inert atmosphere, usually nitrogen, to $300-500^{\circ} \mathrm{C}$. Further heating $(600$ $1600^{\circ} \mathrm{C}$ ) of green foam under an inert atmosphere often leads to rejection of hydrogen and the fission of side groups on the molecular structure, a process known as calcination. Heating of select carbon foam still further $\left(1700-3000^{\circ} \mathrm{C}\right)$, under inert atmosphere, leads to dehydrogenation and the formation of graphite planes in the bulk structure. This last heating is known as graphitization and is usually accompanied by significant alteration of the physical and chemical properties of the foam ${ }^{18}$. For example, Figure 2.5 gives a general overview of the effect on electrical resistivity during heating processes for a graphitizable foam.

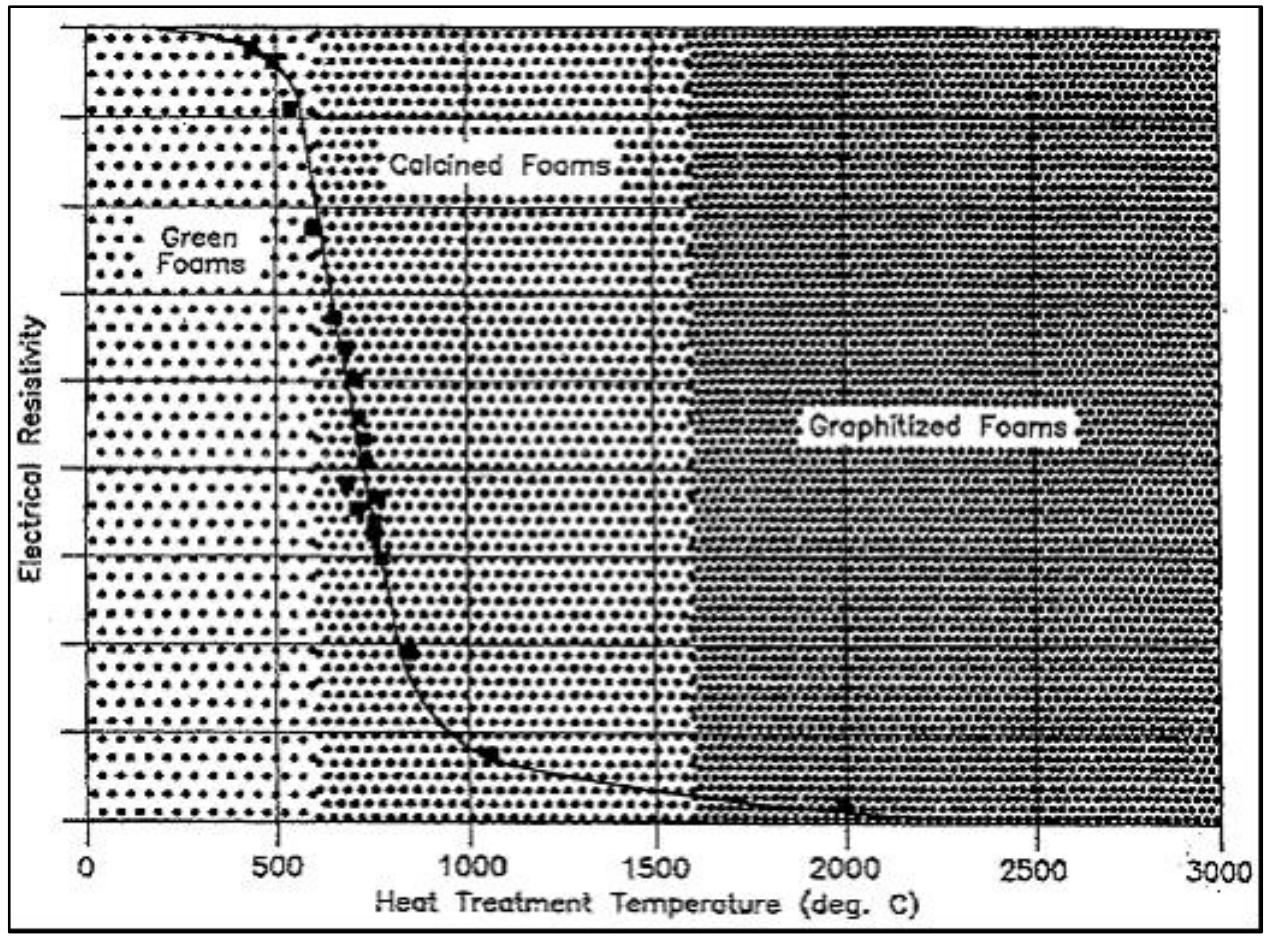

Figure 2.5: Electrical resistivity versus heat treatment temperature for carbon foam produced in reference ${ }^{18}$.

\subsubsection{Taylorable Properties of Carbon Foam}

Similar to polymeric foams, carbon foams retain significant strength for the reduction in density of the solid starting material (Figure 2.6). But, in addition to this, other physical 
properties of carbon foam can be tailored. Most of the tailorability depends upon the organization of the carbon molecules. Foams made from highly graphitic precursors (anisotropic and mesophase pitch) have much higher electrical and thermal conductivity in the same direction as the graphitic plane (Figure 2.5). The thermal conductivity in the plane of direction is so high that it can rival solid aluminum or copper for heat transfer per weight due to the high surface transfer area. Conversely, the electrical and thermal conductivity for isotropic non-graphitic carbon foams can be similar to that of ceramic insulators due to the absence of a continuous graphitic plane structure.

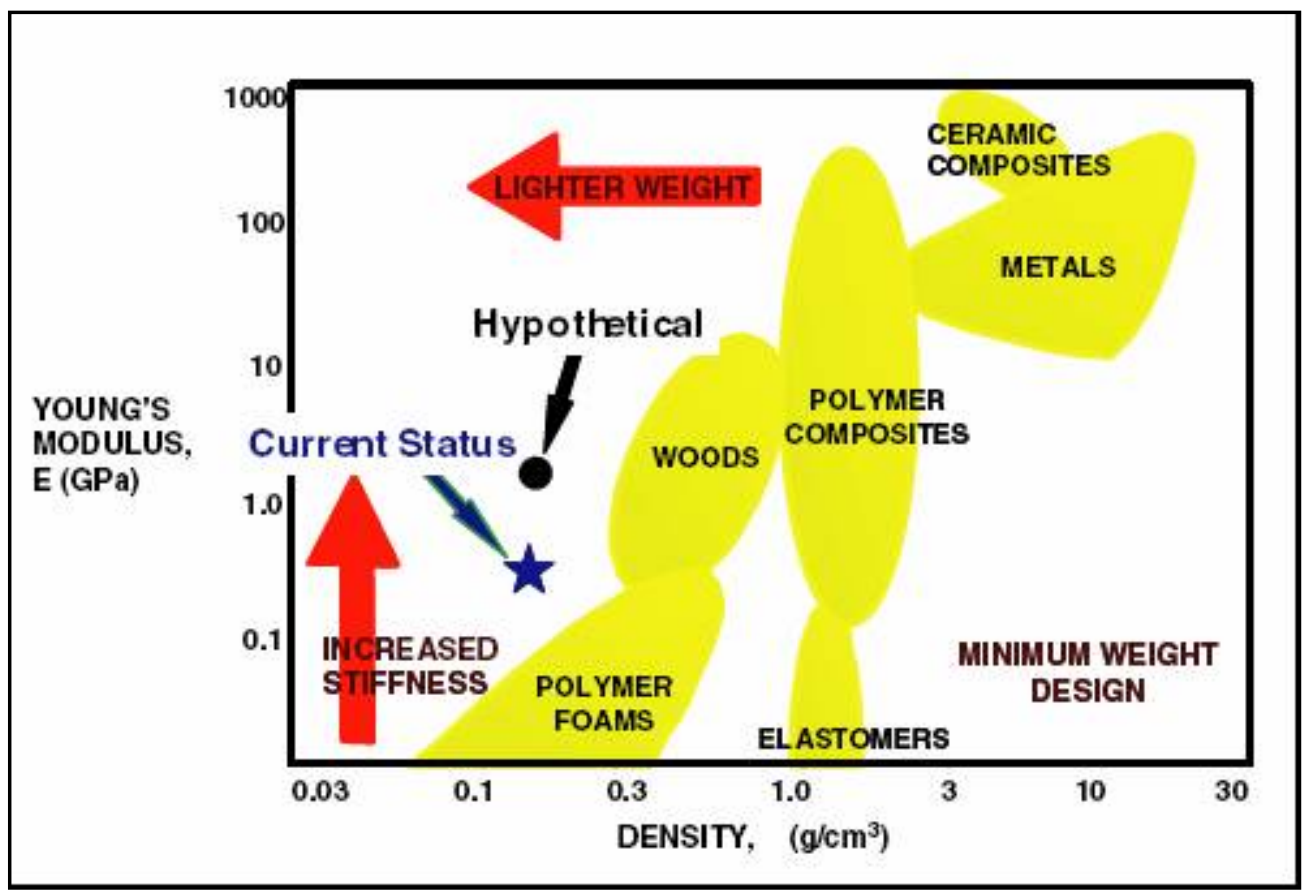

Figure 2.6: Estimated specific modulus/property chart of pitch-based carbon foam and competing materials $^{14}$.

\subsubsection{Carbon Foam Applications}

From the strength-to-weight ratio and the variety of properties of carbon, a number of applications have been proposed. Some of the fields that would take advantage of this mix of properties include transportation, energy, and military industries. 
The aerospace, automotive, and transportation industries share many of the same interests in carbon foam and are continually looking for materials that would reduce the weight and cost of their vehicles while maintaining performance. For these industries, the energy absorption properties of carbon foam have been of particular interest for bumpers and replaceable impact absorbing tiles. The large energy absorption is not only due to the strong carbonaceous matrix material, but also the energy necessary to crush the foam structure. The automotive industry, along with catalysis researchers, is additionally looking at using carbon foam as a substrate for catalysts and as a catalyst itself through surface modification.

There has even been some interest in using carbon foam in fuel cells. One of the proposals is to use carbon foam for the bipolar plates in proton exchange membrane (PEM) fuel cells ${ }^{1}$. Another is to use the carbon foam as a fuel in high performance direct carbon fuel cells (DCFC).

\subsection{Rheology and Foam Production}

Bubbles can be formed a number of ways in liquids, but most bubble collapsing or bursting occurs before the matrix material solidifies. The key to making a solid foam is to stabilize the molten material to a solid before the cell structure collapses. Controlling rheology and melt strength of the base material makes foam production possible. The formation of foam is a complex function of temperature, pressure, surface tension, heat and momentum transfer, diffusion, and viscosity. Most of the listed parameters have a significant effect on the rheology of the molten material that is used. An understanding of how each effect, particularly diluents and temperature, influences the pitch rheology aides tremendously in forming process conditions without much additional trial and error. The first step is to identify the type of long range 
molecular structure, or crystallinity, present in the base material. The crystallinity gives an indication of how the melt rheology behaves and is discussed below.

\subsubsection{Crystallinity}

The repeated arrangement of molecules in a solid material is known as crystallinity. Solids are divided into crystalline or amorphous structural arrangement depending upon the degree of long range orientation of the atoms or molecular units.

Crystalline materials have regular long range lattice orientation of their atoms or molecules. The molecular order leads to defined melting and boiling points. Often polymers considered crystalline rarely have a purely crystalline structure but rather partly crystalline domains.

Amorphous materials, as the name implies, lack long range lattice orientation. This lack of orientation is usually a result of the material having a broad variety of molecules of varying molecular weight. Amorphous materials can also be formed by cooling liquids faster than a minimum thermodynamic orientation can be reached. Due to this irregular structure, amorphous materials do not have defined melting points. Instead, they often undergo a rubbery transition in a material-specific temperature range as they are heated from a solid to a fluid state. The point at which this transition occurs is known as the glass transition temperature, $\mathrm{T}_{\mathrm{g}}$. The glass transition temperature is a reference point that is often used in the calculation of several physical properties of amorphous materials. Additional information concerning the glass transition temperature is given in the following section.

\subsubsection{Glass Transition Temperature, $\mathrm{T}_{\mathrm{g}}$}

The Glass Transition Temperature is an important characteristic in the processing of polymers and pitches. It is used extensively in estimating several rheologic properties of both 
materials. To begin, the $T_{g}$ is defined as the point at which an amorphous glassy state transitions to a mobile rubbery state ${ }^{19}$. In the solid state, only intermolecular vibrations of the molecules occur. At the $\mathrm{T}_{\mathrm{g}}$ short range intermolecular motion begins along with some molecular slippage. The range of motion in and around the molecules increases until free motion of the entire molecule is achieved forming a liquid solution. There is also a significant increase in the fractional free volume of the system due to the molecular relaxation ${ }^{20}$. Fractional free volume is defined as the fraction of the total volume accessible to solutes of any size.

Generally, the $T_{g}$ increases as molecular weight and intermolecular forces increase. The $\mathrm{T}_{\mathrm{g}}$ of a material can change over time due to the thermal history of the material. For example, if the material is heated above a temperature at which lower molecular weight molecules begin to escape from the melt, a general rise of the $\mathrm{T}_{\mathrm{g}}$ is seen. Heat treatments, depending on the material, can also result in degradation, charring, cross-linking, and cracking of the heavier molecules to further increase the $T_{g}$. Eventually, mass loss will occur before the $T_{g}$ is reached resulting in no melt phase formation. This is one method that is used to stabilize pitch-based products ${ }^{20}$.

The glass transition temperature is usually evaluated through the use of Differential Scanning Calormetery (DSC), though thermogravimetric analysis, mechanical thermal analysis, coefficient of thermal expansion, and nuclear magnetic resonance imaging can be used and yield similar results. At the $\mathrm{T}_{\mathrm{g}}$, there is a significant change in the heat capacity between the glassy to rubbery state in the material, which is detected with DSC through an increase in energy needed to maintain a constant heating ramp. The inflection point of the heat input curve is then taken as the $\mathrm{T}_{\mathrm{g}}$. This is usually within $\pm 2^{\circ} \mathrm{C}$ of the actual $\mathrm{T}_{\mathrm{g}}$. 


\subsubsection{Metler Softening Point Correlation}

A simple correlation was developed by Barr et al. for approximating the $T_{g}$ of pitches from the Mettler Softening Point Temperature, $\mathrm{T}_{\mathrm{MS}}$. The Mettler Softening point is a standard ASTM test method D3104-99 (2005) that gives a point of near constant viscosity for pitch. It is valid over a temperature range of $50^{\circ} \mathrm{C}$ to $180^{\circ} \mathrm{C}$, and gives results comparable to those obtained by ASTM test method D $2319^{21}$. Barr et al. suggested a linear correlation between $\mathrm{T}_{\mathrm{g}}$ and $\mathrm{T}_{\mathrm{MS}}$ (Equation 2.13) where both are in degrees Kelvin. Khandare, at West Virginia University, confirmed the form of the equation, but found a slightly different value of the constant, $x$ in Equation 2.13. Barr et al. calculated an experimental value of $0.84 \pm 0.02$ while Khandare $^{22}$ obtained a value of $0.89 \pm 0.01$. Khandare attributed the variation to differences in preparation and measuring techniques (Differential Scanning Calorimetry for Barr and Dilatometry for Khandare).

$$
T_{g}=x T_{M S}
$$

\subsubsection{Viscosity}

Viscosity, $\eta$, is one of the most influential parameters in forming foam. As shown in Equation 2.14, viscosity describes a fluid's internal resistance to flow and is commonly thought of as fluid "thickness", where $\sigma$ and $\varsigma$ are the shear stress and shear rate respectively. As such, water would be a "thin" fluid, at ambient temperature and pressure, having a low viscosity, while motor oil would be considered a "thick" fluid due to its higher flow resistance. For foam production, if the viscosity is too high, the material is difficult to process easily and efficiently and stunts cell formation and growth. If, on the other hand, the viscosity is too low, the gas easily escapes and the foam matrix collapses. The viscosity of a melt is influenced by several factors, though the primary ones are temperature, pressure, and amount and nature of the diluent components in the melt. 


$$
\eta=\frac{\sigma}{\varsigma}
$$

Every fluid has a unique viscosity profile for a give temperature and pressure. Most fall into three general categories: Newtonian, power law (shear thickening or thinning), or Bingham plastic (Figure 2.7). A Bingham Plastic is ideal for foaming due to the minimum shear stress needed for its deformation. This behavior would permit the foam matrix structure to hold till the matrix material has an opportunity to cool or cure.

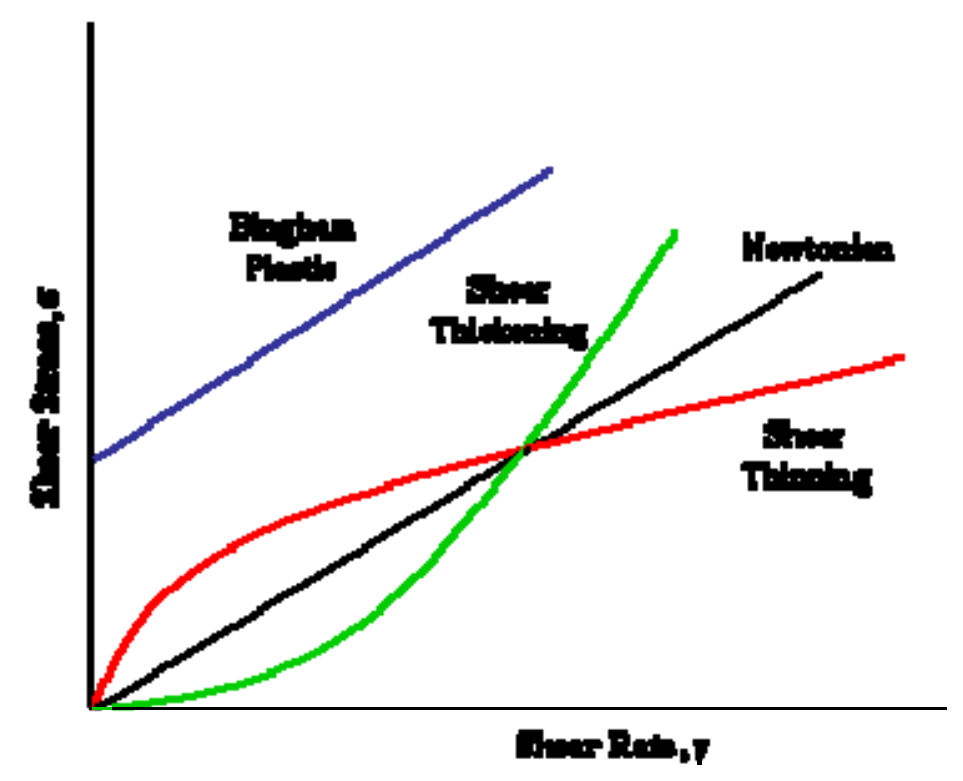

Figure 2.7: Comparison of viscosity profiles for Bingham plastic, Newtonian, and power law fluids (shear thickening \& thinning).

Most polymer and pitch melts exhibit shear thinning behavior. Though shear thinning is less than ideal for foam stabilization, it is still capable of producing high quality foams. The viscosity and melt strength need to be sufficient to allow time for the matrix material to freeze, locking the structure in place.

\subsubsection{Plasticizing Effects of Dissolved Gases}

The viscosity and glass transition temperature of a system diluted with gas are often lower than that of the pure system. This reduction of viscosity and $T_{g}$ is generally referred to as 
plasticization of the material and has been attributed to both an increase of the free volume of the material and the real dilution effect of the gas or other plasticizing agent. The plastization behavior has been acceptably modeled for polymers through the work of T.S. Chow and the William-Landel-Ferry Equation which are discused in Section 2.3.8 Rheologic Models.

Plasticizing additives for polymers are most commonly phthalates, and they tend to increase the flexibility and durability of hard plastics such as PVC. They are often based on esters of polycarboxylic acids with linear or branched aliphatic alcohols of moderate chain length. Plasticizers work by embedding themselves between the polymer chains, increasing the free volume and chain slippage, and significantly lowering the glass transition temperature for the plastic thereby making it more flexible.

In time plasticizers diffuse out of the material, returning it to the properties of the pure system. For gases, this diffusion process is fast, especially for light gases, and can be taken advantage of by increasing the freezing rate of melt systems.

\subsubsection{Gas Uptake/Solubility}

Diffusion of gases occurs in most solids and liquids. A natural result is that gases in the material will be in equilibrium with the surrounding fluid. The amount of gas that a material is able to take in is unique to the gas/material system and is referred to as the solubility of a gas in that material. Being able to rapidly alter the solubility of a gas in a melt resulting in a thermodynamic instability provide a means for producing foam with physical blowing agents.

For most gases, the solubility in a polymer changes at the $T_{g}$. Below the $T_{g}$, the solubility is usually described by the dual-mode sorption model (Equation 2.15) which is a combination of Henry's law gas and the Langmuir adsorption equation. In Equation 2.15, C is the concentration 
of the gas in the polymer, $\mathrm{P}$ is the gas pressure, $\mathrm{k}_{\mathrm{H}}$ is the Henry's law constant, and $\mathrm{C}_{\mathrm{L}}$ and $\mathrm{b}$ are the Langmuir capacity and affinity respectively ${ }^{10}$.

$$
C=k_{H} P+\frac{C_{L} b P}{1+b P}
$$

Above the $\mathrm{T}_{\mathrm{g}}$ and in the lower pressure regimes, the Langmuir capacity approaches zero resulting in a linear correlation that follows the Henry's law model. Following this, solute gas concentrations can generally be increased by increasing pressure (Figure 2.8). It is important to note that the Henry's law constant, $\mathrm{k}_{\mathrm{H}}$, is a function of both temperature and total absorbed concentration at high pressures. As the temperature increases, the Henry's law constant decreases, corresponding to a decease in solubility for most materials.

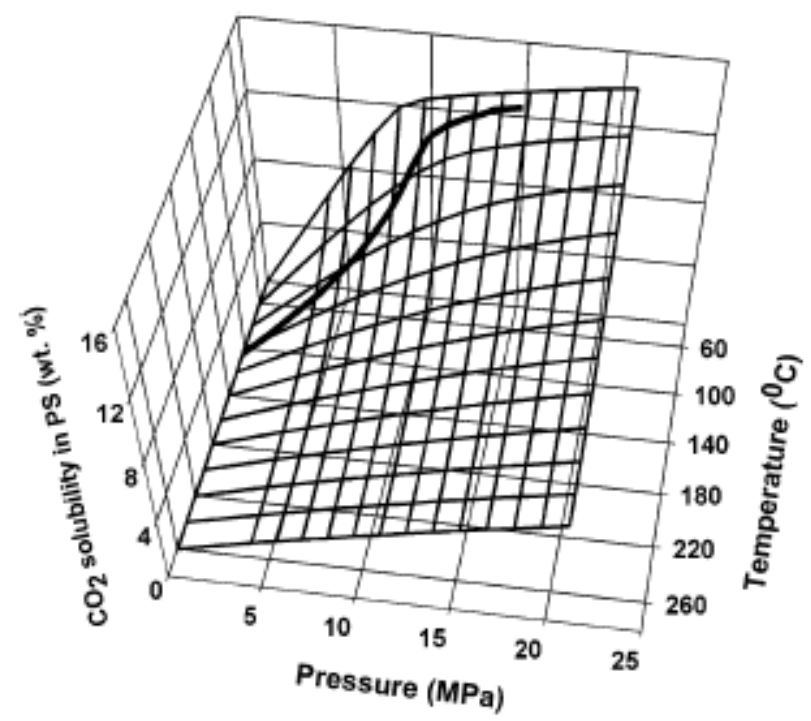

Figure 2.8: $\mathrm{CO} 2$ solubility in polystyrene at different pressures and temperatures (the thick line on the surface is the $\left.T_{g}\right)^{10}$.

\subsubsection{Solubility Models}

Accurately modeling the solubility of gases in the polymer melt is of great interest in calculating properties of polymer/gas mixtures. This is due to the effect that the diluent gas has on the melt and the resulting temperature dependent viscosity of the melt. Design of equipment and processing of melts has forced the development of correlations between equation of state 
(EOS) models and solubility for these systems. From a review of the literature for polymer processing and macromolecules, the Sanchez-Lacombe $24{ }^{, 24}$ (S-L), and Panayiotou-Vera (P-V) equations yield fairly accurate predictions for pure polymer melt and diluted melt polymer solutions ${ }^{10,25-28}$. Both use equilibrium chemical potentials in the melt and gas phases to correlate solubility to the pure phase through a binary interaction parameter. The models and modeling techniques may possibly be extended to pitch as well.

\subsubsection{Sanchez-Lacombe Equation of State}

The Sanchez-Lacombe (S-L) EOS (Equation 2.16) is patterned after the Flory-Higgins $(\mathrm{F}-\mathrm{H})$ model $^{29}$ that is based on hole theory. In the F-H model, the hole density is fixed by the lattice structure, whereas in the S-L model it is allowed to vary. $\widetilde{P}, \widetilde{T}$, and $\widetilde{\rho}$ are the reduced pressure, temperature and density, respectively. $\mathrm{P}^{*}, \mathrm{~T}^{*}, \rho^{*}$ are the characteristic pressure, temperature and density at the critical point of the gas, respectively. $\mathrm{R}_{\mathrm{g}}$ is the ideal gas constant, $v^{*}$ is the characteristic volume of a lattice site, $\varepsilon^{*}$ interaction energy, $\mathrm{r}$ is the number of lattice sites occupied by a molecule, and $\mathrm{M}$ is the molecular weight of the occupying molecule.

$$
\begin{gathered}
\frac{\widetilde{P}}{\widetilde{T}}=\ln (1-\widetilde{\rho})-\left(1-\frac{1}{r}\right) \widetilde{\rho}-\frac{\widetilde{\rho}^{2}}{\widetilde{T}} \\
\widetilde{T}=T / T^{*} ; \quad T^{*}=\varepsilon^{*} / R_{g} \\
\widetilde{P}=P / P^{*} ; \quad P^{*}=\varepsilon^{*} / v^{*} \\
\widetilde{\rho}=\rho / \rho^{*} ; \quad \rho^{*}=M /\left(r v^{*}\right)
\end{gathered}
$$

\subsubsection{Panayiotou-Vera Equation of State}

The P-V EOS (Equation 2.17) is a modification of the S-L EOS and incorporates concepts developed by Guggenheim ${ }^{25}$. In the Panayiotou-Vera Equation, $\widetilde{P}, \widetilde{T}$, and $\widetilde{v}$ are the reduced pressure, temperature and volume, respectively. $\mathrm{P}^{*}, \mathrm{~T}^{*}, v^{*}$ are the characteristic 
pressure, temperature and volume at the critical point of the gas, respectively. $R_{g}$ is the ideal gas constant, $\mathrm{Z}$ is a finite coordination number, $v^{*}$ is the characteristic volume of a lattice site, $\varepsilon^{*}$ interaction energy, $\mathrm{q}$ is the effective chain length, $\mathrm{r}$ is the number of lattice sites occupied by a molecule, $\theta$ is the fraction of total external contacts in the system that are mer-mer contacts in a random array of molecules and holes, and $\mathrm{N}$ is the number of external contacts present in the system.

$$
\begin{gathered}
\frac{\widetilde{P}}{\widetilde{T}}=\ln \left(\frac{\widetilde{v}}{\widetilde{v}-1}\right)+\frac{Z}{2} \ln \left(\frac{\widetilde{v}+q / r-1}{\widetilde{v}}\right)-\frac{\theta^{2}}{\widetilde{T}} \\
\frac{Z}{2} \varepsilon=P^{*} v_{H}=R_{g} T^{*} \\
\widetilde{v}=\frac{V}{V^{*}}=\frac{v_{s p}}{v_{s p}} ; \quad V^{*}=N r v_{H} \\
\widetilde{T}=\frac{T}{T^{*}} ; \quad \widetilde{P}=\frac{P}{P^{*}} \\
q=\frac{(Z-2) r+2}{Z}
\end{gathered}
$$

\subsubsection{Rheologic Models}

It is also known from Henry's Law, and has been further verified by experimental work with polymers, that physical properties are also affected by temperature, pressure and diluent concentration. An accurate understanding of the blowing agent/pitch system over a broad range of temperature and pressure is needed to accurately produce a melt system with the appropriate rheologic properties. This is particularly needed in ascertaining the rheologic behavior with blowing agent concentrations below and at equilibrium concentrations in the pitch at elevated temperatures and pressures. Two equations that have been developed to aid in this modeling are the William-Landel-Ferry equation and the Chow correlation. 


\subsubsection{William-Landel-Ferry Equation}

Below the $\mathrm{T}_{\mathrm{g}}$ and above the melting temperature, $\mathrm{T}_{\mathrm{m}}\left(\sim \mathrm{T}_{\mathrm{g}}+100^{\circ} \mathrm{C}\right.$ to $150^{\circ} \mathrm{C}$ for amorphous polymers and pitches), amorphous materials follow an Arrhenius-type relationship for the temperature dependence of viscosity. But between $T_{g}$ and $T_{m}$, the viscosity behavior deviates greatly from the Arrhenius-type relation ${ }^{8,26}$ (Figure 2.9). The William-Landel-Ferry Equation (Equation 2.18) was developed for this temperature region and accurately describes viscosities of amorphous materials. ${ }^{20,30}$

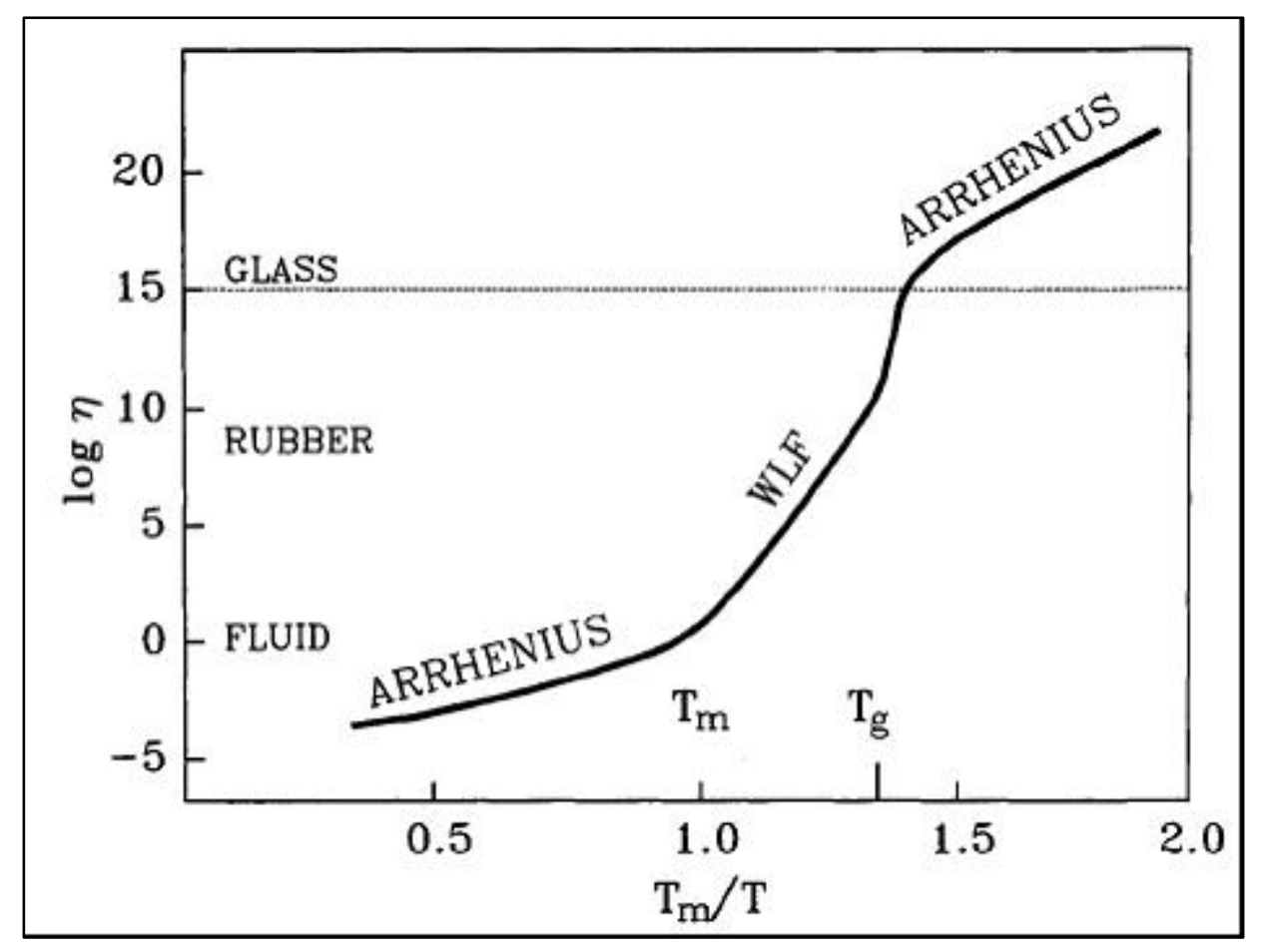

Figure 2.9: Viscosity-temperature relationship for amorphous materials ${ }^{8}$.

The Williams-Landel-Ferry (WLF) equation was originally developed in 1955 as an empirical equation for amorphous polymers. It has since been shown to accurately model most amorphous materials including pitches. William, Landel, and Ferry later gave physical meaning to the equation by comparing it with the Doolittle free volume equation ${ }^{31}$. The WLF equation: 


$$
\log \left(\frac{\eta}{\eta_{s}}\right)=-\frac{c_{1}\left(T-T_{s}\right)}{c_{2}+T-T_{s}}
$$

has since been correlated to free volume theory for predicting the viscosity of amorphous materials that are between the $\mathrm{T}_{\mathrm{g}}$ and approximately $100-150^{\circ} \mathrm{C}$ above the $\mathrm{T}_{\mathrm{g}}$. Beyond $150^{\circ} \mathrm{C}$ above the $\mathrm{T}_{\mathrm{g}}$, the effects of free volume become insignificant and Arrhenius type behavior better describes the viscosity observations. In the WFL equation (Equation 2.18), $\mathrm{T}_{\mathrm{s}}$ and $\eta_{\mathrm{s}}$ are temperature and viscosity respectively at a selected reference temperature $\mathrm{T}_{\mathrm{g}}<\mathrm{T}_{\mathrm{s}}<\mathrm{T}_{\mathrm{g}}+100^{\circ} \mathrm{C}, \mathrm{c}_{1}$ and $c_{2}$ are experimentally determined constants at constant shear rate for the material, $T$ and $\eta$ are temperature and viscosity respectively for $\mathrm{T}_{\mathrm{g}}<\mathrm{T}<\mathrm{T}_{\mathrm{g}}+100^{\circ} \mathrm{C}$. It was been suggested that values of 17.44 and 51.6 for $c_{1}$ and $c_{2}$ respectively can be used generally for polymer system, but these should be experimentally determined for the best correlation fit ${ }^{20}$.

\subsubsection{Chow Equation}

Routinely, it is seen that the presence of gaseous or liquid diluents alters the $T_{g}$ of amorphous materials ${ }^{26,34}$. T. S. Chow showed for polymers that the change in $T_{g}$ could be modeled as a function of the diluent's mass fraction $(\omega)$ and characteristic parameters of the polymer/diluent mixture. Chow proposed a model (Equation 2.19) based on classical and statistical thermodynamics to account for the change in $T_{g}$ for binary polymer-diluents systems ${ }^{32}$ :

$$
\begin{aligned}
& \ln \left(\frac{T_{g}}{T_{g 0}}\right)=\Psi[(1-\theta) \ln (1-\theta)+\theta \ln (\theta)] \\
& \theta=\frac{M_{p}}{z M_{d}} \frac{\omega}{1-\omega} ; \quad \Psi=\frac{z R_{g}}{M_{p} \Delta C_{p}}
\end{aligned}
$$

where $\mathrm{T}_{\mathrm{g}}$ and $\mathrm{T}_{\mathrm{g} 0}$ are glass transition temperature with diluent and without diluent respectively, $\omega$ is the mass fraction of the diluent, $\mathrm{M}_{\mathrm{p}}$ and $\mathrm{M}_{\mathrm{d}}$ are the molecular weight of the polymer repeat unit and the diluent respectively, $\Delta \mathrm{C}_{\mathrm{p}}$ is the heat capacity at the glass transition temperature, $\mathrm{R}_{\mathrm{g}}$ is the ideal gas constant, and $\mathrm{z}$ is a lattice constant. The use of the Bragg-William approximation 
in the development of the above expression requires $\theta$ to be numerically small for best results ${ }^{32}$. As such, this correlation works best with lower molecular weight diluents and small mass fractions of diluent. The lattice constant has been found to usually be 1 or 2 for polymers. The selection of either makes only a minor variation in $\mathrm{T}_{\mathrm{g}}$.

Through the use of the Chow correlation and the WFL equation, the reduced viscosity can be calculated. This is accomplished by shifting the viscosity profile predicted from the WFL equation by the change in the $\mathrm{T}_{\mathrm{g}}$ predicted from the Chow correlation. This calculation assumes a lateral shift of the entire viscosity profile and has been shown experimentally to be an acceptable $\operatorname{assumption}^{10}$.

\subsubsection{Surface Tension}

Surface tension is an effect within the surface layer of a liquid that causes the layer to behave as an elastic sheet. It is what allows water striders (a small aquatic insect) to stand on the surface of the water. In producing foam, one is attempting to increase the surface area and freeze it in place and surface tension is a measure of the resistance to increase that area. The surface tension is the energy required to increase the surface area of a liquid by a unit amount and is a significant parameter in foam production. Simply put, the higher the surface tension, the more energy is needed to increase the surface area above that of the minimum energetic shape state. The thermodynamic definition of surface tension is the derivative of the Gibbs free energy of the system, G, with respect to area at constant temperature and pressure ${ }^{35}$ (Equation 2.20).

$$
\gamma=\left(\frac{\partial G}{\partial A}\right)_{T, P}
$$

Surface tension is an effect within the surface layer of a liquid that causes the layer to behave as an elastic sheet and is due to attraction between the molecules of the liquid, which is a result of various intermolecular forces. In the bulk of the liquid each molecule is pulled equally 
in all directions by neighboring liquid molecules, resulting in a net force of zero. At the surface there are no liquid molecules on the outside to balance these forces resulting in molecules being pulled inwards by molecules deeper inside the liquid. The surface molecules are then subject to an inward-directed pulling force of molecular attraction which is counteracted by the resistance of the liquid to compression. There may also be a small outward attraction resulting from interaction with the phase interface, but usually this interaction force is negligible.

Using water as an example, it has a relatively high surface tension for its density and is difficult to form suds due to the significance that surface tension plays in minimizing surface energy. By adding soap, a surfactant which lowers surface tension, forming bubbles becomes much easier. Not only does surface tension affect the stability of the matrix, but the nucleation growth, and stability of cells are also effected (Section 2.1.5 Foam Formation Models).

\subsection{Pitch}

Pitch has had a long history of uses. Some of the earliest applications were as waterproofing on reed and wooden vessels. It is still used for this purpose in certain parts of the world. Some of the more modern uses of pitch include binders for electrodes and other carboncarbon composites, fillers for polymer, raw material for carbon fibers and synthetic graphite. The product quality of each is highly dependent upon the viscosity and thermal processing which the pitch undergoes.

\subsubsection{Defining Pitch}

Pitch is the name commoly given to any of a number of highly viscous organic materials which are liquid at elevated temperture but solid at room tempertaure. Pitch can be produced from petroleum residue, coal extracts and processing of plant extracts. Pitch produced directly from plants is called resin or rosin. 
Petroleum and coal-derived pitches are in a category of organic liquids known as bitumen which are highly viscous, black, sticky and wholly soluble in carbon disulfide. Asphalt and tar are the most common forms of bitumen. Petroleum and coal pitches are the amorphous residues left after petroleum or coal tar is distilled. The elemental composition of pitch includes $\mathrm{C}, \mathrm{H}, \mathrm{O}$, $\mathrm{N}, \mathrm{S}$, and other inorganic impurities ${ }^{36}$, usually determined by ultimate elemental analysis. These atoms are generally arranged into four generic molecular groups (saturates, napthene aromatics, polar aromatics, and asphaltenes) with varying proportions. All of the molecular groups may possess side chains and/or functional groups. The higher the ratio of asphaltene to other components, the higher the softening point, thermal stability, and carbon yield ${ }^{37}$. Origin and processing determine composition and ratios of the organic molecules present. Petroleum pitches generally have more uniform molecular distribution than that of coal-derived pitches ${ }^{20}$.

The composition of molecules determines the physical characteristics of the pitch. The characteristics are elemental composition, molecular mass distribution, $\mathrm{H} / \mathrm{C}$ ratio, solids inclusion and phase composition. These characteristics have a direct effect on the $\mathrm{T}_{\mathrm{g}}$, temperature dependence of rheologic parameters, surface tension, thermal decomposition, carbon yield, and solubility spectrum ${ }^{36}$. Frequently though, pitch is characterized just by softening point, toluene or quinoline insolubles, carbon yield, and viscosity/temperature relationships. The various commercial grades have softening points that typically range from $65-240^{\circ} \mathrm{C}^{38}$. Higher softening points are achievable, though coking begins to occur before the $\mathrm{T}_{\mathrm{g}}$ is reached ${ }^{36}$.

Pitch has been characterized as having thermoplastic melt characteristics. That is, it behaves as a thermoplastic in that it softens and melts upon reheating provided that the pitch has not been stabilized or pyrolyzed. This thermoplastic behavior is utilized in the production of carbon fibers by melt spinning. 


\subsubsection{Polymers and Pitches}

Polymer melts have gathered more interest than pitch melts due to their extensive use in consumer goods. Several studies have found similar rheologic behavior between pitch thermoplastic melts and characterized pitch as a thermoplastic ${ }^{36,39}$. The studies have successfully applied several viscosity models for polymer melts to pitch melts, such as the William-LandelFerry Equation (Equation 2.18) and the Fulcher-Vogel equation (Equation 2.21).

$$
\log \eta=c_{1}-\frac{c_{2}}{T-T_{0}}
$$

Compositionally, polymer and pitch share a number of characteristics such as elemental composition, and molecular weight distributions. From an elemental standpoint, both are macroorganic molecules primarily composed of carbon and hydrogen with other secondary atoms $(\mathrm{N}$, $\mathrm{O}, \mathrm{S}$, etc.) incorporated to a lesser extent. In polymers the secondary atoms are often part of the base monomer, whereas in pitch, the distribution of these secondary atoms is in a more random arrangement.

The arrangement of the atoms in the molecules is fairly different between the two with the organic molecules in pitch being more aromatic or globular in structure whereas in polymers the arrangement is more linear or chainlike in nature. Additionally, the average molecular weight of pitch is in the range of 100 's-1000's Da whereas that of various polymers is 1000 's$1,000,000{ }^{\prime} \mathrm{Da}^{19}$. In the melt, primary interactions between molecules for the pitch and polymer vary but have similar overall results. Polymer molecules, due to their extremely long length-towidth ratio tend to become entangled with each other. Pitches do not have the same length to width ratio and consequently entanglement of pitch molecules is of less influence than other interactions. Both experience Van der Waals interactions and some hydrogen bonding can occur if polar functional groups are present in the molecular structure. 
Despite the variation of dominant interaction between the molecules, many of the measurable physical properties, such as the glass transition temperature, $\mathrm{T}_{\mathrm{g}}$, and rheology are similar. An important physical property in polymer processing is the, $\mathrm{T}_{\mathrm{g}}$. Due to molecular weight distribution there is no defined melting point, but rather a change from solid to rubbery and then to the liquid state. The rheology of pitches and polymers are extremely similar, experiencing shear thinning character in comparable shear fields.

\subsubsection{Pitch Thermoplastic Processing: Pitch Fibers}

One current application that utilizes the thermoplastic character of pitch is for carbon and graphite fiber production. The distinguishing difference between carbon fiber and graphite fiber is that the former is composed of $90 \%$ or greater carbon, while the later is $99 \%$ or greater carbon. It should be noted that carbon fibers can be produced from polyarcrylonitrile (PAN), rayon, and pitch. Fibers from the first two are produced by standard synthetic textile methods (i.e. melt spinning, or solution spinning). Pitch-based fibers can be produced by both methods, but are usually produced by melt spinning. The properties of the fiber vary according to the base starting material and treatment. Generally, pitch-based fibers have higher stiffness and thermal conductivity than PAN-based fibers ${ }^{40}$.

Melt spinning fibers usually requires a melt viscosity of between 100 to 2000 poise ${ }^{42}$. To achieve this viscosity range, the pitch is heated above its Mettler Softening point and is forced through a spinneret and drawn onto a spindle. This process often involves extruders to produce the required pressure to force the melt through the spinneret. A process diagram for general carbon fiber production from pitch is shown in Figure 2.10. 


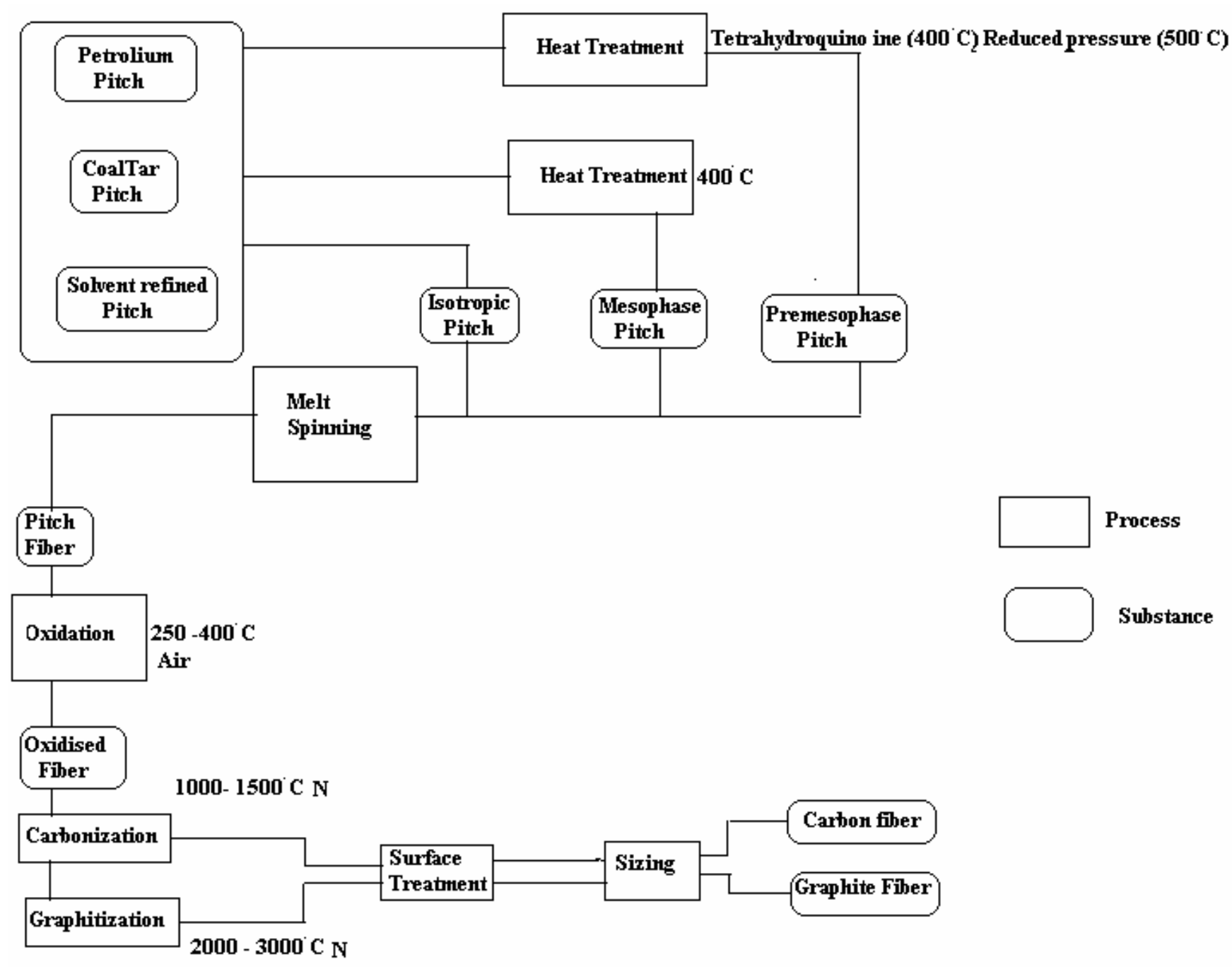

Figure 2.10: Manufacturing process schematic for pitch-based carbon fibers ${ }^{43}$, for oxidation and graphitization processes, $\mathrm{N}$ stands for inert atmosphere (nitrogen). 


\section{Chapter III \\ Investigation}

In this section the experimental design, analytical tests, pitch processing and foaming procedures are described.

\subsection{Experimental Design Overview}

The purpose of this project is first to determine if pitch foam can be produced by use of physical blowing agents, in a manner similar to polymeric foams. Second, to determine if pitch foams follow the same general trends in process conditions that are encountered for polymeric foams. Third to show if pitch foam could be extruded. And, fourth, to analyze the produced foam and report the results.

Table 3.1: Planed sets of experiments

\begin{tabular}{|c|l|l|}
\hline Experimental Sets & \multicolumn{1}{|c|}{ Testing } & \multicolumn{1}{|c|}{ Result } \\
\hline 1 & $\begin{array}{l}\text { Can foam be produced with PBA, } \\
\text { Proof of Concept Experiment, section } \\
3.2\end{array}$ & Proceed to set 2 if successful \\
\hline 2 & $\begin{array}{l}\text { Physical properties and preparation of } \\
\text { pitch, section 3.3 }\end{array}$ & $\begin{array}{l}\text { Compare findings to that of select } \\
\text { polymers, proceed to set 3 }\end{array}$ \\
\hline 3 & $\begin{array}{l}\text { Test and compare effects of T, P and } \\
\text { dP/dt, attempt foam extrusion, process } \\
\text { variable experiments, section 3.5 }\end{array}$ & $\begin{array}{l}\text { Observe if trends and process similar } \\
\text { to polymer, proceed to set 4 }\end{array}$ \\
\hline 4 & $\begin{array}{l}\text { Produce foams and compare } \\
\text { principles, section 3.6 }\end{array}$ & Report results \\
\hline
\end{tabular}

\subsection{Proof of Concept Experiment}

The evaluation of the first objective was a simple proof of concept experiment to determine if foaming of pitch in this manner is possible. The design of this experiment was to construct a small pressure vessel, load it with a low softening point pitch, pressurize with inert gas and heat the vessel, then rapidly release the pressure and examine the pitch for cells. A $110^{\circ} \mathrm{C}$ softening point pitch was placed in a stainless steel tube. The tube was pressurized with $\mathrm{N}_{2}$ to between 200 and $400 \mathrm{psig}$. The tube and contents were heated to between $90^{\circ} \mathrm{C}$ and $150^{\circ} \mathrm{C}$ 
and held at temperature for up to 4 hours. A valve was opened to allow rapid depressurization of the tube. The pitch was allowed to cool, and then removed for optical examination of the cells. It was found that cells were formed. Upon proof of concept, the selected physical properties related to foaming of the pitches used in this work were tested.

\subsection{Pitch Preparation and Properties Tests}

The pitches selected for use in this work were a $110^{\circ} \mathrm{C}$ softening point and $180^{\circ} \mathrm{C}$ softening point coal tar pitch, both supplied by Koppers Industries Inc. The $110^{\circ} \mathrm{C}$ pitch arrived as approximately $3 / 4$ inch diameter by $1-2$ inch cylindrical pellets. The $180^{\circ} \mathrm{C}$ pitch arrived as a solid mass in a 5 gallon canister. The pitches were stored under normal atmosphere in a cold room at $\sim 60^{\circ} \mathrm{F}$ till ground for use.

The $110^{\circ} \mathrm{C}$ softening point pitch was ground with dry ice to between 50-60 U.S. mesh size $(250-300 \mu \mathrm{m})$. The dry ice was used to prevent heat from accumulating in the grinding process, softening the pitch and leading to fowling of the equipment. Once ground, the pitch was stored at ambient conditions till used (less than 1 week).

The $180^{\circ} \mathrm{C}$ softening point pitch was ground to a slightly larger mesh size range $40-60$ $(250-420 \mu \mathrm{m})$ in the same manner as the $110^{\circ} \mathrm{C}$ SP pitch without the addition of dry ice. Once ground, the pitch was stored at ambient conditions till used (less than 1 week).

\subsubsection{Pitch Properties}

The heat capacity, glass transition temperature, particulate content, and density of the pitches were experimentally determined. These parameters are significant in describing the rheologic, nucleation and surface tension characteristics which in turn have been significant in foam formation for polymers. 


\subsubsection{Proximate Analysis}

Proximate analysis is a test commonly used to determine the amounts of moisture, volatiles, mineral ash, and fixed carbon content of organic materials ${ }^{41}$. The motivation for this test is to determine the solid mineral ash content, which if present, could act as a nucleating agent similar to that of talc or silicate in polymers.

The proximate analysis of the samples preformed in-house on a model 701 LECO Corporation thermogravimetric analysis instrument. Three representative samples for each pitch were analyzed and the mean average taken. Raw data are shown in Appendix D: Proximate Analysis Raw Data. Results are listed on Table 3.2.

Table 3.2: Mean average proximate analysis of pitches used in experimentation expressed as weight percent.

\begin{tabular}{|c|c|c|c|c|}
\hline Mass Fraction & Fixed Carbon wt $\%$ & Moisture wt $\%$ & Volatile wt $\%$ & Ash wt $\%$ \\
\hline $110^{\circ}$ C SP Pitch & $54.29 \pm 0.12$ & $0.44 \pm 0.33$ & $45.23 \pm 0.21$ & $0.04 \pm 0.07$ \\
\hline $180^{\circ}$ C SP Pitch & $67.84 \pm 0.09$ & $0.19 \pm 0.26$ & $31.80 \pm 0.15$ & $0.17 \pm 0.01$ \\
\hline
\end{tabular}

\subsubsection{Differential Scanning Calorimetry}

Differential scanning calorimetry (DSC) can be used to measure a number of characteristic parameters of a sample. Using this technique it is possible to observe fusion, crystallization, and glass transition temperatures. It is also possible to obtain absolute heat capacity with the aid of a known reference. The purpose of using DCS is to determine the glass transition temperature, verify the Mettler Softening point/glass transition temperture correlation, and to determine the heat capacity of the pitch.

The glass transition temperature and absolute heat capacity were tested on a TA Instruments Q100 Differential Scanning Calorimeter using helium at $25.0 \mathrm{ml} / \mathrm{min}$. For the absolute heat capacity, the DSC was calibrated with a sapphire calibration sample supplied by TA Instruments. Sample were prepared, annealed and tested according to the operating manual 
for the Q100. Results for the heat capacity and $\mathrm{T}_{\mathrm{g}}$ are listed on Table 3.3. Representative plots of DSC heat flow curves for $110^{\circ} \mathrm{C}$ softening point coal tar pitch showing $\mathrm{T}_{\mathrm{g}}$ and melting point are in Figure 3.1 and Figure 3.2.

Table 3.3: Properties of Koppers Industries Inc. Coal Tar Pitch used in work.

\begin{tabular}{|l|c|c|}
\hline Koppers Industries Inc. Coal Tar Pitch & $\mathbf{1 1 0}^{\circ} \mathbf{C}$ & $\mathbf{1 8 0}^{\circ} \mathbf{C}$ \\
\hline Mettle Softening Point $\left({ }^{\circ} \mathrm{C}\right)$ & $111.0 \pm 0.2$ & $176.4 \pm 0.2$ \\
\hline $\mathrm{T}_{\mathrm{g}}$ from DSC $\left({ }^{\circ} \mathrm{C}\right)$ & $49.7 \pm 2$ & Not Measured \\
\hline $\mathrm{T}_{\mathrm{g}}$ from Barr et al. Correlation $\left({ }^{\circ} \mathrm{C}\right)$ & $49.5 \pm 6.5$ & $104.7 \pm 9.0$ \\
\hline Density $\left(\mathrm{g} / \mathrm{cm}^{3}\right)$ & $1.18 \pm 0.05$ & $1.32 \pm 0.05$ \\
\hline Abs. Heat Capacity at $\mathrm{T}_{\mathrm{g}}\left(\mathrm{J} / \mathrm{g}^{\circ} \mathrm{C}\right)$ & $0.088 \pm 0.007$ & Not Measured \\
\hline Surface Tension $($ dynes $/ \mathrm{cm})$ & $35.7 \pm 3.1$ & $55.9 \pm 4.9$ \\
\hline
\end{tabular}

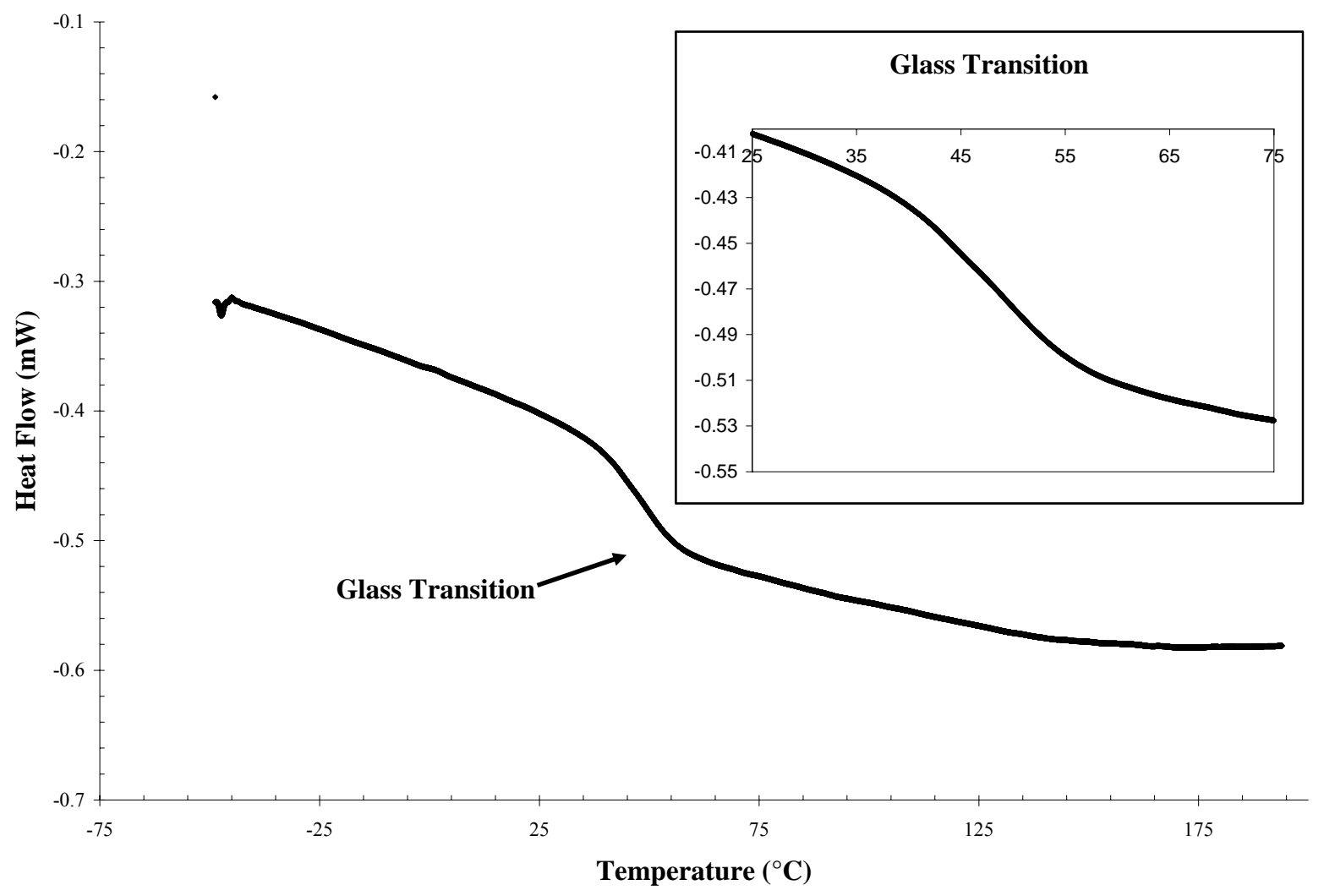

Figure 3.1: DSC of $110^{\circ} \mathrm{C}$ softening point pitch displaying the glass transition. 


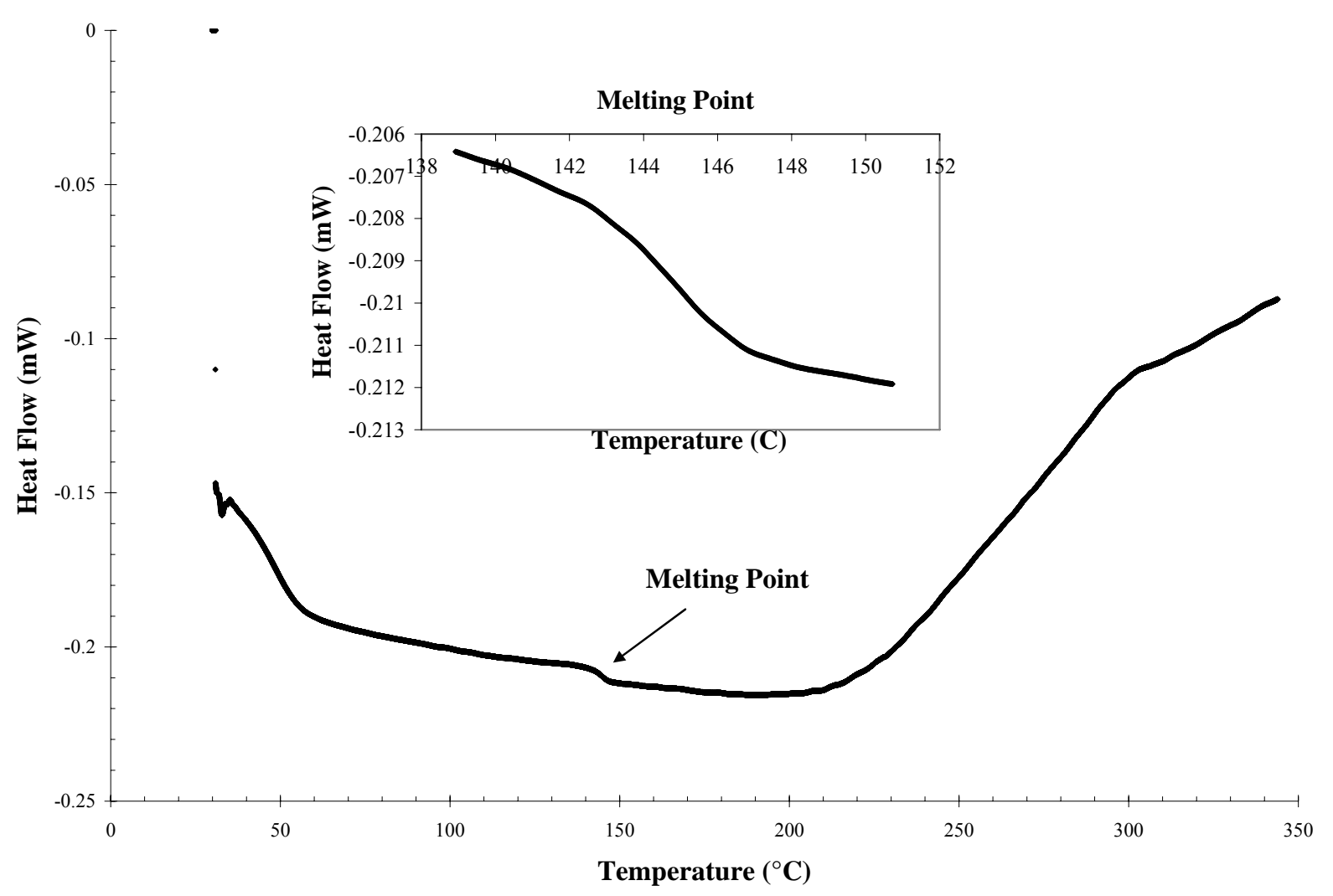

Figure 3.2: DSC of $110^{\circ} \mathrm{C}$ softening point pitch displaying the melting point.

\subsubsection{Mettler Softening Point}

The Mettler softening point is a standard characterization technique for pitches and some other glassy materials. The purpose of this test is to verify the softening point of the pitch as well as to use it in a correlation for the glass transitions temperature.

The pitches were reported to have a Mettler Softening point of $\sim 110^{\circ} \mathrm{C}$ and $\sim 180^{\circ} \mathrm{C}$ respectively by Koppers Industries Inc. This was verified by use of a Mettler Toledo FP80 controller with FP83 dropping point/softening point measuring cell. Samples for the Mettler Softening point samples were first annealed, then heated at $2^{\circ} \mathrm{C} / \mathrm{min}$ in accordance to procedures outline in the unit's operation manual and ASTM D3104-99 (2005) ${ }^{21}$. The correlation of Barr et al. was then used to calculate a $\mathrm{T}_{\mathrm{g}}$ of $104^{\circ} \mathrm{C}$ for the $180^{\circ} \mathrm{C}$ softening point pitch and $49^{\circ} \mathrm{C}$ for the $110^{\circ} \mathrm{C}$ softening point pitch. The Barr et al. correlation was used rather than that of Khandare 
because, upon attempting to air stabilize the $180^{\circ} \mathrm{C}$ softening point pitch at $110^{\circ} \mathrm{C}$, the foam matrix experienced relaxation below the $\mathrm{T}_{\mathrm{g}}$ predicted by Khandare. There was good agreement between the Barr et al. correlation and that determined from DSC. Results of these tests are listed on Table 3.2.

\subsubsection{Mass and Density Measurements}

The mass loss during the foaming operation is of interest in determining the mechanism for blowing the foam. Current coal and pitch foaming utilizes the inherent volatile mater in the pitch or coal as a blowing agent. This project is seeking to show that the use of soluble gases can produce the same effect with better control. Additionally foam making may be possible for pitch with little or no volatile content.

The mass of the samples and molds were measured and recorded with a Denver Instrument M-310 electronic balance before and after foaming to check the mass loss of the pitch.

The bulk density of the foam is one of the three main foam characteristics, the other two being cell size and cell number density. Consistent control of the bulk density is one of the primary goals in foam production.

The densities of the solid pitches were measured by a volumetric method. The mass of the pitch and volume of distilled water displaced by the pitch in a graduated cylinder for representative samples were recorded. The values listed on Table 3.3 are the mean average of three samples for the pitches used in this study

\subsubsection{Surface Tension}

Due to the difficultly in measurement and lack of test equipment, a correlation for surface tension was used. D.K.H. Briggs developed a correlation between surface tension and density for 


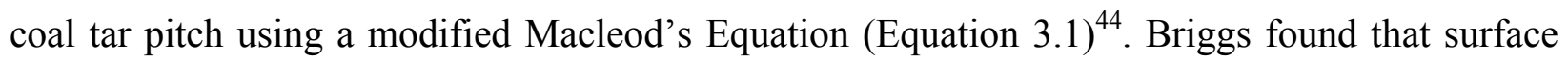
tension varied nearly linearly with temperature. Briggs used a value of $0.00056 \mathrm{~g} / \mathrm{cm}^{3 \circ} \mathrm{C}$ for the coefficient of change of density with temperature to account for the density change during heating. Briggs found that the surface tension could be calculated to $\pm 8.8 \%$ with a $95 \%$ confidence level for a variety of pitches for a temperature range of $120-220^{\circ} \mathrm{C}$. Using the Briggs correlation the surface tension for the pitches was calculated and these values are also listed on Table 3.3.

$$
\gamma=18.4 \rho^{4}
$$

It was assumed that equilibrium concentrations of $\mathrm{CO}_{2}$ and $\mathrm{N}_{2}$ had only slight impact on the surface tension at elevated pressures. This assumption is based on the effect that $\mathrm{CO}_{2}$ only reduces the surface tension by one order of magnitude for polystyrene at $4500 \mathrm{psia}^{10}$ which is well above the present experimental conditions. A similar reduction of approximately 1 order of magnitude of surface tension is seen for other polymers under similar conditions. Assuming a linear relationship between pressure-induced solubility and surface tension reduction, the reduction of surface tension per 500psi would be $\sim 2.8$ dynes $/ \mathrm{cm}$, which is within the initial error for the surface tension of the Briggs correlation at ambient pressure conditions. Additionally, the solubility of $\mathrm{CO}_{2}$ below the critical pressure is much lower than above the critical pressure (critical pressure of $\mathrm{CO}_{2}$ 1070psia), thus $\mathrm{CO}_{2}$ concentration would be significantly less in this works experimental range.

\subsubsection{Viscosity Measurements}

To produce foam, the matrix material must have some melt stability to maintain the cell structure till the bulk material is stabilized. Viscosity is one of the primary means of controlling melt stability. 
The apparent viscosity of the $110^{\circ} \mathrm{C}$ pitch was tested using a Brookfield DV-III Ultra programmable rheometer with a Themocell ${ }^{\mathrm{TM}}$ controller and Rheocalc ${ }^{\circledR}$ (ver. 1.3) control software using spindle SC-4 for low viscosity ranges. A Bohlin Instruments Rosand RH2000 capillary rheometer with a $1 \times 16 \mathrm{~mm}$ capillary was used for the $180^{\circ} \mathrm{C}$ SP pitch and for higher viscosity for the $110^{\circ} \mathrm{C}$ pitch. Raw data from these tests are in Appendix C: Raw Viscosity Data. Figure 3.3 shows viscosity curves for $180^{\circ} \mathrm{C}$ SP pitch at three different temperatures which clearly demonstrate non-Newtonian behavior.

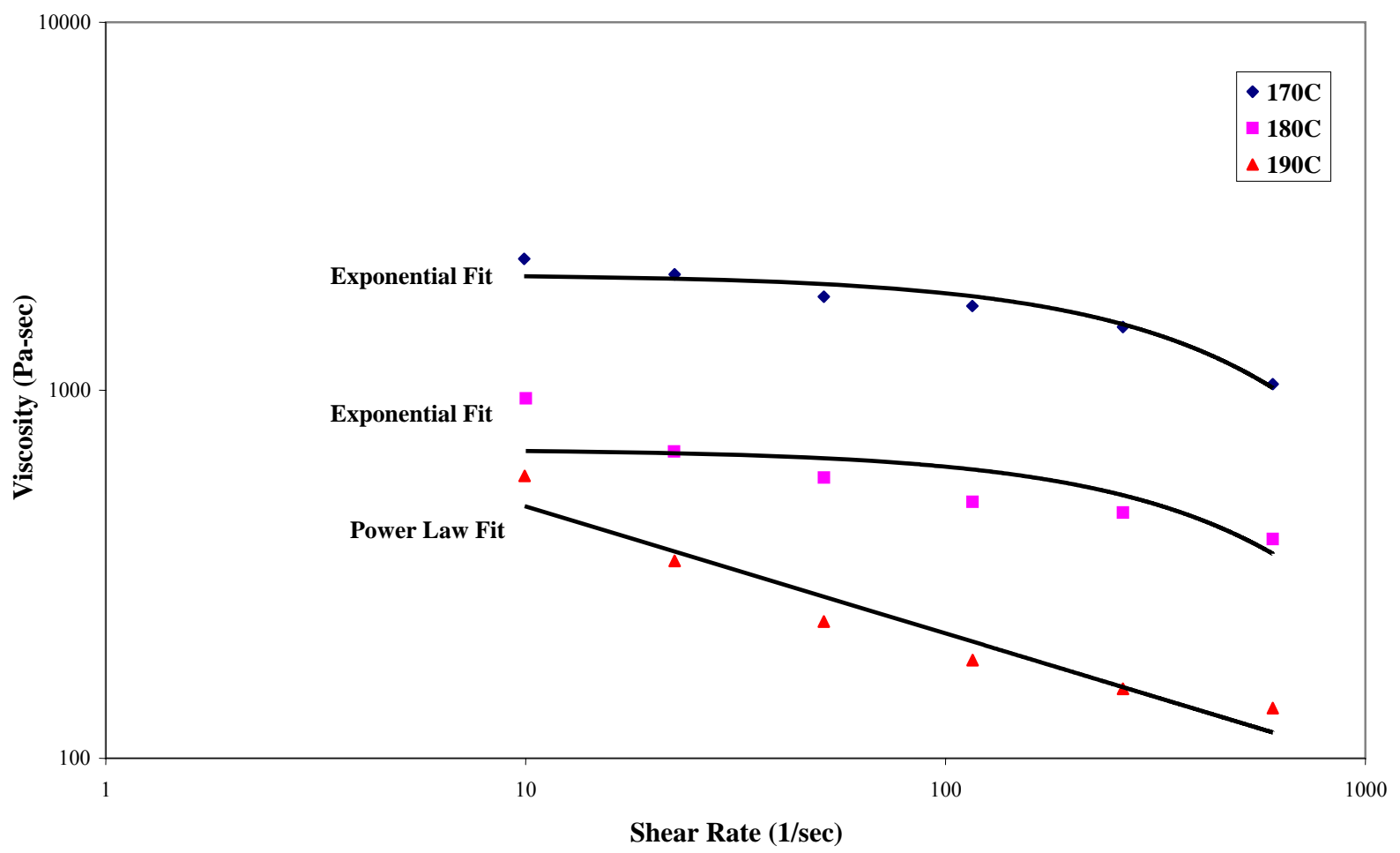

Figure 3.3: Viscosity curves for $180^{\circ} \mathrm{C}$ Softening Point Coal Tar Pitch at $170^{\circ} \mathrm{C}, 180^{\circ} \mathrm{C}$, and $190^{\circ} \mathrm{C}$.

From the data of viscosity at constant shear rate, the constants for the WFL equation (Equation 2.18) were fitted using Oakdale Engineering's DataFit (version 6.1.10) software. The calculated constants at a shear rate of $10 \sec ^{-1}$ are listed on Table 3.4. The larger error for the 
$110^{\circ} \mathrm{C}$ pitch is due to variation in the sample data obtained from the Brookfield spindle rheometer which is better suited to low viscosity fluids as apposed to viscous pitches. Figure 3.4 and Figure 3.5 show the fits of the data to the WFL model.

Table 3.4: William-Ferry-Landel Equation constants and error.

\begin{tabular}{|l|c|c|}
\cline { 2 - 3 } \multicolumn{1}{c|}{} & $\mathrm{c}_{1}$ & \multicolumn{1}{c|}{$\mathrm{c}_{2}$} \\
\hline $110^{\circ} \mathrm{C}$ & $2.54 \pm 1.14$ & $93.3 \pm 24.8$ \\
\hline $180^{\circ} \mathrm{C}$ & $1.92 \pm 0.26$ & $42.9 \pm 4.4$ \\
\hline
\end{tabular}

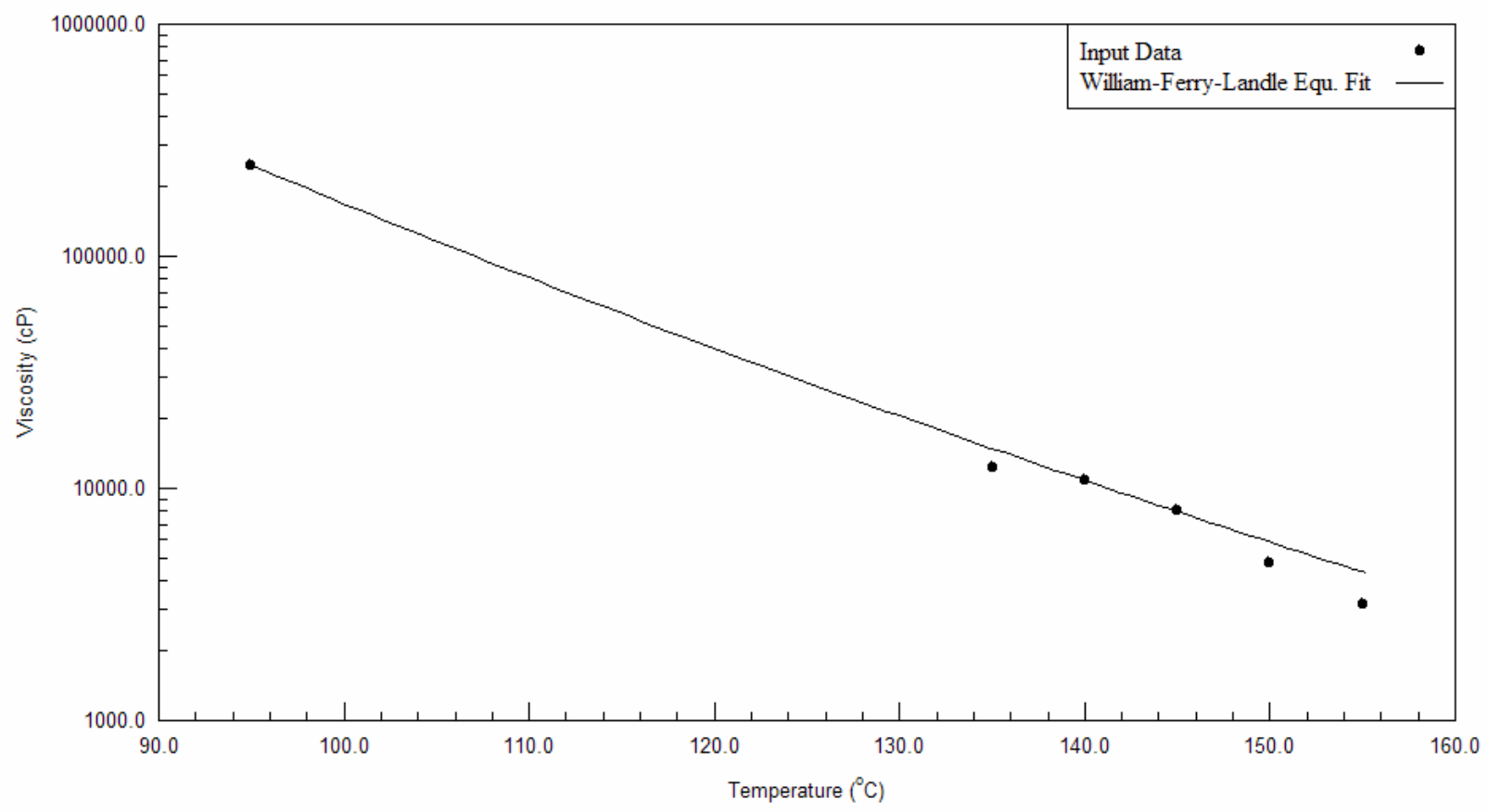

Figure 3.4: William-Landel-Ferry fit of a $110^{\circ} \mathrm{C}$ softening point coal tar pitch at a shear rate of $10 \mathrm{sec}^{-1}$ fitted by Oakdale Engineering's DataFit version 6.1.10 software. 


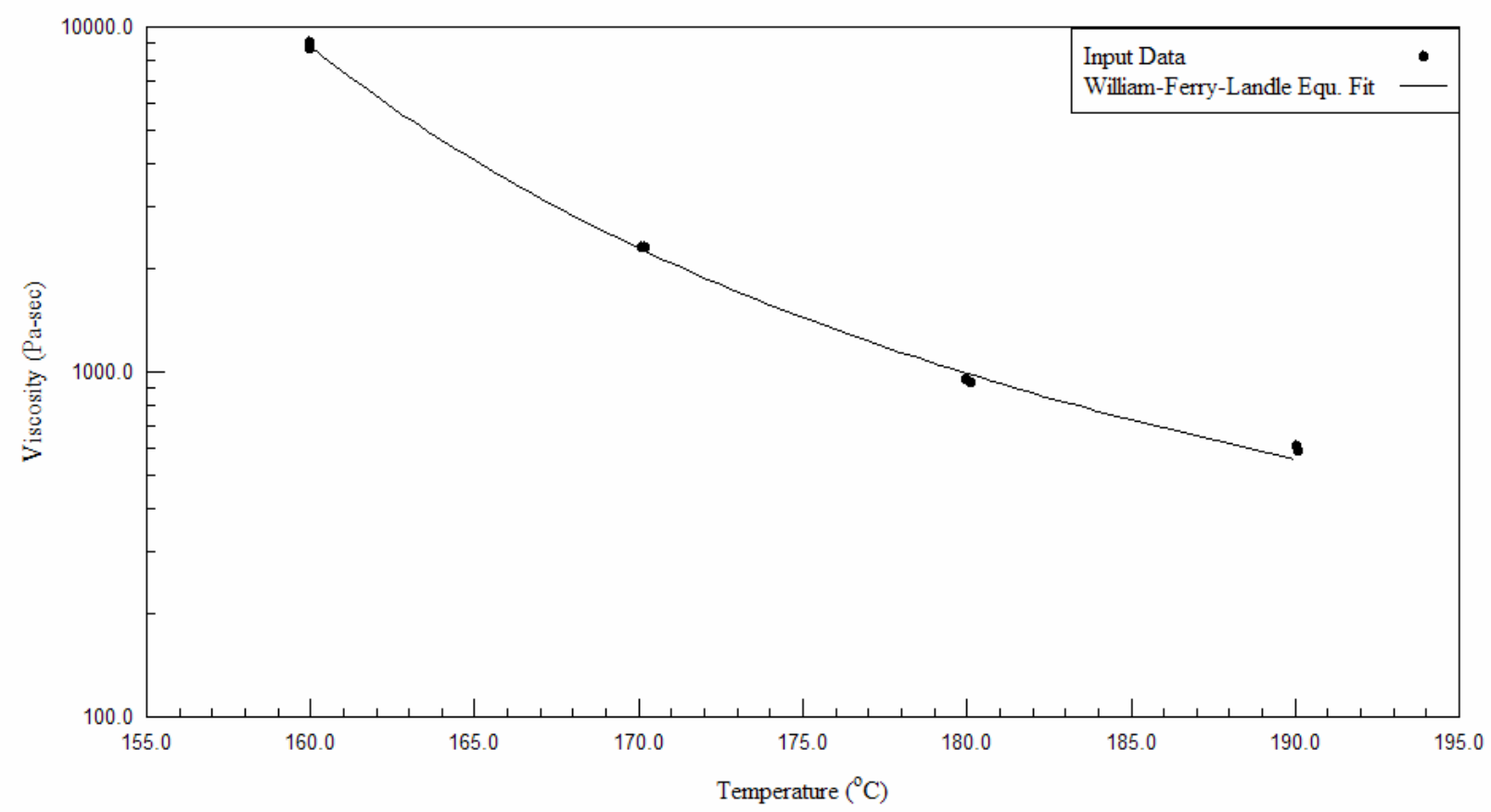

Figure 3.5: William-Landel-Ferry fit of a $180^{\circ} \mathrm{C}$ softening point coal tar pitch at a shear rate of $10 \mathrm{sec}^{-1}$ fitted by Oakdale Engineering's DataFit version 6.1.10 software.

\subsection{Blowing Agents}

Carbon dioxide, nitrogen, and water where selected as blowing agents. Both the $\mathrm{CO}_{2}$ and $\mathrm{N}_{2}$ were industrial grade, provided by Airgas Inc. and were used as received. Distilled water was produced by an in-house distillation water system. All experiments to evaluate the effects of temperature, pressure and pressure release rate were carried out using $\mathrm{CO}_{2}$ as the blowing agent due to its higher solubility in polymers than $\mathrm{N}_{2}$. Additionally, the diffusivity for $\mathrm{CO}_{2}$ is generally lower in most materials than $\mathrm{N}_{2}$ which is partly due the larger size of the $\mathrm{CO}_{2}$ molecule. $\mathrm{N}_{2}$ and water were tested to see if the process could be repeated for these physical blowing agents. Properties of the gases and water are listed in Table 3.5. 
Table 3.5: Properties of Blowing Agents at 1atm., gas densities are for $20^{\circ} \mathrm{C}^{4}$.

\begin{tabular}{|l|c|c|c|c|c|c|c|}
\hline \multicolumn{1}{|c|}{ Gas } & $\begin{array}{c}\text { Mol. } \\
\text { Wt. }\end{array}$ & $\begin{array}{c}\text { Melting } \\
\text { Point }\left({ }^{\circ} \mathrm{C}\right)\end{array}$ & $\begin{array}{c}\text { Boiling Point } \\
\left({ }^{\circ} \mathrm{C} @ 1 \mathrm{~atm}\right)\end{array}$ & $\begin{array}{c}\text { Vapor Press. at } \\
20^{\circ} \mathrm{C}(\mathrm{psia})\end{array}$ & $\begin{array}{c}\text { Gas Desn. } \\
(\mathrm{g} / \mathrm{ml})\end{array}$ & $\begin{array}{c}\text { Crit. Temp. } \\
\left({ }^{\circ} \mathrm{C}\right)\end{array}$ & $\begin{array}{c}\text { Crit. Press. } \\
(\mathrm{psia})\end{array}$ \\
\hline $\begin{array}{l}\text { Carbon } \\
\text { Dioxide, } \\
\mathrm{CO}_{2}\end{array}$ & 44.01 & -56.6 & -78.4 & 844.7 & 0.0022 & 31 & 1070 \\
\hline Nitrogen, $\mathrm{N}_{2}$ & 28.01 & -214.9 & -195.8 & N/A & 0.0012 & -146.9 & 34 \\
\hline Water, $\mathrm{H}_{2} \mathrm{O}$ & 18.02 & 0.00 & 100.0 & 17.5 & N/A & 374.2 & 3200.8 \\
\hline
\end{tabular}

\subsubsection{Gas Solubility}

It is important to remember that the solubility of gas in pitch varies as a function of composition of the pitch, temperature and pressure. As such, the solubility of blowing agents was not directly measured but a general mass percentage range of $\mathrm{CO}_{2}$ solubility for heavy petroleum fractions and bitumens was complied (Table 3.6). Due to the scope of this research, the solubility of $\mathrm{CO}_{2}$ in coal tar pitch was assumed to be similar to that of other heavy petroleum products and bitumens $^{45-48}$ of which pitch is a subcategory. By comparison to other bitumens and heavy petroleum crude at comparable conditions, the weight percent was estimated to be approximately $0.7-0.8 \mathrm{wt} \%$ at $200 \mathrm{psi}$ and $100^{\circ} \mathrm{C}$. The mass percentage is assumed to be essentially 0 at standard temperature and pressure. This assumption was made due to the low $\mathrm{CO}_{2}$ concentration $(<0.1 \mathrm{wt} \%)$ naturally present in the atmosphere and linear relationship of Henry's law between solubility and pressure. For bitumens, the linear relationship yields a mass percentage of $\sim 0.05 \mathrm{wt} \%$ under an atmosphere of pure $\mathrm{CO}_{2}$ atmosphere at $14.7 \mathrm{psia}$ and $20^{\circ} \mathrm{C}$. 
Table 3.6: Mass percentage of $\mathrm{CO}_{2}$ in select heavy petroleum fractions and bitumens ${ }^{45-48}$.

\begin{tabular}{|c|c|c|c|c|c|c|c|c|}
\hline \multicolumn{3}{|c|}{ Athabasca Bitumen } & \multicolumn{3}{|c|}{ Tar Sand Triangle Bitumen } & \multicolumn{3}{|c|}{ PR Spring Rainbow I Bitumen } \\
\hline $\begin{array}{l}\text { Temp } \\
\left({ }^{\circ} \mathrm{C}\right)\end{array}$ & $\begin{array}{l}\text { Pressure } \\
\text { (psia) }\end{array}$ & $\begin{array}{l}\text { Percent } \\
\text { Weight } \\
(\mathrm{wt} \%)\end{array}$ & $\begin{array}{l}\text { Temp } \\
\left({ }^{\circ} \mathrm{C}\right)\end{array}$ & $\begin{array}{l}\text { Pressure } \\
\text { (psia) }\end{array}$ & $\begin{array}{l}\text { Percent } \\
\text { Weight } \\
(\mathrm{wt} \%)\end{array}$ & Temp $\left({ }^{\circ} \mathrm{C}\right)$ & $\begin{array}{c}\text { Pressure } \\
\text { (psia) }\end{array}$ & $\begin{array}{l}\text { Percent } \\
\text { Weight } \\
(\mathrm{wt} \%)\end{array}$ \\
\hline 27 & 100 & 0.31 & 27 & 100 & 0.44 & 27 & 100 & 0.36 \\
\hline 27 & 894 & 3.62 & 27 & 803 & 3.19 & 27 & 803 & 3.18 \\
\hline 100 & 100 & 0.28 & 100 & 100 & 0.36 & 100 & 100 & 0.43 \\
\hline 100 & 894 & 3.37 & 100 & 803 & 2.94 & 100 & 803 & 3.02 \\
\hline $\begin{array}{l}\text { Interp. } \\
\left(100^{\circ} \mathrm{C}\right)\end{array}$ & 200 & 0.72 & $\begin{array}{c}\text { Interp. } \\
\left(100^{\circ} \mathrm{C}\right)\end{array}$ & 200 & 0.73 & $\begin{array}{c}\text { Interp. } \\
\left(100^{\circ} \mathrm{C}\right)\end{array}$ & 200 & 0.8 \\
\hline \multicolumn{3}{|c|}{ WCLP Faction } & \multicolumn{3}{|c|}{ Exxon B Cut 4} & & & \\
\hline 103 & 83.5 & 0.46 & 200 & 109 & 0.19 & & & \\
\hline 103 & 256.3 & 1.62 & 200 & 265 & 1.16 & & & \\
\hline 275 & 117.6 & 0.36 & 298 & 102 & 0.37 & & & \\
\hline 275 & 247 & 0.8 & 298 & 265 & 1 & & & \\
\hline $\begin{array}{l}\text { Interp. } \\
\left(200^{\circ} \mathrm{C}\right)\end{array}$ & 200 & 0.78 & $\begin{array}{l}\text { Interp. } \\
\left(200^{\circ} \mathrm{C}\right)\end{array}$ & 200 & 0.75 & & & \\
\hline
\end{tabular}

\subsubsection{Reduction of Glass Transition by Blowing Agent}

As stated in Section 2.3.8 Rheologic Models, the reduction of $\mathrm{T}_{\mathrm{g}}$ due to diluents can be estimated from the Chow Correlation (Equation 2.19). The reduction in $T_{g}$ was calculated from the experimental data for the heat capacity and glass transition of the pure pitch (Table 3.3), and the properties of the blowing agent (Table 3.5). The repeat molecular weight unit of the pitch, $\mathrm{M}_{\mathrm{p}}$, and lattice constant, $z$, were assumed to be 81 Daltons and 1 respectively due to the cyclic and aromatic structure of pitch. Normally a value for $z$ set to 1 or 2 causes only a slight variation in results. The reductions of the $\mathrm{T}_{\mathrm{g}}$ due to $\mathrm{CO}_{2}$ and $\mathrm{N}_{2}$ diluted pitch systems were calculated and are shown on Table 3.7. 
Table 3.7: Reduction of glass transition temperature due to diluent predicted by Chow Correlation.

\begin{tabular}{|l|c|c|c|c|c|c|c|c|c|}
\cline { 2 - 10 } \multicolumn{1}{c|}{} & \multicolumn{8}{c|}{ Weight Percent of Diluent (wt\%) } \\
\cline { 2 - 11 } \multicolumn{1}{c|}{} & 0 & 0.25 & 0.5 & 1.0 & 2.0 & 3.0 & 5.0 & 10 & 15 \\
\hline $\mathbf{C O}_{2}$ & & & & & & & & & \\
\hline $\begin{array}{l}110^{\circ} \mathrm{C} \text { Softening Point } \\
\text { Pitch } \mathrm{T}_{\mathrm{g}}\left({ }^{\circ} \mathrm{K}\right)\end{array}$ & 323.0 & 319.6 & 316.1 & 309.4 & 296.4 & 283.9 & 260.6 & 211.2 & 174.0 \\
\hline $\begin{array}{l}180^{\circ} \mathrm{C} \text { Softening Point } \\
\text { Pitch } \mathrm{T}_{\mathrm{g}}\left({ }^{\circ} \mathrm{K}\right)\end{array}$ & 453.0 & 450.9 & 448.9 & 444.8 & 436.8 & 428.9 & 413.6 & 378.5 & 348.6 \\
\hline $\mathbf{N}_{\mathbf{2}}$ & & & & & & & & & \\
\hline $\begin{array}{l}110^{\circ} \mathrm{C} \text { Softening Point } \\
\left.\text { Pitch } \mathrm{T}_{\mathrm{g}}{ }^{\circ} \mathrm{K}\right)\end{array}$ & 323.0 & 317.6 & 312.3 & 302.0 & 282.6 & 264.7 & 233.0 & 174.8 & 142.9 \\
\hline $\begin{array}{l}180^{\circ} \mathrm{C} \mathrm{Softening} \mathrm{Point} \\
\text { Pitch } \mathrm{T}_{\mathrm{g}}\left({ }^{\circ} \mathrm{K}\right)\end{array}$ & 453.0 & 449.8 & 446.6 & 440.3 & 428.1 & 416.4 & 394.5 & 349.3 & 320.7 \\
\hline
\end{tabular}

As can be seen from Table 3.7, the reduction of $\mathrm{T}_{\mathrm{g}}$ decreases about $13^{\circ} \mathrm{C}$ for a $\mathrm{CO}_{2}$ diluent weight percent of $1.0 \mathrm{wt} \%$ which is about the equilibrium concentration at the experimental temperature and pressure conditions employed in this work.

\subsection{Foam Process Variables Experiments}

The third objective was to evaluate how the variables for pitch production compare to those for polymer foams. This involved evaluation of some of the pitch properties (viscosity, heat capacity, gas solubility, etc.) in comparison to various polymers and then comparing pitch to polymer foams. From the review of polymer foaming theory, three significant and readily adjustable variables were identified. These are temperature, initial pressure and pressure release rate. The experimental matrix for the temperature, pressure, and pressure drop rate variables is shown on Table 3.14. Due to the size of the pressure vessel, multiple samples could be produced simultaneously. This allowed testing of nucleating agent concentration effect (Table 3.13). This was carried out with a batch foaming method similar to that preformed by Maio et $\mathrm{al}^{13}$. Three blowing agents were selected for consideration and comparison: carbon dioxide, nitrogen, and water. 
The temperature is a significant controller for viscosity of pitches and polymers. From polymer foaming theory, the viscosity influences the cell size and cell number density of the foam. By varying the temperature, and thus controlling the viscosity while maintaining constant saturation pressure and pressure release rate, the general effect of viscosity can be observed and compared (Table 3.8). The temperature was varied so that a suitable viscosity range for foaming could be determined for the $110^{\circ} \mathrm{C}$ softening point pitch. This data were then used to achieve a similar viscosity range for the $180^{\circ} \mathrm{C}$ softening point pitch.

Table 3.8: Temperature evaluation experiments.

\begin{tabular}{|c|c|c|c|c|c|}
\hline Run & $\begin{array}{c}\text { Pitch SP } \\
\left({ }^{\circ} \mathrm{C}\right)\end{array}$ & $\begin{array}{c}\text { Saturation } \\
\text { Temperature }\left({ }^{\circ} \mathrm{C}\right)\end{array}$ & Saturation Gas & $\begin{array}{c}\text { Saturation Pressure } \\
(\mathrm{psi})\end{array}$ & $\begin{array}{c}\text { Pressure Release Rate } \\
(\mathrm{psi} / \mathrm{sec})\end{array}$ \\
\hline 1 & 110 & 95 & $\mathrm{CO}_{2}$ & 200 & 22 \\
\hline 2 & 110 & 100 & $\mathrm{CO}_{2}$ & 200 & 22 \\
\hline 3 & 110 & 110 & $\mathrm{CO}_{2}$ & 200 & 22 \\
\hline
\end{tabular}

The initial pressure influences the equilibrium concentration of blowing agent in the melt. From Henry's Law, the concentration of gas dissolved increases proportionately with increasing pressure. By controlling the initial pressure, and thereby controlling the concentration of blowing agent in the melt, the effect of concentration can be observed while holding the temperature and pressure release rate constant (Table 3.9). These experiments were conducted with the $180^{\circ} \mathrm{C}$ softening point pitch.

Table 3.9: Initial pressure evaluation experiments

\begin{tabular}{|c|c|c|c|c|c|}
\hline Run & $\begin{array}{c}\text { Pitch SP } \\
\left({ }^{\circ} \mathrm{C}\right)\end{array}$ & $\begin{array}{c}\text { Saturation } \\
\text { Temperature }\left({ }^{\circ} \mathrm{C}\right)\end{array}$ & Saturation Gas & $\begin{array}{c}\text { Saturation Pressure } \\
(\mathrm{psi})\end{array}$ & $\begin{array}{c}\text { Pressure Release } \\
\text { Rate }(\mathrm{psi} / \mathrm{sec})\end{array}$ \\
\hline 5 & 180 & 155 & $\mathrm{CO}_{2}$ & 80 & 16 \\
\hline 6 & 180 & 155 & $\mathrm{CO}_{2}$ & 150 & 21 \\
\hline 7 & 180 & 155 & $\mathrm{CO}_{2}$ & 200 & 8 \\
\hline
\end{tabular}


The pressure release rate is the third variable to be examined. High pressure release rates in polymer foam, thermodynamically favor new cell nucleation rather than cell growth by diffusion. The pressure release rate experiments were conducted with the $180^{\circ} \mathrm{C}$ softening point pitch (Table 3.10).

Table 3.10: Pressure release rate evaluation experiments.

\begin{tabular}{|c|c|c|c|c|c|}
\hline Run & $\begin{array}{c}\text { Pitch SP } \\
\left({ }^{\circ} \mathrm{C}\right)\end{array}$ & $\begin{array}{c}\text { Saturation } \\
\text { Temperature }\left({ }^{\circ} \mathrm{C}\right)\end{array}$ & Saturation Gas & $\begin{array}{c}\text { Saturation Pressure } \\
(\mathrm{psi})\end{array}$ & $\begin{array}{c}\text { Pressure Release } \\
\text { Rate (psi/sec) }\end{array}$ \\
\hline 7 & 180 & 155 & $\mathrm{CO}_{2}$ & 200 & 8 \\
\hline 8 & 180 & 155 & $\mathrm{CO}_{2}$ & 220 & 13 \\
\hline 9 & 180 & 155 & $\mathrm{CO}_{2}$ & 200 & 15 \\
\hline
\end{tabular}

The experimental tests listed above were conducted using $\mathrm{CO}_{2}$ as the blowing agent for direct comparison of cell formation results. Additionally, $\mathrm{N}_{2}$ and water were tested as blowing agents in comparison to $\mathrm{CO}_{2}$ as possible alternate blowing agents (Table 3.11).

Table 3.11: Evaluation of other blowing agents experiments.

\begin{tabular}{|c|c|c|c|c|c|}
\hline Run & $\begin{array}{c}\text { Pitch SP } \\
\left({ }^{\circ} \mathrm{C}\right)\end{array}$ & $\begin{array}{c}\text { Saturation } \\
\text { Temperature }\left({ }^{\circ} \mathrm{C}\right)\end{array}$ & Saturation Gas & $\begin{array}{c}\text { Saturation Pressure } \\
(\mathrm{psi})\end{array}$ & $\begin{array}{c}\text { Pressure Release } \\
\text { Rate (psi/sec) }\end{array}$ \\
\hline 1 & 110 & 95 & $\mathrm{CO}_{2}$ & 200 & 22 \\
\hline 4 & 110 & 90 & $\mathrm{~N}_{2}$ & 200 & 20 \\
\hline 9 & 180 & 155 & $\mathrm{CO}_{2}$ & 200 & 15 \\
\hline 10 & 180 & 155 & $\mathrm{CO} 2 \& \mathrm{H} 2 \mathrm{O}$ & 200 & 28 \\
\hline
\end{tabular}

Experimental runs 11 to 14 were used to produce samples for mechanical strength testing in compression Instron tests (Table 3.12). 
Table 3.12: Evaluation sample runs for mechanical testing.

\begin{tabular}{|c|c|c|c|c|c|}
\hline Run & $\begin{array}{c}\text { Pitch SP } \\
\left({ }^{\circ} \mathrm{C}\right)\end{array}$ & $\begin{array}{c}\text { Saturation } \\
\text { Temperature }\left({ }^{\circ} \mathrm{C}\right)\end{array}$ & Saturation Gas & $\begin{array}{c}\text { Saturation Pressure } \\
(\mathrm{psi})\end{array}$ & $\begin{array}{c}\text { Pressure Release } \\
\text { Rate (psi/sec) }\end{array}$ \\
\hline 11 & 180 & 160 & $\mathrm{CO}_{2}$ & 200 & 28 \\
\hline 12 & 180 & 155 & $\mathrm{CO}_{2}$ & 240 & 37 \\
\hline 13 & 180 & 155 & $\mathrm{CO}_{2}$ & 220 & 8 \\
\hline 14 & 180 & 155 & $\mathrm{CO}_{2}$ & 200 & 33 \\
\hline
\end{tabular}

Due to the size of the pressure vessel, four samples can be run at a time (Table 3.13). This allows the production of four samples under identical experimental conditions. Thus variations of pitch and foaming additives can be observed. This feature was utilized while observing the effect of talc addition, a nucleating agent in polymeric foam production, to the pitch. A pure pitch sample together with three other samples containing talc mass percentage from none up to $10 \mathrm{wt} \%$ were foamed simultaneously and examined.

Table 3.13: Sample Talc weight percent example

\begin{tabular}{|c|c|c|c|c|}
\hline Sample \# & a & b & c & d \\
\hline Talc wt $\%$ & 0 & $\sim 0.1$ & $\sim 0.5$ & $\sim 2.0$ \\
\hline
\end{tabular}


Table 3.14: Complete experimental variable matrix. A specific matrix is given for each variable in the section discussed.

\begin{tabular}{|c|c|c|c|c|c|}
\hline Run & $\begin{array}{c}\text { Pitch SP } \\
\left({ }^{\circ} \mathrm{C}\right)\end{array}$ & $\begin{array}{c}\text { Saturation } \\
\text { Temperature }\left({ }^{\circ} \mathrm{C}\right)\end{array}$ & Saturation Gas & $\begin{array}{c}\text { Saturation Pressure } \\
(\mathrm{psi})\end{array}$ & $\begin{array}{c}\text { Pressure Release Rate } \\
(\mathrm{psi} / \mathrm{sec})\end{array}$ \\
\hline 1 & 110 & 95 & $\mathrm{CO}_{2}$ & 200 & 22 \\
\hline 2 & 110 & 100 & $\mathrm{CO}_{2}$ & 200 & 22 \\
\hline 3 & 110 & 110 & $\mathrm{CO}_{2}$ & 200 & 22 \\
\hline 4 & 110 & 90 & $\mathrm{~N}_{2}$ & 200 & 16 \\
\hline 5 & 180 & 155 & $\mathrm{CO}_{2}$ & 80 & 21 \\
\hline 6 & 180 & 155 & $\mathrm{CO}_{2}$ & 150 & 8 \\
\hline 7 & 180 & 155 & $\mathrm{CO}_{2}$ & 200 & 13 \\
\hline 8 & 180 & 155 & $\mathrm{CO}_{2}$ & 220 & 28 \\
\hline 9 & 180 & 155 & $\mathrm{CO}_{2}$ & 200 & 37 \\
\hline 10 & 180 & 155 & $\mathrm{CO}_{2} \& \mathrm{H}_{2} \mathrm{O}$ & 200 & 8 \\
\hline 11 & 180 & 160 & $\mathrm{CO}_{2}$ & 200 & 33 \\
\hline 12 & 180 & 155 & $\mathrm{CO}_{2}$ & 240 & 220 \\
\hline 13 & 180 & 155 & $\mathrm{CO}_{2}$ & 200 & \\
\hline 14 & 180 & 155 & $\mathrm{CO}_{2}$ & & 20 \\
\hline
\end{tabular}

\subsubsection{Batch Foaming Operation}

Sample preparation for pure ground pitch and samples containing talc are as follows. Approximately $25 \mathrm{~g}$ of coal tar pitch was weighed into a beaker. An amount of talc was added to the pitch and was varied from 0 to $10 \%$ by weight. The contents of the beaker where transferred to a plastic bag and tumble mixed to provide uniform talc distribution. The pitch or pitch/talc mixtures were placed in $250 \mathrm{ml}$ beakers lined with aluminum foil (Figure 3.6). The foil lining was to aid in removal of the foam samples without damage to the beakers. Sample beakers were placed in a high-temperature pressure vessel (Figure 3.7) which was then sealed. The pressure vessel was placed in a Paragon TnF-82-3 kiln equipped with a DTC 1000 temperature controller. High-pressure gas fittings were connected to the vessel and the vessel was pressurized with $\mathrm{CO}_{2}$ to the predetermined pressure. The vessel was then heated to the predetermined temperature (Table 3.14) from the results of the proof of concept experiments where viscosity was sufficient to maintain cell integrity. A heating rate of $5^{\circ} \mathrm{C} / \mathrm{min}$ was used and the temperature held for 2 
hours. Thermal equilibrium was assumed to be reached at the end of the 2 hours. It is unknown if the gas concentration in the melt reached the equilibrium concentration, but the equilibrium concentration from other heavy petroleum fractions and bitumens provides an upper concentration limit for the pitch. Upon completion of the thermal saturation period, the pressure was quickly released via a needle valve in the exit line. Pressure release rate was measured as the saturation pressure divided by the time to reach atmospheric. It was assumed that the pressure release rate was linear in character for ease of calculation. The pressure release rate to atmospheric pressure was varied between 9 and $28 \mathrm{psi} / \mathrm{sec}(62$ to $193 \mathrm{kPa} / \mathrm{sec})$ depending upon test conditions. The pressure vessel was removed hot from the kiln and the samples were removed from the vessel as quickly as possible to increase cooling of the samples. Upon solidifying, the samples were removed from the foil-lined beakers for examination and testing.

To test if $\mathrm{N}_{2}$ was sufficiently soluble to produce foam, the same process as outlined above was repeated, except that $\mathrm{N}_{2}$ was substituted for $\mathrm{CO}_{2}$ to pressurize the vessel. To test the possible synergism of water as a blowing agent, liquid water was added to the ground pitch and blended. The pitch/water mixture was placed in the pressure vessel as above and the vessel was pressurized with $\mathrm{CO}_{2}$ to maintain the water in liquid form until the pressure release was performed. These samples were then compared to samples prepared using $\mathrm{CO}_{2}$ alone as the blowing agent. 


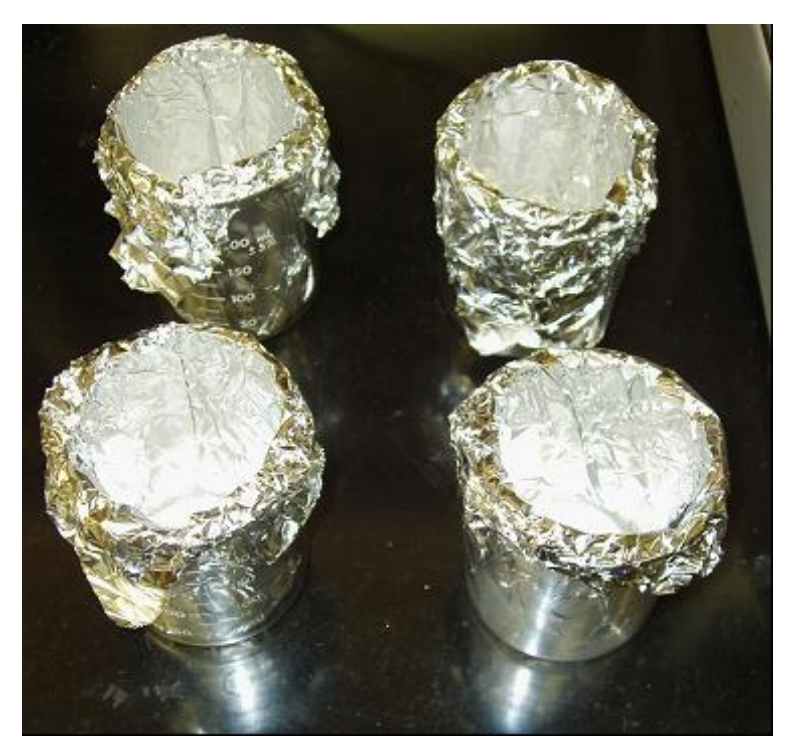

Figure 3.6: Batch sample molds.

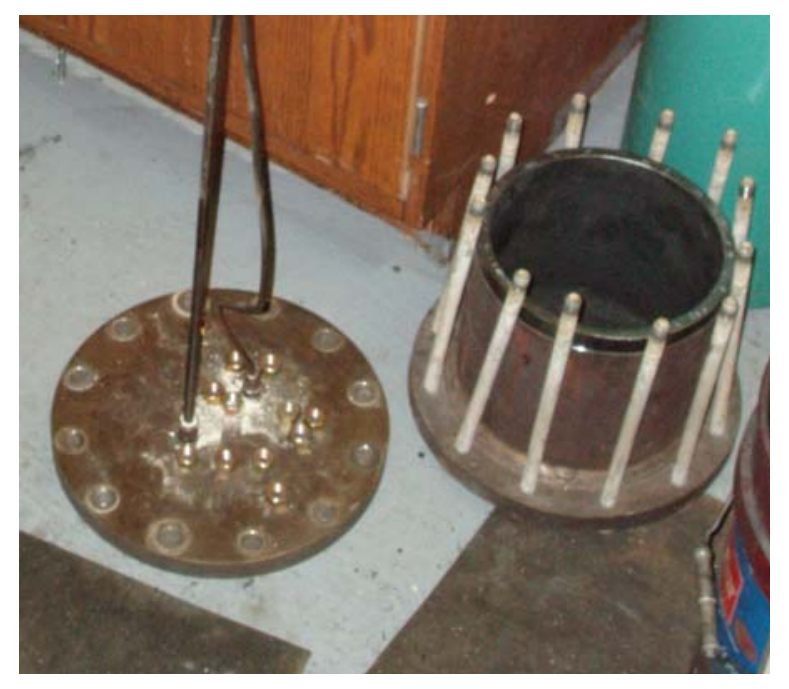

Figure 3.7: High temperature pressure vessel.

\subsubsection{Batch Extrusion}

An apparatus was constructed to test the applicability of pitch foam production by an extrusion process. The apparatus consisted of 1-inch OD stainless-steel tube equipped with pressure fittings and wrapped in heating tape (Figure 3.8). The apparatus was loaded with between 30-50grams of pitch and sealed. The apparatus was then pressurized to between 200 to 500 psig with the desired gas and heated to soften the pitch and further increase the pressure in the vessel until the predetermined temperature was reached $\left(70-155^{\circ} \mathrm{C}\right.$ for $110^{\circ} \mathrm{C}$ softening point 
pitch). The temperature was then held for 30 minutes to allow for thermal equilibrium and gas dissolution. After thirty minutes, a ball valve located at the bottom of the apparatus was opened and the pitch forced out to the atmosphere by the back pressure of the system. This results in near instantaneous pressure release and foam formation. Higher pressures and temperatures were used for this process in comparison to the batch process due to the pressure and lower viscosity needed to force the pitch out of the valve.

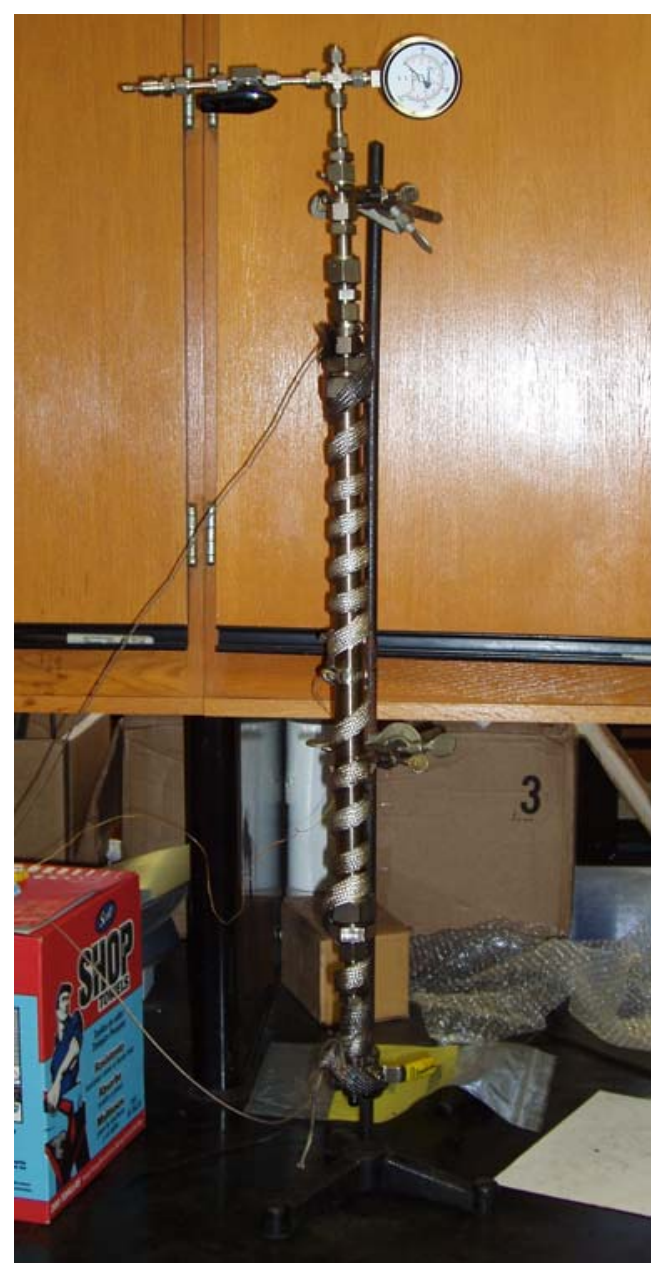

Figure 3.8: Experimental batch extrusion apparatus. 


\subsection{Analysis of Produced Foams}

The produced foam was analyzed by optical microscopy and by SEM to determine cell size and character. Mechanical analysis and physical density measurements will also be carried out in order to compare with commercial carbon foams.

\subsubsection{Bulk Density Measurements}

The bulk densities of the foam were determined by measuring the dimensions of the sample and calculating its volume. The mass of the foam was recorded by Denver Instrument M310 electronic balance and divided by the calculated volume to give bulk density. The bulk densities thus determined are approximate as the samples are irregular in shape. Some of the representative bulk densities are listed on Table 4.4 through Table 4.6.

\subsubsection{Scanning Electron Microscopy}

Determination of the cell size and foam character can be difficult due to the size of the cells (can be in tenths of micrometers). Visual inspection via optical microscopy can provide data on the cell structure provided there is a powerful enough light source and a material that is somewhat reflective. Another technique for surface imaging is Scanning Electron Microscopy (SEM). SEM uses an electron beam which scatters upon striking the samples surface. The scattered electron patterns are detected and converted into images by a computer.

Pitch foam samples were characterized on a Hitachi S-4700 SEM with a cold-field emission source. SEM was used to visually characterize the size and number density of cells formed in the pitch. SEM was used instead of optical microscopy due the availability and higher quality imaging capabilities. All images used in direct comparison of foam samples are of the same magnification (30X or $60 \mathrm{X})$ as indicated on the micrographs. 


\subsubsection{Mechanical Testing}

One of the driving factors in developing materials is to improve performance per some key variable (i.e. cost, weight, strength, etc.). For foam, some of the important mechanical performance parameters are compressive modulus and strength which relate to how much energy the foam can receive without damage and how much energy can be absorbed by the cell structure under impact.

Multiple cylindrical samples were fashioned from parent samples of foam using a carbide-tipped hole saw with approximately 1 inch interior diameter yielding a cylinder of 1 -inch O.D. The top and bottom surface of the compression samples are planed flat and parallel with a carbide-tipped band saw resulting in sample between 0.5-1.5inchs long. An Instron table-top load frame Model 5869 with a $50 \mathrm{kN}$ load cell was used to obtain compressive modulus and strength of some of the pitch foam samples. Currently, there is no standard test method for measuring foam compressive modulus and strength of carbon and pitch foams. Therefore the method developed by Carpenter was employed ${ }^{49}$. Data obtained on the foam made in this work are compared with other carbon foams tested by the same method. They are also compared to properties reported by Koppers Industries Inc. and Touchstone Research Laboratory Ltd. for their $\mathrm{KFOAM}^{\mathrm{TM}}$ and $\mathrm{CFOAM}{ }^{\circledR}$ carbon foams products.

\subsection{Stabilization}

Air stabilization is a process of heating pitch in the presence of oxygen to promote crosslinking and evaporation of volatiles in the pitch thereby reducing the soluble content, and increasing its softening point and $\mathrm{T}_{\mathrm{g}}$. The hydrogen-to-carbon ratio $(\mathrm{H} / \mathrm{C})$ can be used as an indicator of the degree of stabilization ${ }^{36}$. Usually, the stabilization process is continued below the $T_{g}$ till softening does not occur. Once this point is reached, other thermal processes can be carried out without concern for the pitch remelting. 
Air stabilization was attempted on some of the $180^{\circ} \mathrm{C}$ softening point pitch samples. This involved heating the foam samples in air at a rate of $5^{\circ} \mathrm{C} / \mathrm{min}$ to $110^{\circ} \mathrm{C}$ and holding for 18 hours in an oven, then raising the temperature to $125^{\circ} \mathrm{C}$ at $5^{\circ} \mathrm{C} / \mathrm{min}$ and holding for an additional 24 hours. No stabilization was attempted on the $110^{\circ} \mathrm{C}$ softening point pitch samples due to their low $\mathrm{T}_{\mathrm{g}}\left(\sim 50^{\circ} \mathrm{C}\right)$. 


\section{Chapter IV \\ Results}

\subsection{Proof of Concept}

Optical examination of the low softening point pitch that underwent pressurization, heating and pressure drop showed the formation of cells within the pitch. The product fits the description of cellular material as described in Section 2.1.2 Cellular Materials. This result was considered positive and encouraged the further detailed study described earlier. From these results, pitch properties were examined and the effect of the selected process variable was investigated. The focus of this study is on parameters known to effect foam manufacture using external blowing agents and polymers. Those parameters are: temperature, blowing agent concentration, and pressure release rate. Additionally, investigations were done on the strength of the foam produced, application of various blowing agents, and nucleating agents.

\subsection{Pitch Examination}

The properties of pitch are in many ways comparable to polymers (Table 4.1). One of the significant differences is the presence of volatile content in the pitch. The volatile content does not have a counterpart in polymers. Because the process temperature is less than the degradation temperature, it is expected that the volatile content will not affect the processing techniques. The high volatile content is of concern in stabilizing the pitch foam to produce carbon foam. The pitch also has higher heat capacity than the common polymers listed in Table 4.1. The higher heat capacity should not affect the processing techniques other than increasing the heat input needed to reach proper processing temperature. 
Table 4.1: Comparison of the two coal tar pitches with some common polymers ${ }^{10} . M_{p}$ is the molecular weight of the repeat unit of the molecule.

\begin{tabular}{|l|c|c|c|c|c|c|c|}
\cline { 2 - 8 } \multicolumn{1}{c|}{} & Pitch $110^{\circ} \mathrm{C} \mathrm{SP}$ & Pitch $180^{\circ} \mathrm{C} \mathrm{SP}$ & PVC & PS & PC & PET & PMMA \\
\hline Density $(\mathrm{g} / \mathrm{cm} 3)$ & 1.18 & 1.32 & 1.36 & 1.05 & 1.2 & 1.33 & 1.18 \\
\hline $\mathrm{Tg}\left({ }^{\circ} \mathrm{C}\right)$ & 49 & 104 & 75 & 100 & 148 & 74 & 105 \\
\hline $\mathrm{Cp}\left(\mathrm{Cal} / \mathrm{g}^{\circ} \mathrm{C}\right)$ & 0.021 & Not Measured & 0.0693 & 0.0767 & 0.0585 & 0.0812 & 0.0746 \\
\hline $\mathrm{Mp}(\mathrm{g} / \mathrm{mol})$ & $81^{*}$ & $81^{*}$ & 62.5 & 104 & 254 & 192 & 100 \\
\hline
\end{tabular}

* assumed repeat unit of pitch from aromatic structure.

It is documented in the polymer literature that $\mathrm{CO}_{2}$ and other gases cause a plasticizing effect on polymer melts. Using the same method for calculating the reduction of $\mathrm{T}_{\mathrm{g}}$ in polymers, via the Chow correlation, Equation 2.19, it as shown that the reduction of $\mathrm{T}_{\mathrm{g}}$ due to dissolution of $\mathrm{CO}_{2}$ in pitch under experimental conditions of the present work was approximately $1^{\circ} \mathrm{C}$ (Table 3.7). From the calculations, the plasticization effect due to $\mathrm{N}_{2}$ was about double that of $\mathrm{CO}_{2}$ due to its lower molecular weight though $\mathrm{N}_{2}$ is less soluble in most polymers. $\mathrm{N}_{2}$ solubility in polymers is usually about one order of magnitude less than $\mathrm{CO}_{2}$ under the same conditions. Information concerning the solubility of $\mathrm{N}_{2}$ in pitch and other heavy organic fractions at elevated temperatures and pressures is basically nonexistent at this time. This lower solubility of $\mathrm{N}_{2}$ seen in polymers may hold true for pitch as well. For the scope of this research, the plasticization effect of the soluble blowing agent is not significant until the weight percent is $\sim 4 \%$ or more. The general trend shown from the Chow correlation for the $110^{\circ} \mathrm{C}$ softening point pitch is approximately a $1{ }^{\circ} \mathrm{C}$ reduction in $\mathrm{T}_{\mathrm{g}}$ per $1 \mathrm{wt} \%$ of $\mathrm{CO}_{2}$ up to $10 \mathrm{wt} \%$, at which point the Chow correlation become invalid due to assumptions in the theory. A weight percent of $4 \mathrm{wt} \%$, or greater, may well occur if supercritical $\mathrm{CO}_{2}$ is used due to superior solvent properties over gaseous $\mathrm{CO}_{2}$, though the Chow equation may not be applicable for supercritical fluids.

\subsection{Foam Examination: Batch}

Upon removal of pitch foam samples from the pressure vessel, samples were first examined visually. All samples resembled hockey pucks. Most samples had a smooth polished 
surface. Samples containing high talc mass percentage had a powdery or dusty surface. Samples ranged in height from $\sim 1 / 2$ to 2 inches depending upon processing conditions. Visual examination of cut samples showed a majority of the cells to be closed with limited interconnection.

Mass measurements of the pitch sample before and after foaming showed an average mass loss of $0.2 \%$ with standard deviation of $0.08 \%$ per sample for the $180^{\circ} \mathrm{C}$ softening point pitch. Thus, mass loss from the samples during the foaming processing of the samples was negligible. The mass loss coupled with the large volatile fraction shown by proximate analysis raises the question as to where the mass loss comes from, and if cell formation and growth maybe due to the mass loss. The mass loss is less than $1 \%$ of the volatile content present in the pitch, whereas it is $\sim 100 \%$ of the moisture content present in the $180^{\circ} \mathrm{C}$ softening point pitch before addition of any blowing agent or thermal treatment.

Coal tar pitch volatiles are composed of polycyclic aromatic hydrocarbons, PAHS, which consist of benzo(a)pyrene, anthracene, phenanthrene, pyrene, carbazole, and many other compounds. Of the five primary volatile components, only one has a melting point below $155^{\circ} \mathrm{C}$ (phenanthrene) with a vapor pressure of $0.005 \mathrm{psia}$ (Table 4.2). Thus all of these components should not evaporate under the experimental conditions. In addition, the process conditions are too mild to facilitate cracking of the pitch and no other compounds were added that would evaporate during the heating process.

The vapor pressure of water on the other hand, is $83.7 \mathrm{psia}$ at $155^{\circ} \mathrm{C}$ (Table 4.2). The average mass fraction of water from proximate analysis was $0.19 \%$ (Table 3.2 ), practically identical to the mass lost during foaming process. 
Table 4.2: Common boiling, fusion points, and vapor pressure (from Antoine equation) at $155^{\circ} \mathrm{C}$ for coal tar pitch volatiles and water ${ }^{46}$.

\begin{tabular}{|l|c|c|c|}
\hline Name & Boiling Point $\left({ }^{\circ} \mathrm{C}\right)$ & Melting $\left({ }^{\circ} \mathrm{C}\right)$ & Vapor Pressure (psia) \\
\hline Benzo(a)pyrene & 495 & 177 & n/a \\
\hline Anthracene & 340 & 217 & n/a \\
\hline Phenanthrene & $328-340$ & 99 & 0.005 \\
\hline Pyrene & None listed & 423 & n/a \\
\hline Carbazole & 355 & 248 & n/a \\
\hline Water & 100 & 0 & 83.7 \\
\hline
\end{tabular}

The comparison of the temperatures of melting and vapor pressures between coal tar volatiles and water makes it likely that the mass loss is due to evaporation of the moisture at some point during processing, most likely during the final pressure release to atmospheric pressure.

The minimum quantity of blowing agent to account for the increase of bulk density change (bulk density, $\rho_{\mathrm{s}}$ minus pitch density, $\rho_{\mathrm{f}}$ ), assuming no diffusion, isothermal conditions, and no relaxation of the foam structure, can be calculated from Equation 4.1. For example, a foam sample of $180^{\circ} \mathrm{C}$ softening point pitch foamed at $155^{\circ} \mathrm{C}$, had a final density of $0.66 \mathrm{~g} / \mathrm{cm}^{3}$ (averages quantities for $180^{\circ} \mathrm{C}$ pitch foam from all samples), a $97 \%$ increase in volume per unit mass over the starting pitch feedstock. The minimum mass of blowing agent needed per unit mass of pitch was calculated from Equation 4.1 using a table of fluid properties from the National Institute of Standards and Technology for $\mathrm{CO}_{2}, \mathrm{~N}_{2}$ and water. Assuming no loss of blowing agent and isothermal conditions, the results are listed in Table 4.3. From Table 4.3, the weight percentage of $\mathrm{CO}_{2}$ needed for the average bulk density reduction is $0.27 \mathrm{wt} \%$, which is about $2 / 5$ the estimated equilibrium concentration $(0.7-0.8 \mathrm{wt} \%)$ of $\mathrm{CO}_{2}$ in heavy petroleum fractions and bitumens at the previous experimental conditions. For water, a weight percentage of only $0.10 \mathrm{wt} \%$ is needed for the same bulk density reduction. It is highly possible that the moisture present in the pitch is at least partly responsible for cell formation in the pitch. This can 
be inferred from the significant change in bulk density produced above and below $100^{\circ} \mathrm{C}$ for the $110^{\circ} \mathrm{C}$ softening point pitch samples (see Table 4.4, in Section 4.3.1.1 Temperature below).

$$
\left(\frac{1}{\rho_{s}-\rho_{f}}\right)\left(\frac{\text { mass blowing agent }}{\text { mass matrix material }}\right)=\text { Blowing Agent Volume Change }
$$

Table 4.3: Change in volume per gram of blowing agent at $155^{\circ} \mathrm{C}$ from a pressure release of $215 p s i a$ to $15 p s i a$ from NIST phase data ${ }^{46}$ and mass of blowing agent needed per mass of pitch to reduce bulk density from $1.3 \mathrm{~g} / \mathrm{ml}$ to $0.66 \mathrm{~g} / \mathrm{cm}^{3}$ assuming isothermal conditions and no loss of blowing agent.

\begin{tabular}{|l|c|c|}
\hline & $\Delta$ Sp. Vol. $(\mathrm{ml} / \mathrm{g})$ & Minimum Mass of Blowing Agent/Mass Pitch $(\mathrm{g} / \mathrm{g})$ \\
\hline $\mathrm{CO}_{2}(\mathrm{ml} / \mathrm{g})$ & 727.545 & 0.0027 \\
\hline $\mathrm{N}_{2}(\mathrm{ml} / \mathrm{g})$ & 1142.944 & 0.0017 \\
\hline Water $(\mathrm{ml} / \mathrm{g})$ & 1932.905 & 0.0010 \\
\hline
\end{tabular}

It should be further noted that a number of samples in the higher temperature tests experienced coalescence of the cell in the center of the samples and formed large voids. This may be due to the temperature gradient in the sample during removal, which caused the center of the sample to take longer for stabilization of the cell matrix. Physical jarring during removal coupled with the temperature gradient in the samples may be the cause of the structural collapse and void formation (Figure 4.1). 


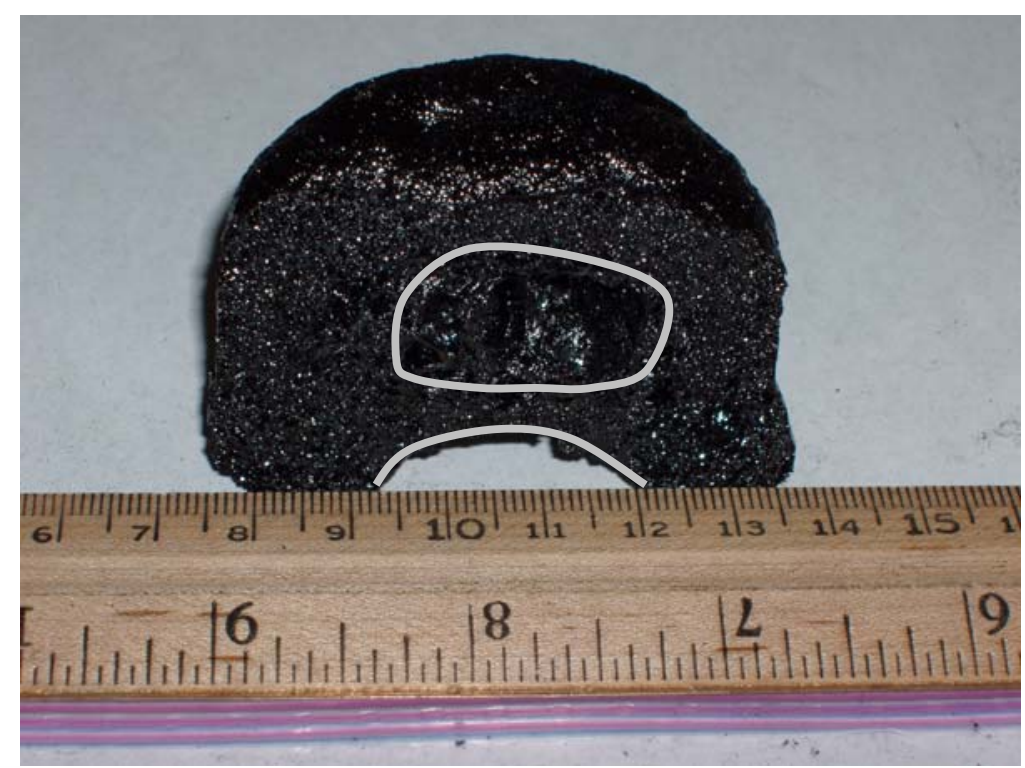

Figure 4.1: Voids present in some of pitch foam samples, possibly due to shock during removal from kiln.

\subsubsection{Effect of Variables}

The properties of fluids vary but the equations governing the nucleation and growth of cells in fluids are essentially the same for all fluids. For viscous polymers, the effect of temperature, blowing agent concentration and pressure release rate on cell nucleation and growth behavior are fairly consistent. This uniformity of viscous polymer melts appears to hold for viscous pitch melts as well. Each of these effects are separately described below in detail. Table 3.14 describes the experimental conditions each for sample and is reproduced below. Samples 110 were produced for SEM examination, while samples 11-14 were produced for mechanical testing. 
Table 3.14: Complete experimental variable matrix. A specific matrix is given for each variable and discussion is given in Chapter 3.

\begin{tabular}{|c|c|c|c|c|c|}
\hline Run & $\begin{array}{c}\text { Pitch SP } \\
\left({ }^{\circ} \mathrm{C}\right)\end{array}$ & $\begin{array}{c}\text { Saturation } \\
\text { Temperature }\left({ }^{\circ} \mathrm{C}\right)\end{array}$ & Saturation Gas & $\begin{array}{c}\text { Saturation Pressure } \\
(\mathrm{psi})\end{array}$ & $\begin{array}{c}\text { Pressure Release Rate } \\
(\mathrm{psi} / \mathrm{sec})\end{array}$ \\
\hline 1 & 110 & 95 & $\mathrm{CO}_{2}$ & 200 & 22 \\
\hline 2 & 110 & 100 & $\mathrm{CO}_{2}$ & 200 & 22 \\
\hline 3 & 110 & 110 & $\mathrm{CO}_{2}$ & 200 & 22 \\
\hline 4 & 110 & 90 & $\mathrm{~N}_{2}$ & 200 & 16 \\
\hline 5 & 180 & 155 & $\mathrm{CO}_{2}$ & 80 & 21 \\
\hline 6 & 180 & 155 & $\mathrm{CO}_{2}$ & 150 & 8 \\
\hline 7 & 180 & 155 & $\mathrm{CO}_{2}$ & 200 & 13 \\
\hline 8 & 180 & 155 & $\mathrm{CO}_{2}$ & 220 & 28 \\
\hline 9 & 180 & 155 & $\mathrm{CO}_{2}$ & 200 & 37 \\
\hline 10 & 180 & 155 & $\mathrm{CO}_{2} \& \mathrm{H}_{2} \mathrm{O}$ & 200 & 8 \\
\hline 11 & 180 & 160 & $\mathrm{CO}_{2}$ & 200 & 33 \\
\hline 12 & 180 & 155 & $\mathrm{CO}_{2}$ & 240 & 220 \\
\hline 13 & 180 & 155 & $\mathrm{CO}_{2}$ & 200 & \\
\hline 14 & 180 & 155 & $\mathrm{CO}_{2}$ & & 28 \\
\hline
\end{tabular}

\subsubsection{Nucleating Agents}

The proximate analysis of the pitch showed measurable amounts of ash, water, and a significant volatile fraction, all of which could have an influence on cell formation. The ash present in the pitch is likely to act as a nucleating agent similar to talc or other solid particles in polymer melts. The quantities of ash were of the same order of magnitude as most of the talc concentrations added to the pitch. In examination of the samples, no distinguishable difference in cell size or foam density was detected until the talc mass percentage was greater than one order of magnitude over that of the ash present in the pitch (Figure 4.2). This is in agreement with literature because normally a significant difference is not expected in the cell characteristics with the addition of nucleating agent until its mass percentage is greater than one order of magnitude than that of the species already present. 

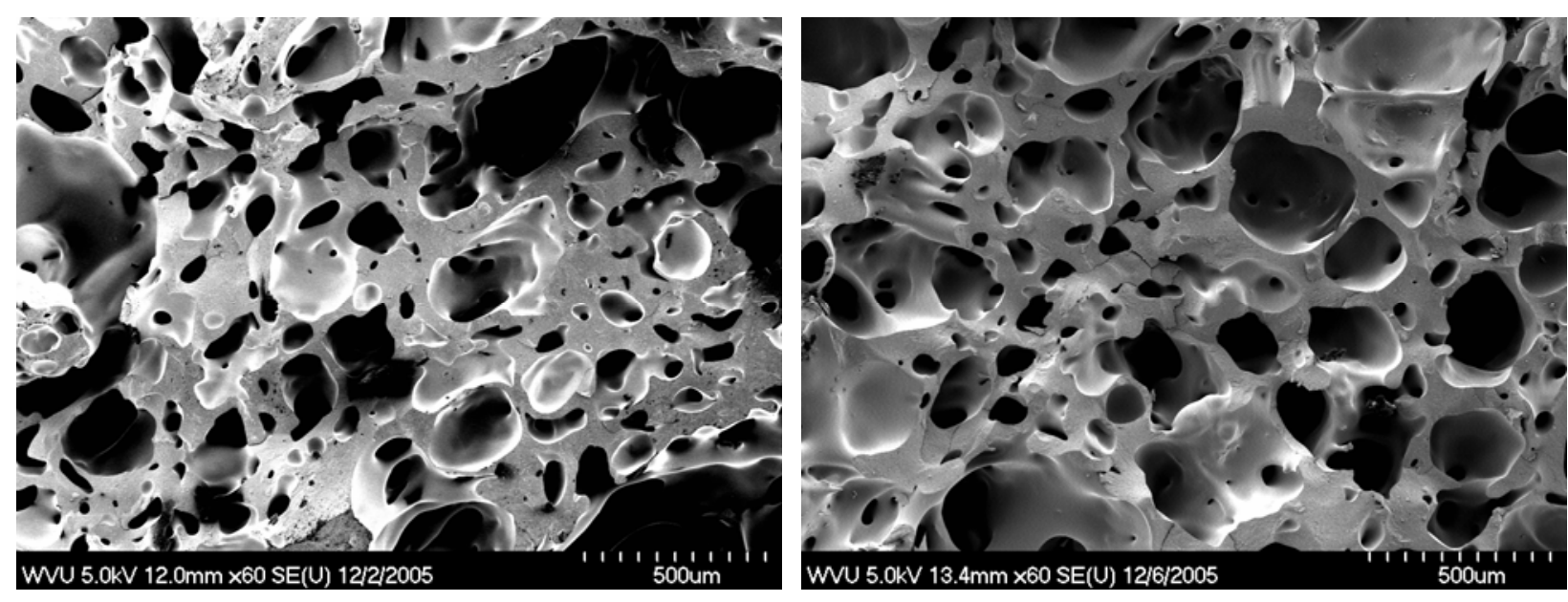

Figure 4.2: No distinguishable difference between pitch foam with and without talc for a talc concentration of the same order of magnitude as ash present in the pitch. $110^{\circ} \mathrm{C}$ softening point pitch foam at $90^{\circ} \mathrm{C}$ and 200psig, Left: no talc, Right: 1.9 wt \% talc.

\subsubsection{Temperature}

As noted in previous sections, temperature is the primary means of controlling the viscosity of thermoplastic materials. From inspection of Equation 2.10, it is evident that viscosity hinders the growth of cells in melts, but aids in the melt stability. As is seen in Equations 2.4, 2.7, and 2.12, temperature also influences the nucleation and diffusion of cells through the exponential term. From Equations 2.4, 2.7, the increased temperature aids in increasing the number of nucleated cells. In Equation 2.12, temperature increases the diffusion of the blowing agent thereby increasing cell growth and countering nucleation at lower blowing agent concentrations. With the competing mechanisms associated with increased temperature, what is normally seen with polymer foams is an increase in cell size and some reduction of cell number density. Comparing SEM micrographs in Figure 4.3 through Figure 4.5 (magnification 30X for all), by increasing the temperature, thereby reducing the viscosity, it can be seen that cell size increases with reduced viscosity. This same effect is seen in polymer foaming practice. It is difficult to determine the size of a cell because it is unknown at what point the examined crosssection intersects a cell and a natural size distribution occurs. Additionally cells can be non- 
spherical in shape. The approximate range of cell sizes could inferred from the scale index on the SEM pictures. Bulk density also decreases with viscosity. This is a consequence of the larger cell size formed at the higher temperature.

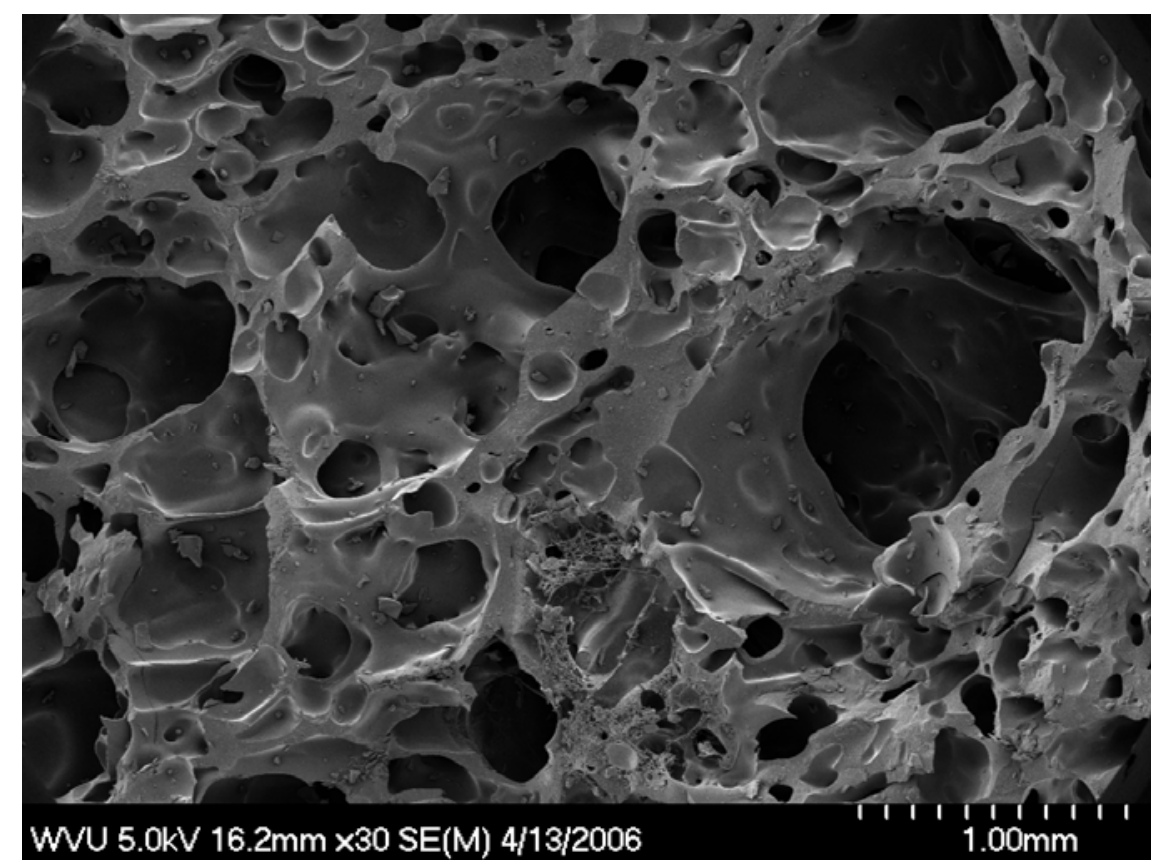

Figure 4.3: SEM of sample $1\left(110^{\circ} \mathrm{C}\right.$ SP pitch foam prepared at $95^{\circ} \mathrm{C}$ and 200psig of $\left.\mathrm{CO}_{2}\right)$.

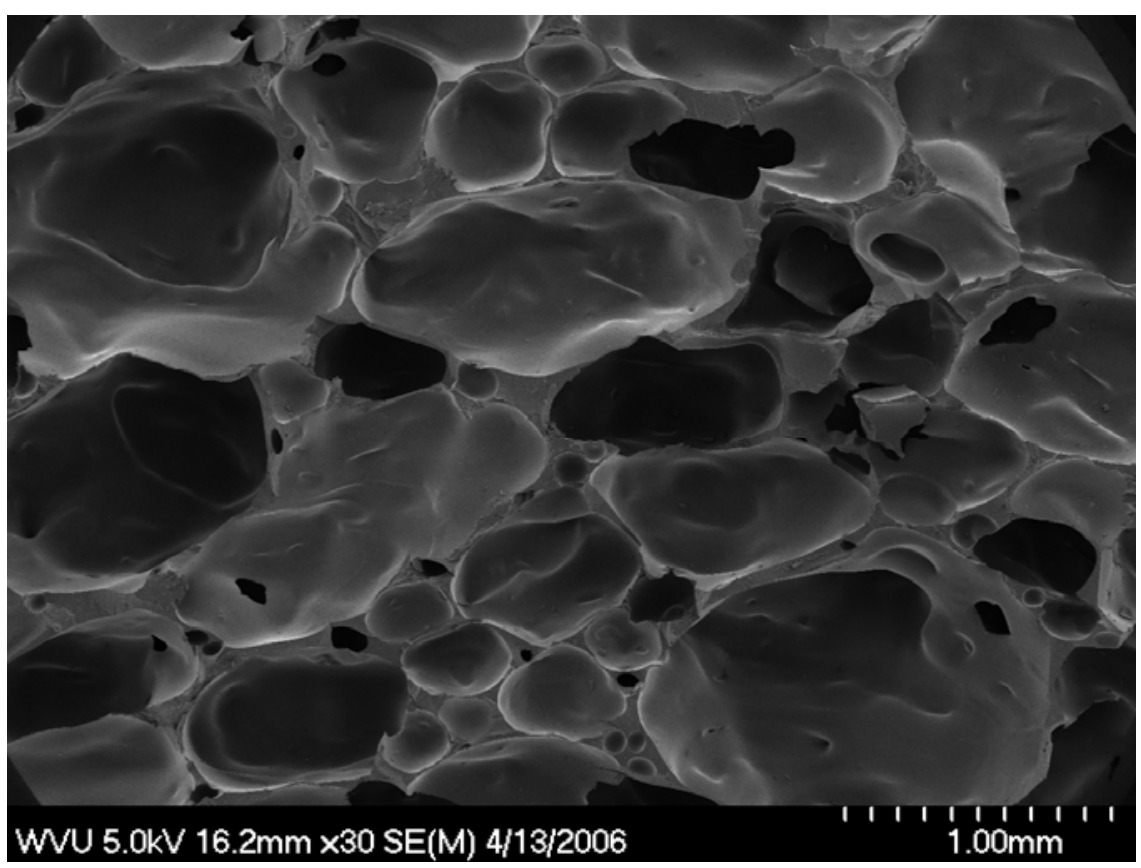

Figure 4.4: SEM of sample $2\left(110^{\circ} \mathrm{C}\right.$ SP pitch foam prepared at $100^{\circ} \mathrm{C}$ and $200 \mathrm{psig}$ of $\left.\mathrm{CO}_{2}\right)$. 


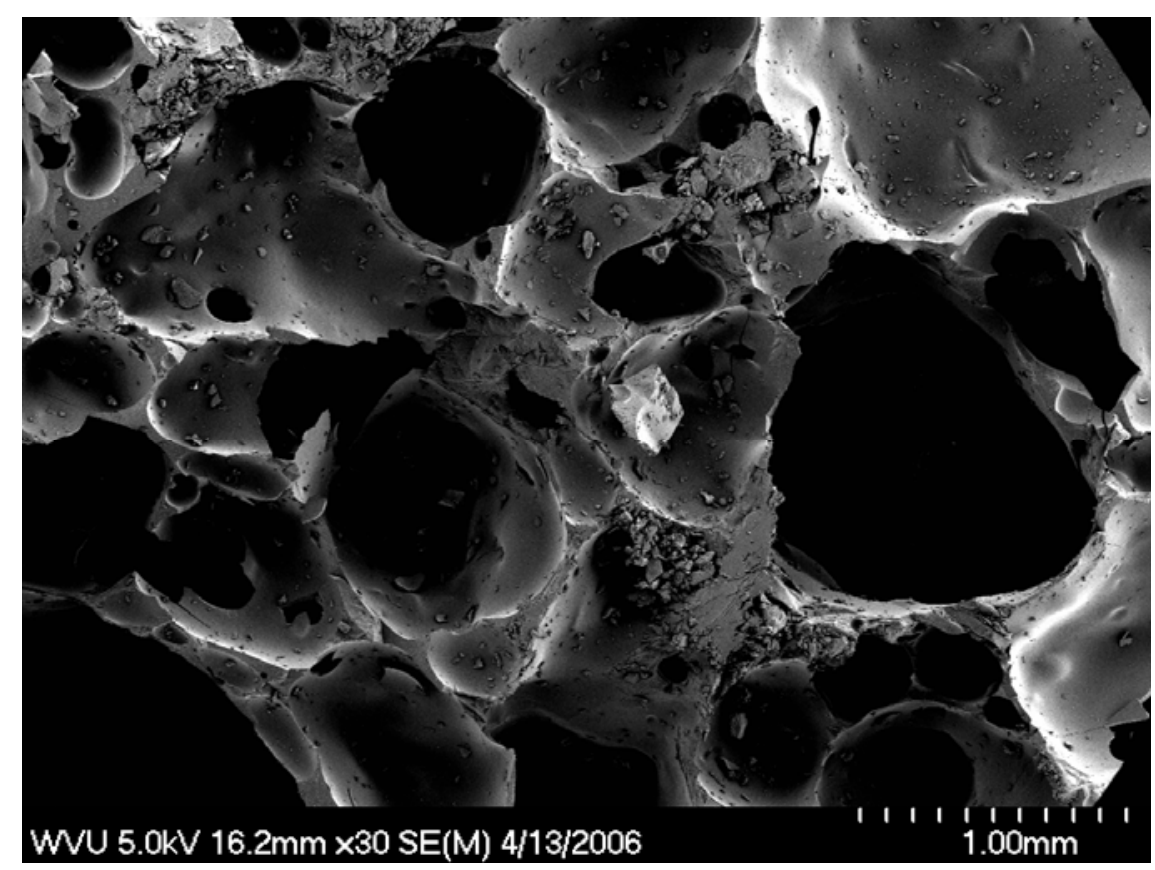

Figure 4.5: SEM of sample $3\left(110^{\circ} \mathrm{C}\right.$ SP pitch foam prepared at $105^{\circ} \mathrm{C}$ and $200 \mathrm{psig}$ of $\left.\mathrm{CO}_{2}\right)$.

Table 4.4: Bulk density variation of samples at increasing temperature (decreasing viscosity) and cell size range of a $110^{\circ} \mathrm{C}$ softening point pitch foamed under $200 \mathrm{psig}$ of $\mathrm{CO}_{2}$.

\begin{tabular}{|c|c|c|c|}
\hline Sample & Process Temperature $\left({ }^{\circ} \mathrm{C}\right)$ & Foam Bulk Density $(\mathrm{g} / \mathrm{cm})$ & Cell Size Range $(\mu \mathrm{m})$ \\
\hline 1 & $95^{\circ} \mathrm{C}$ & $0.65 \pm 0.08$ & $20-150$ \\
\hline 2 & $100^{\circ} \mathrm{C}$ & $0.27 \pm 0.05$ & $40-150$ \\
\hline 3 & $105^{\circ} \mathrm{C}$ & $0.29 \pm 0.03$ & $80-140$ \\
\hline
\end{tabular}

\subsubsection{Initial Pressure}

As noted in previous sections, the pressure controls the concentration of blowing agent in the melt. From Henry's Law, increasing the gas pressure on a melt increases the equilibrium concentration of the blowing agent in the melt. From Equations 2.4, 2.7, 2.10, and 2.12, it can be seen that initial blowing agent concentration influences the nucleation and growth of cells. From polymer foaming practice, generally an increase in cell number density or cell size is observed with increased blowing agent concentration ${ }^{51}$. Figure 4.5 through Figure 4.8 show an increase in cell density when temperature is held constant and $\mathrm{CO}_{2}$ overpressure is increased. It is interesting 
to note that variation of the pressure had little effect on the density of the samples (Table 4.5).

This may be an artifact of the testing, or the change in blowing agent concentration is not significant enough to affect bulk density. It is unclear which this may be.

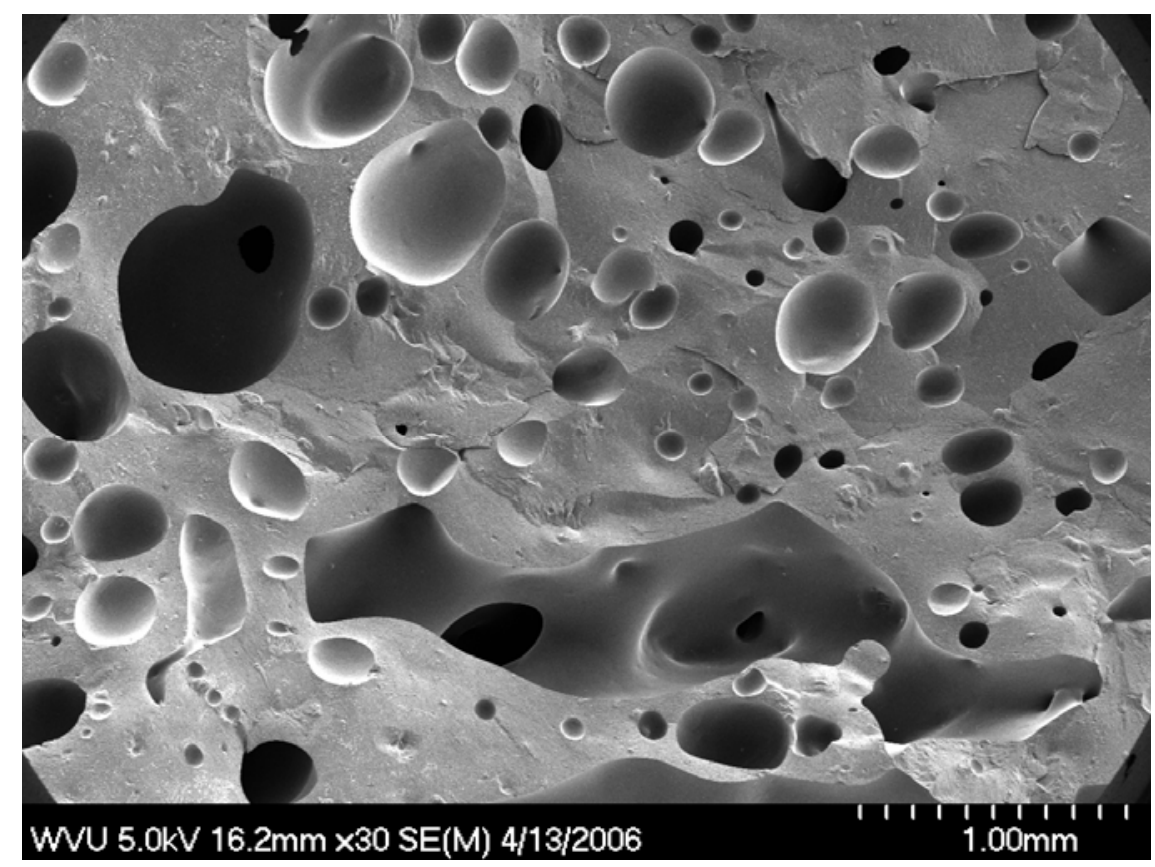

Figure 4.6: SEM of sample $5\left(180^{\circ} \mathrm{C}\right.$ SP pitch foam prepared at $155^{\circ} \mathrm{C}$ and 80psig of $\left.\mathrm{CO}_{2}\right)$.

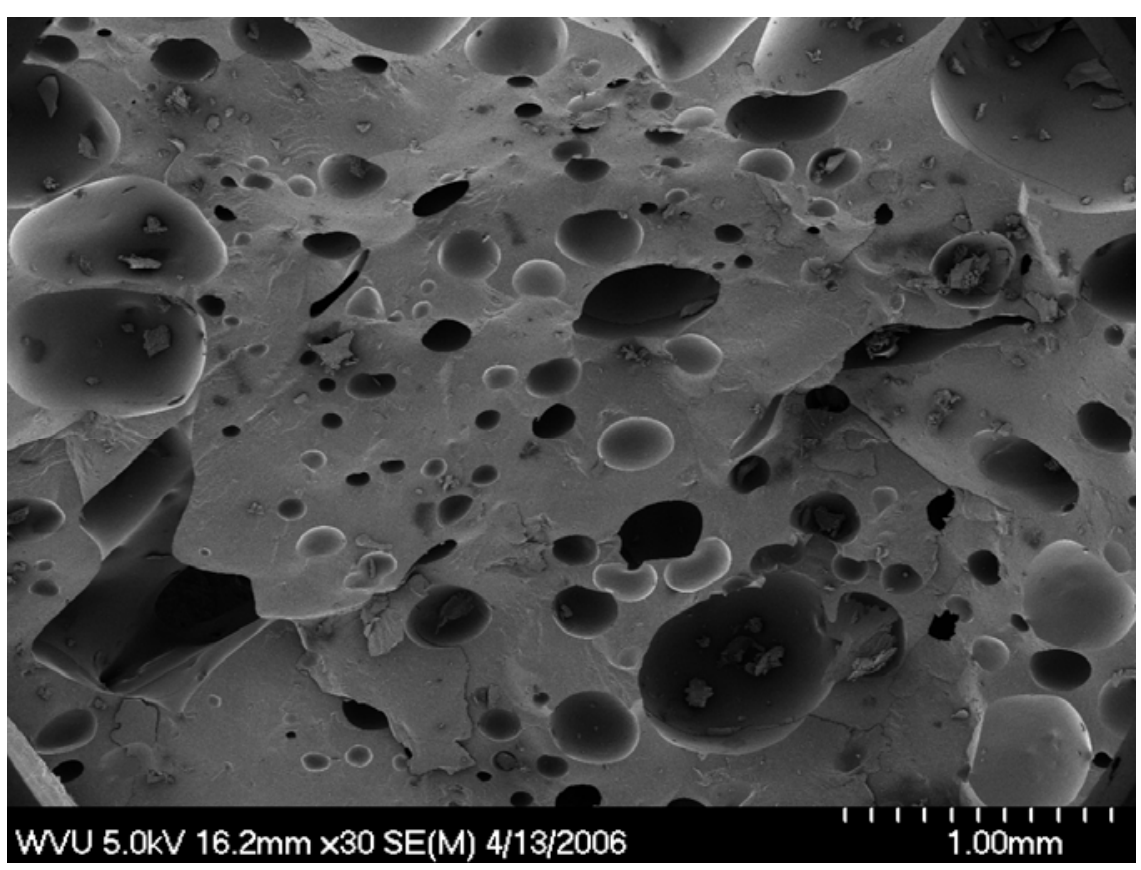

Figure 4.7: SEM of sample $6\left(180^{\circ} \mathrm{C}\right.$ SP pitch foam prepared at $155^{\circ} \mathrm{C}$ and $150 \mathrm{psig}$ of $\left.\mathrm{CO}_{2}\right)$. 


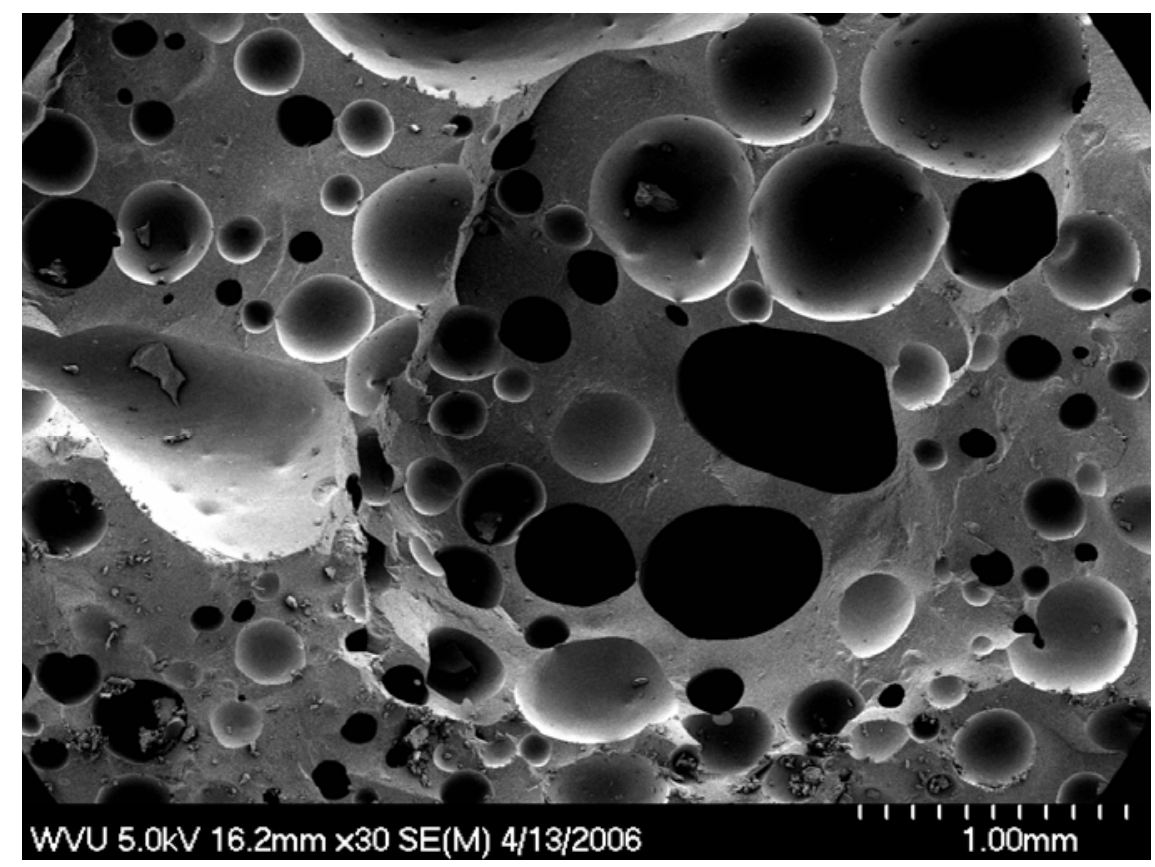

Figure 4.8: SEM of sample $8\left(180^{\circ} \mathrm{C}\right.$ SP pitch foam prepared at $155^{\circ} \mathrm{C}$ and 220psig of $\left.\mathrm{CO}_{2}\right)$.

Table 4.5: Bulk density of samples and cell size range with increasing overpressure of $\mathrm{CO}_{2}$ for foam from the $180^{\circ} \mathrm{C}$ softening point pitch produced at $155^{\circ} \mathrm{C}$ and $\sim 16 \mathrm{psi} / \mathrm{sec}$ pressure release rate.

\begin{tabular}{|c|c|c|c|}
\hline Sample & Overpressure (psig) & Foam Bulk Density $\left(\mathrm{g} / \mathrm{cm}^{3}\right)$ & Cell Size Range $(\mu \mathrm{m})$ \\
\hline 5 & 80 & $0.68 \pm 0.13$ & $10-70$ \\
\hline 6 & 150 & $0.69 \pm 0.14$ & $10-70$ \\
\hline 7 & 200 & $0.68 \pm 0.06$ & $10-80$ \\
\hline
\end{tabular}

\subsubsection{Pressure release Rate}

It should be noted that in processing polymeric foams with melt blowing agents pressuredrop ratea often are in the $\mathrm{kpsi} / \mathrm{sec}$ range and higher. The pressure-drop rate in this examination is two orders of magnitude less than this, but variation in cell structure is distinguishable. Figure 4.9 through Figure 4.11 clearly show that as the pressure release rate is increased from $8.1 \mathrm{psi} / \mathrm{sec}$ to $15 \mathrm{psi} / \mathrm{sec}$, the average cell size decreases and the cell number density increases. Equations 2.4 and 2.11 quantitatively show that cell nucleation is favored rather than cell growth due to diffusion limits at high concentration gradients. The same general trend is seen with polymer processing, i.e., with increasing pressure-drop rate, cell size decreases. A slight decrease in bulk 
density is seen with increased pressure release rate, as shown in Table 4.6, which is probably due to lower blowing agent loss from the melt during expansion.

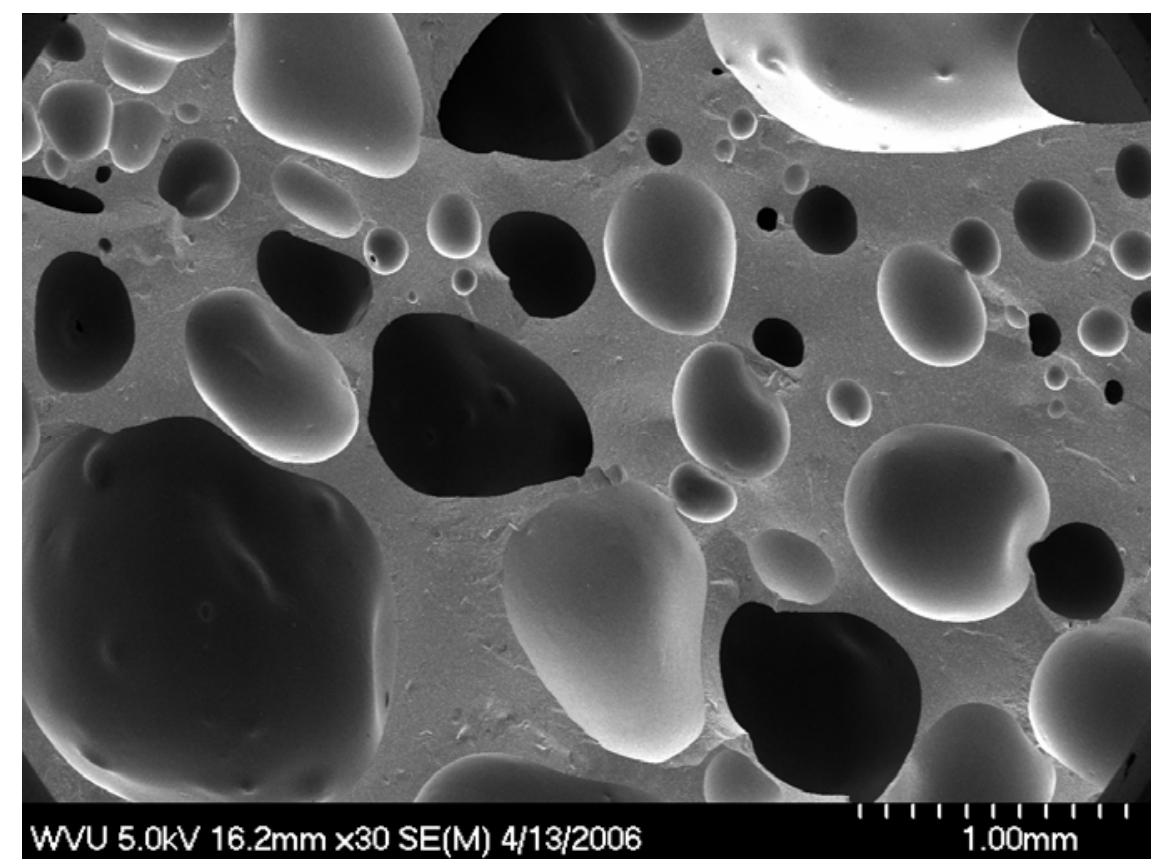

Figure 4.9: SEM of sample $7\left(180^{\circ} \mathrm{C}\right.$ SP pitch foam prepared at $155^{\circ} \mathrm{C}, 220 \mathrm{psig}$ of $\mathrm{CO}_{2}$ and pressure release rated of $8.1 \mathrm{psi} / \mathrm{sec}$ ).

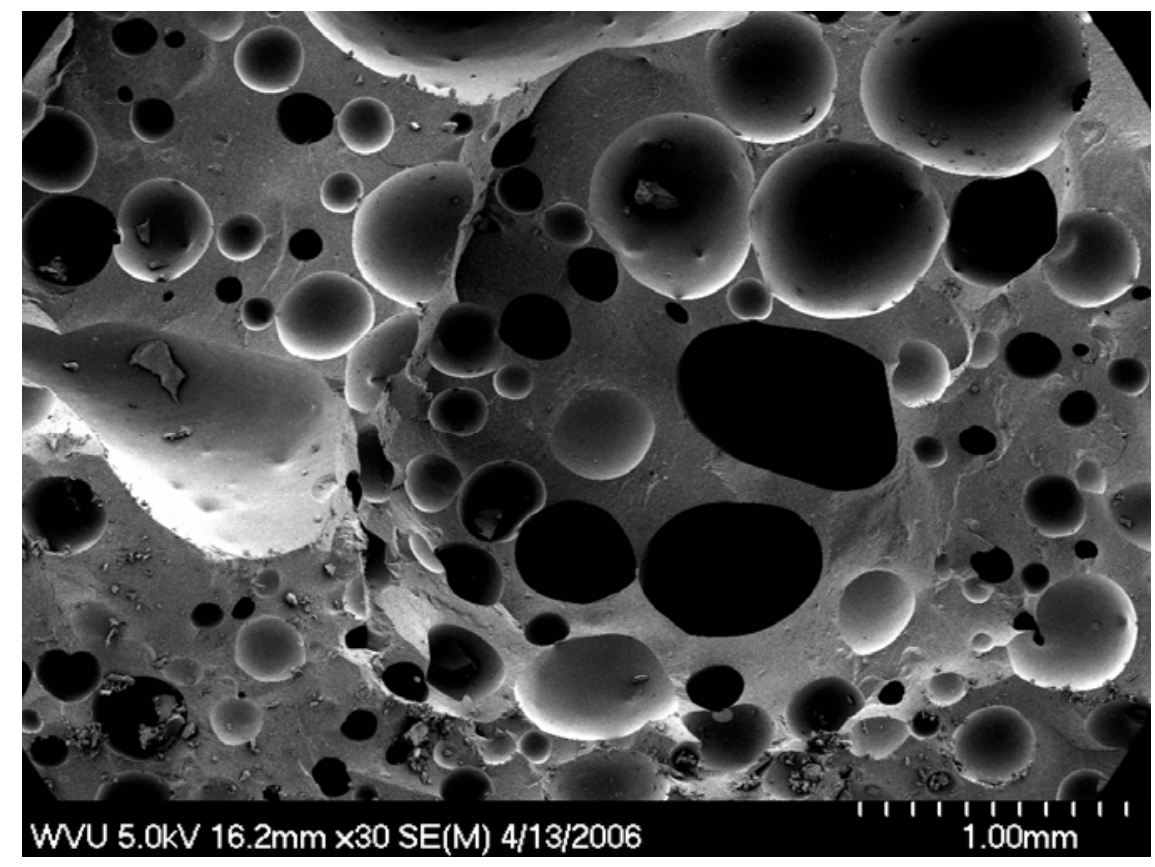

Figure 4.10: SEM of sample $8\left(180^{\circ} \mathrm{C}\right.$ SP pitch foam prepared at $155^{\circ} \mathrm{C}, 220 \mathrm{psig}$ of $\mathrm{CO}_{2}$ and pressure release rated of $13 p s i / s e c)$. 


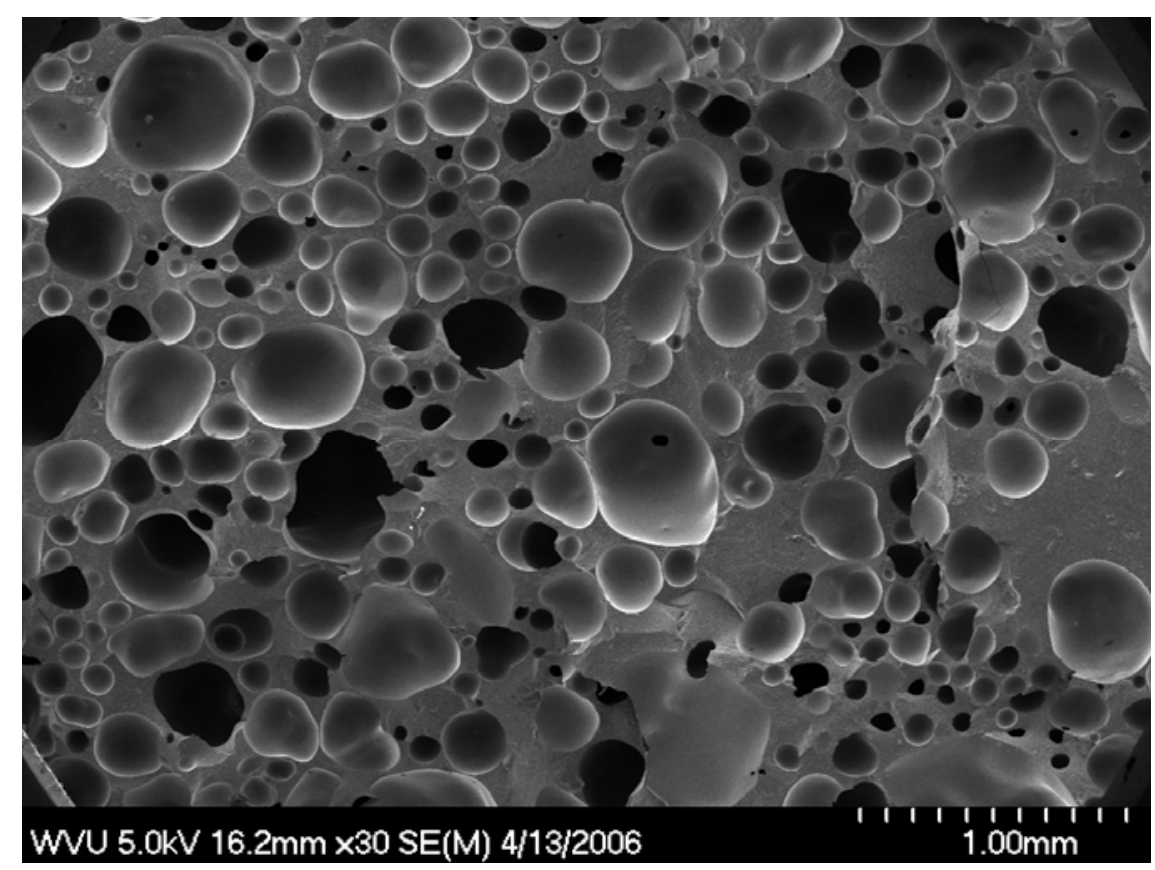

Figure 4.11: SEM of sample $9\left(180^{\circ} \mathrm{C}\right.$ SP pitch foam prepared at $155^{\circ} \mathrm{C}, 200 \mathrm{psig}$ of $\mathrm{CO}_{2}$ and pressure release rated of 15psi/sec).

Table 4.6: Bulk density variation with pressure release rate for a $180^{\circ} \mathrm{C}$ softening point pitch produced at $155^{\circ} \mathrm{C}$ and 200psig of $\mathrm{CO}_{2}$.

\begin{tabular}{|c|c|c|c|}
\hline Sample & $\mathrm{dP} / \mathrm{dt}$ & Foam Bulk Density $\left(\mathrm{g} / \mathrm{cm}^{3}\right)$ & Cell Size Range $(\mu \mathrm{m})$ \\
\hline 7 & 8.1 & $0.73 \pm 0.12$ & $20-160$ \\
\hline 8 & 13.7 & $0.64 \pm 0.07$ & $10-90$ \\
\hline 9 & 15.0 & $0.68 \pm 0.04$ & $10-50$ \\
\hline
\end{tabular}

\subsubsection{Other Blowing Agents}

The addition of $\mathrm{H}_{2} \mathrm{O}$ and $\mathrm{N}_{2}$ were examined to see if they were capable of producing cell formation in pitch. It was found that the use of both produced cells in the pitch. As stated in Section 4.3 Foam Examination, moisture present in the pitch may be party responsible for cell formation. The samples produced with $\mathrm{N}_{2}$ as the blowing agent have smaller cells with higher number density than foam produced with $\mathrm{CO}_{2}$ under the similar conditions $\left(200 \mathrm{psig}, 90^{\circ} \mathrm{C}\right.$ for $\mathrm{N}_{2}$ and $95^{\circ} \mathrm{C}$ for $\mathrm{CO}_{2}$, and $\sim 15 \mathrm{psi} / \mathrm{sec}$ using a $110^{\circ} \mathrm{C}$ softening point pitch). See Figure 4.12 and Figure 4.13 for SEM micrographs of the resultant foams. It is unclear if the cell size and density 
differences are due to blowing agent concentration, diffusion difference between the blowing agents or some other factor. For the sample containing water, $\mathrm{CO}_{2}$ was used to keep the water in the liquid phase until the pressure release. The samples processed with $\mathrm{CO}_{2}$ and water had a larger cell size in comparison to the samples that just used $\mathrm{CO}_{2}$ as the blowing agent under similar processing conditions (Figure 4.14 and Figure 4.15). Thus the water is having some effect.

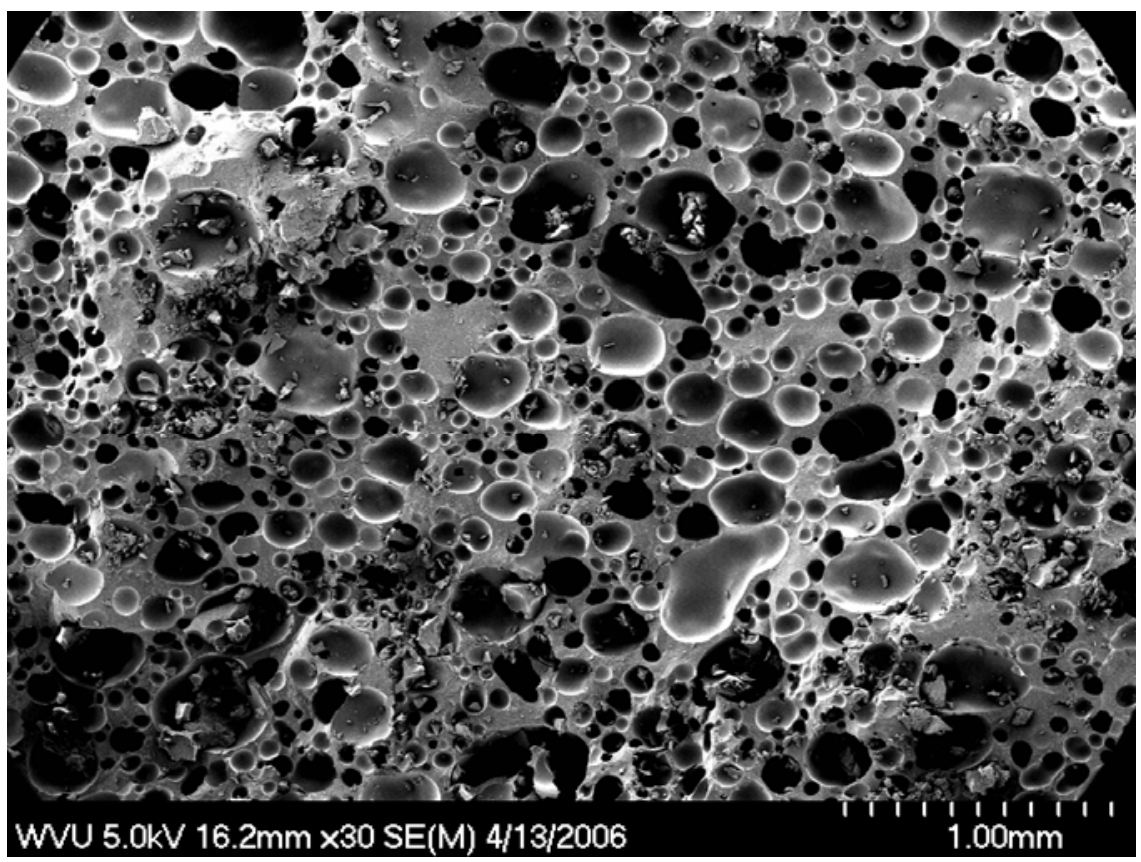

Figure 4.12: SEM of sample $4\left(110^{\circ} \mathrm{C}\right.$ softening point pitch foam produced at $90^{\circ} \mathrm{C}, \mathrm{dP} / \mathrm{dt}$ of $20 \mathrm{psi} / \mathrm{sec}$, and 200psig of $\mathbf{N}_{2}$ ). 


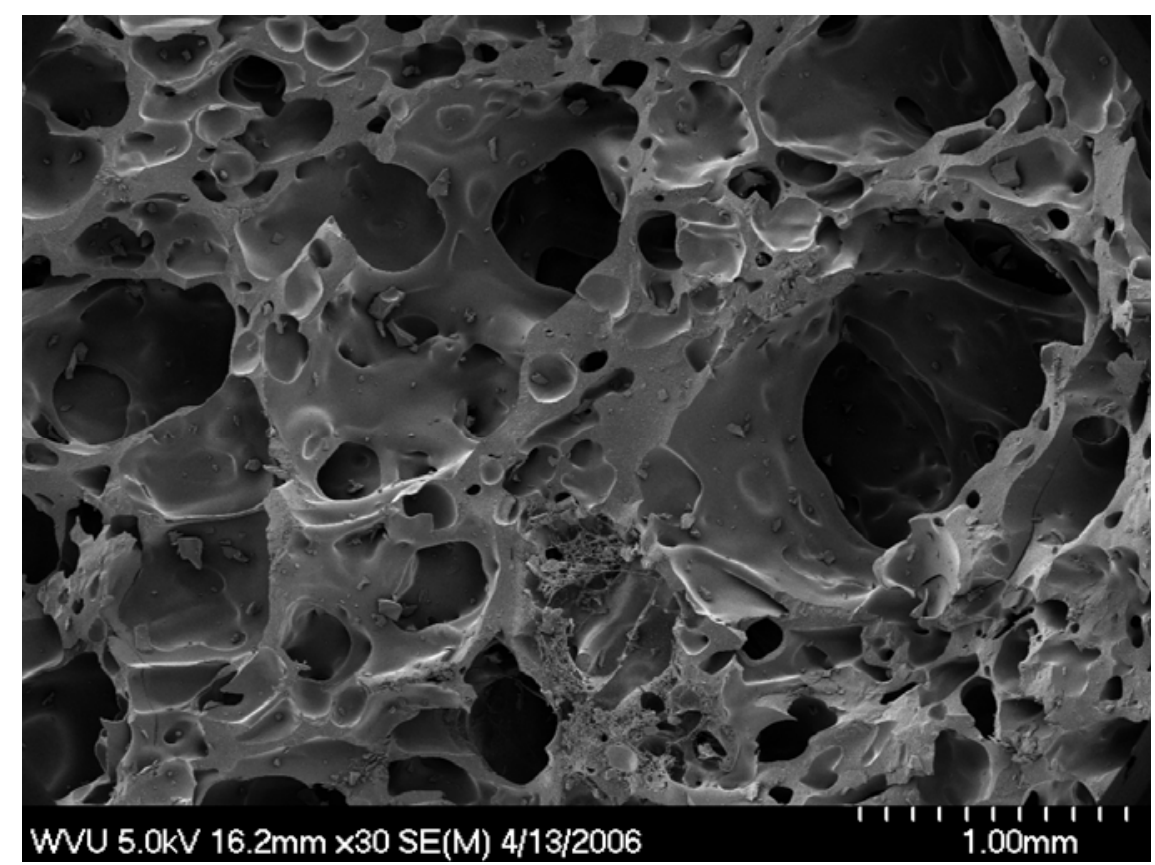

Figure 4.13: SEM of sample $1\left(110^{\circ} \mathrm{C}\right.$ softening point pitch foam produced at $95^{\circ} \mathrm{C}, \mathrm{dP} / \mathrm{dt}$ of $22 \mathrm{psi} / \mathrm{sec}$, and 200psig of $\mathrm{CO}_{2}$ ).

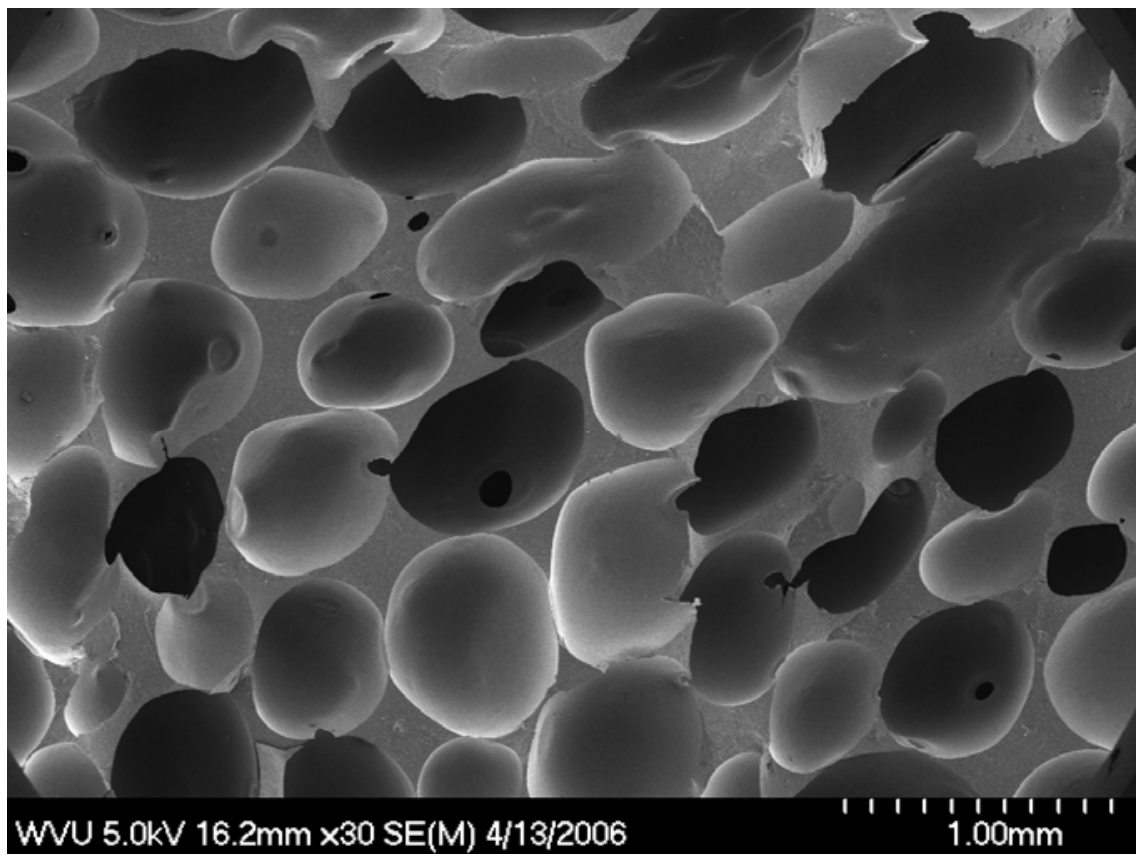

Figure 4.14: SEM of sample $10\left(180^{\circ} \mathrm{C}\right.$ softening point pitch produced at $150^{\circ} \mathrm{C}, \mathrm{dP} / \mathrm{dt}$ of $28 \mathrm{psi} / \mathrm{sec}$, and 200psig $\mathrm{CO}_{2}$ and $0.3 \mathrm{wt} \%$ weight percent water added). 


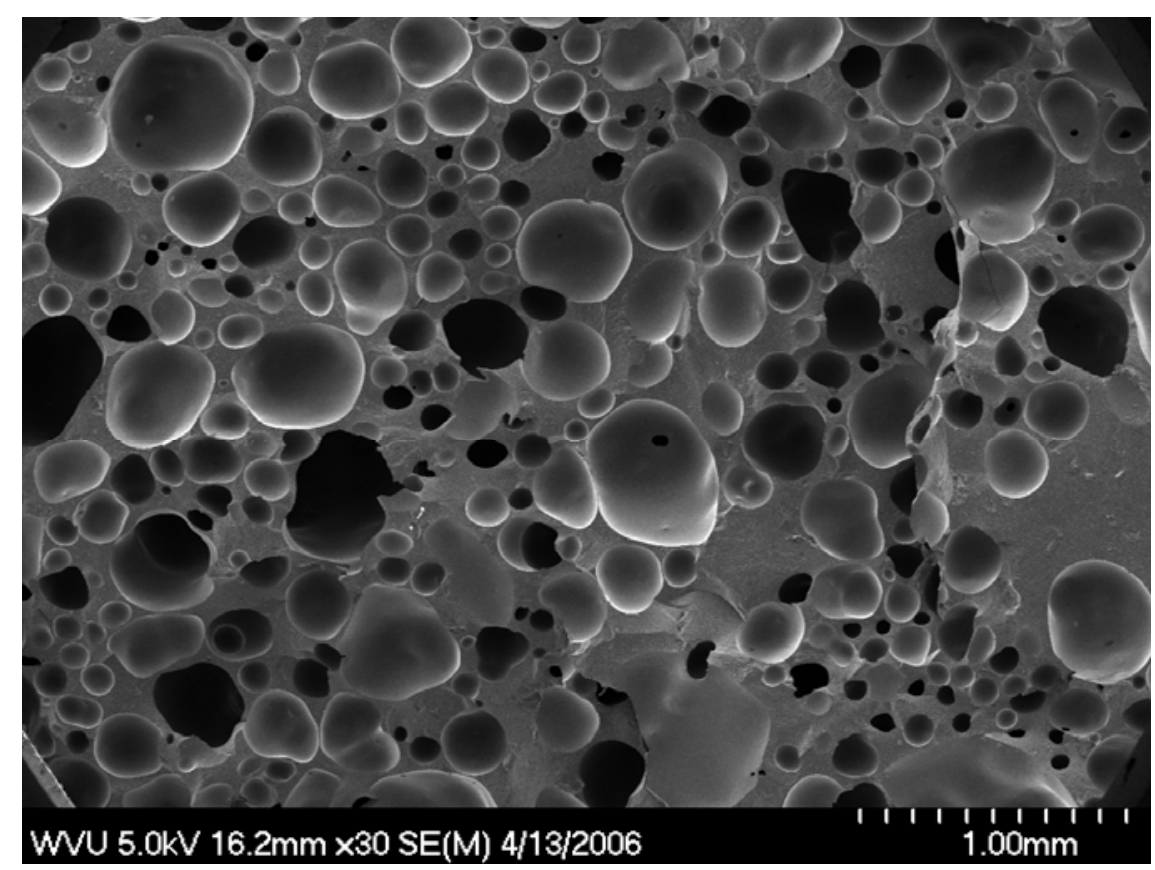

Figure 4.15: SEM of sample $9\left(1^{\circ}{ }^{\circ} \mathrm{C}\right.$ softening point pitch produced at $155^{\circ} \mathrm{C}, \mathrm{dP} / \mathrm{dt}$ of $15 \mathrm{psi} / \mathrm{sec}$ and $180 \mathrm{psig}$ $\mathrm{CO}_{2}$ ).

\subsection{Unoptimized Mechanical Properties}

Pitch foam, like stabilized carbon foam, undergoes brittle fracture under load. The initial linear slope of the stress/strain curve is the compressive Young's modulus. Elastic deformation occurs until the yield strength is reached at which point cell structure ruptures begins to occur. Samples 11 and 12 (Table 4.7) show distinct modulus and yield points (Figure 4.16 and Figure 4.17), whereas samples 13 and 14 though have no distinct modulus or yield strength (Figure 4.18 and Figure 4.19).

Table 4.7: Pitch foam process conditions and mechanical properties for samples produced for mechanical testing using $\mathrm{CO}_{2}$ as the blowing agent.

\begin{tabular}{|l|c|c|c|c|}
\hline Sample & 11 & 12 & 13 & 14 \\
\hline Temperature $\left({ }^{\circ} \mathrm{C}\right)$ & 160 & 155 & 155 & 155 \\
\hline Pressure $(\mathrm{psi})$ & 200 & 240 & 220 & 200 \\
\hline $\mathrm{dP} / \mathrm{dt}(\mathrm{psi} / \mathrm{sec})$ & 28.6 & 37.3 & 8.1 & 33.3 \\
\hline Density $\left(\mathrm{g} / \mathrm{cm}^{3}\right)$ & $0.38 \pm .01$ & $0.52 \pm .01$ & $0.77 \pm .04$ & $0.79 \pm .02$ \\
\hline Compressive Strength $(\mathrm{MPa})$ & 0.2 & 0.5 & 1.4 & $<1.6$ \\
\hline Compressive Modulus $(\mathrm{Mpa})$ & 8 & 38 & 240 & $<160$ \\
\hline
\end{tabular}


Once the yield strength is reached, the stress strain curve plateaus till the cell structure is completely crushed. In this region the majority of the energy absorption occurs in foams.

Upon complete collapse of cell the structure, the solid material undergoes densification and behaves as a solid. Stress/strain curves for two duplicate samples from the same parent foam were measured and the data are shown on Figure 4.16 through Figure 4.19 for comparison. Samples 12 through 14 experience complete destruction of cell structure and proceed to the densification phase at approximately $25-30 \%$ strain (Figure 4.16-Figure 4.19). The densification of sample 11 did not start till about 40\% strain was reached (Figure 4.16). Table 4.7 shows the foam processing conditions, density, measured modulus, and yield strength of four pitch foam samples. It should be noted that no attempt was made to optimize these parameters in the present research.

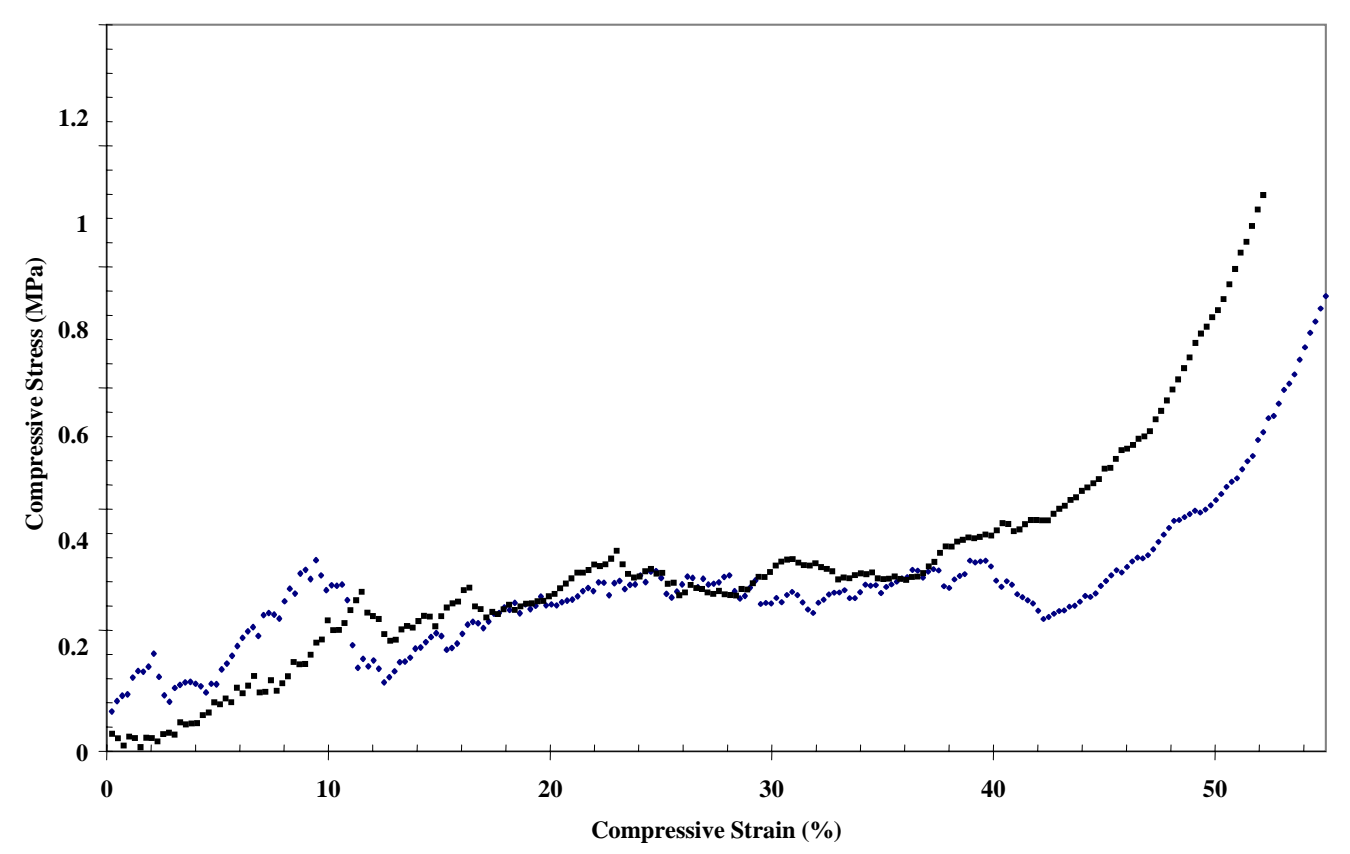

Figure 4.16: Compressive Stress Strain Curves for two $0.38 \mathrm{~g} / \mathrm{cm}^{3}$ pitch foam samples from sample 11 . 


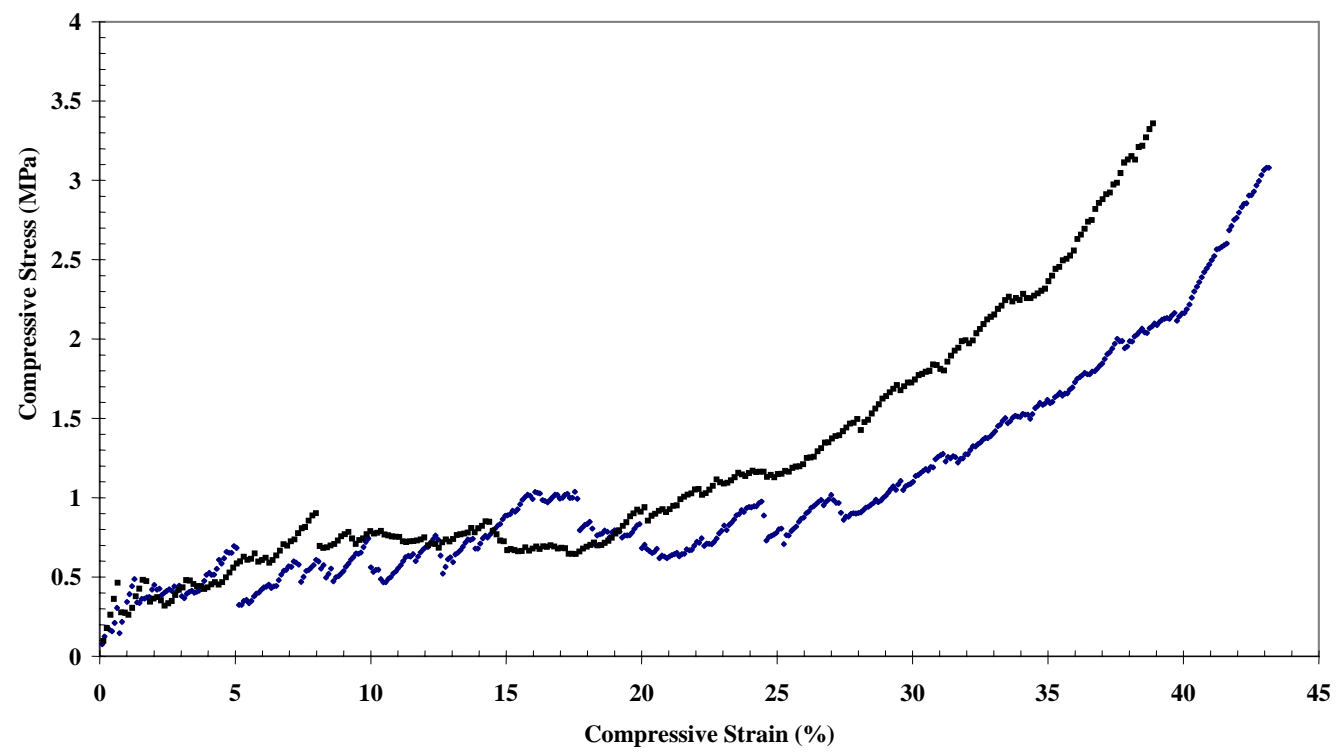

Figure 4.17: Compressive Stress Strain Curves for two $0.52 \mathrm{~g} / \mathrm{cm} 3$ pitch foam samples from sample 12.

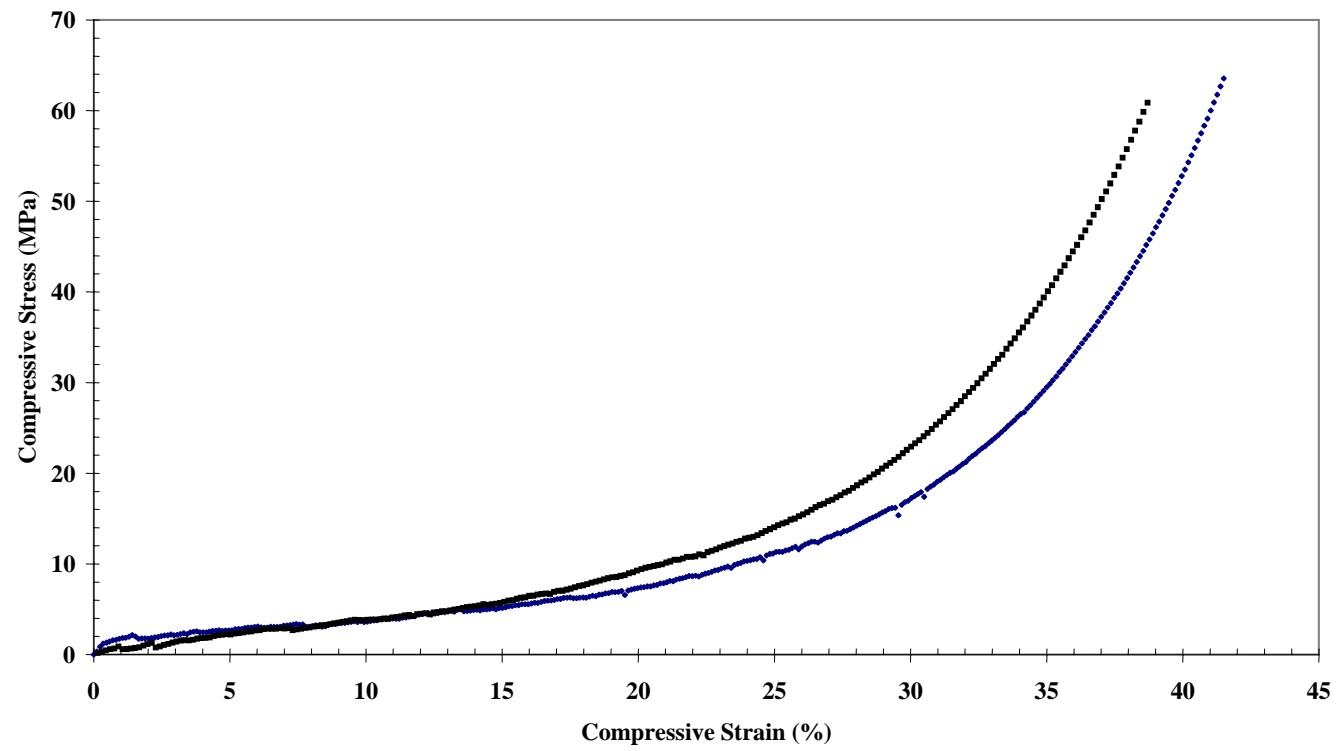

Figure 4.18: Compressive Stress Strain Curves for two $0.77 \mathrm{~g} / \mathrm{cm}^{3}$ pitch foam samples from sample 13. 


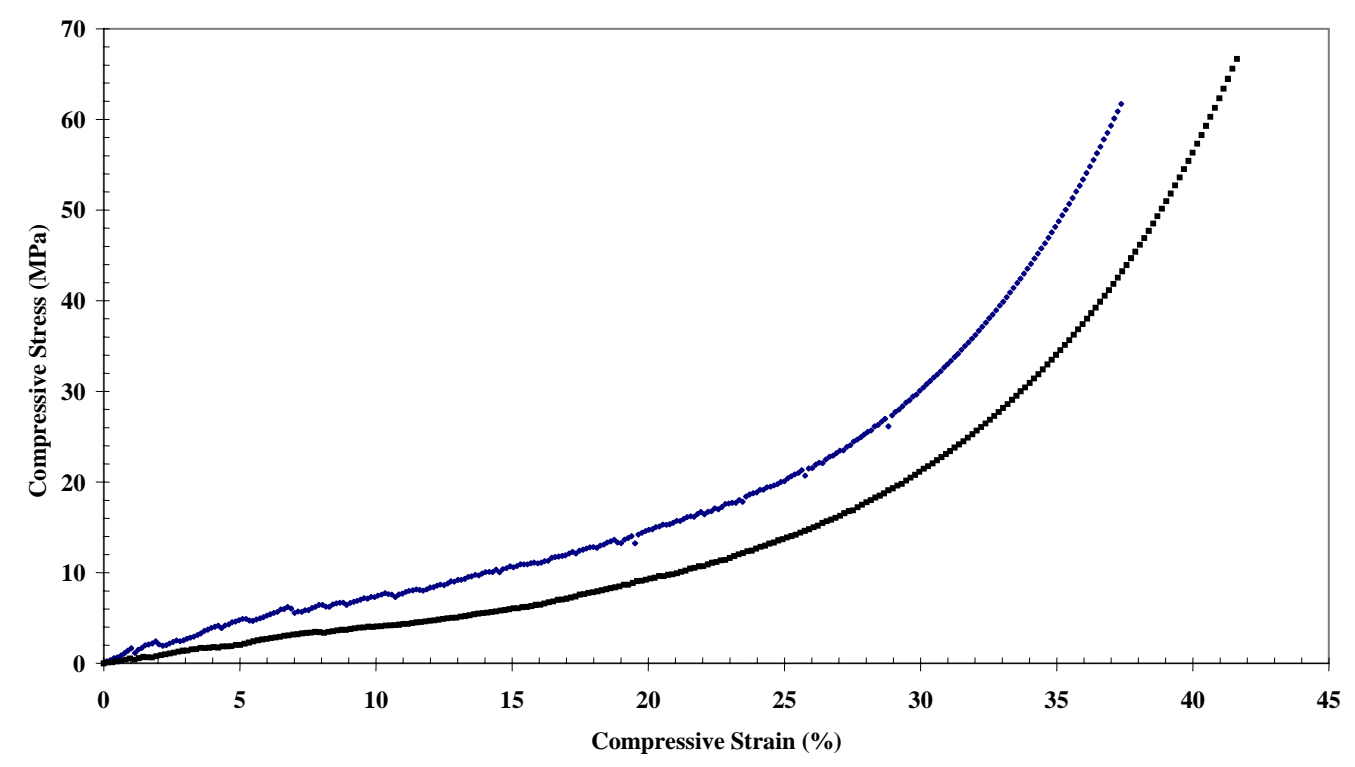

Figure 4.19: Compressive Stress Strain Cures for two $0.80 \mathrm{~g} / \mathrm{cm}^{3}$ pitch foam samples from sample 14 .

The mechanical properties of the pitch foams were compared to that of some commercially available carbon foams. There is currently no standard for measuring the mechanical compression properties of carbon foam, thus the data provided by the manufacturers are difficult to compare directly. Considering this, data for the commercially available foams were taken from the Masters of Science Thesis of Steve Carpenter ${ }^{49}$ and compared to pitch foam samples made in this work using the same test method. Data for carbon foam samples from Touchstone Research Laboratories (TRL), Ultramet, and Poco Graphite (POCO) were reported. Results for graphitized carbon foam from Materials and Electrochemical Research (MER) were also reported. The complete data set appears in Table 4.8. The pitch foam showed lower modulus and yield strength than that of similar density carbon and graphite foams. Optimizing the cell structure, stabilizing and calcining to form carbon foam might yield values that are closer to those commercially available. 
Table 4.8 Comparison of sample pitch foams from Table 4.7 with carbon foam from Touchstone Research Laboratories and Poco Graphite Incorporated and graphite foam from Materials and Electrochemical Research using test method developed by Carpenter ${ }^{49}$.

\begin{tabular}{|l|c|c|c|}
\hline Specimen & Bulk Density $\left(\mathrm{g} / \mathrm{cm}^{3}\right)$ & Modulus $(\mathrm{MPa})$ & Yield Strength (MPa) \\
\hline Ultramet & 0.16 & 41 & 0.7 \\
\hline TRL & 0.30 & 142 & 6.2 \\
\hline Sample 1 & $\mathbf{0 . 3 8}$ & $\mathbf{8}$ & $\mathbf{0 . 2}$ \\
\hline MER & 0.50 & 81 & 1.5 \\
\hline Sample 2 & $\mathbf{0 . 5 2}$ & $\mathbf{3 8}$ & $\mathbf{0 . 5}$ \\
\hline POCO & 0.62 & 142 & 2.2 \\
\hline Sample 3 & $\mathbf{0 . 7 7}$ & $\mathbf{2 4 0}$ & $\mathbf{1 . 4}$ \\
\hline Sample 4 & $\mathbf{0 . 8 0}$ & $<\mathbf{1 6 0}$ & $<\mathbf{1 . 6}$ \\
\hline
\end{tabular}

Properties of the pitch foam produced in this work compared to properties reported by Koppers Inc. and Touchstone Research Laboratories (Table 4.9) for their commercial line of foams. As stated earlier, there is no standard method for testing the mechanical compressive properties of carbon and graphite foams, so direct comparison is difficult.

Table 4.9: Comparison of properties of pitch foam samples from Table 4.7 to carbon foam properties reported by Koppers Inc. and Touchstone Research Laboratories using unspecified compression tests for commercially available carbon foams sorted by bulk density.

\begin{tabular}{|l|c|c|c|}
\hline & $\begin{array}{c}\text { Bulk Density } \\
\left(\mathrm{g} / \mathrm{cm}^{3}\right)\end{array}$ & $\begin{array}{c}\text { Compressive } \\
\text { Strength (MPa) }\end{array}$ & $\begin{array}{c}\text { Compressive } \\
\text { Modulus (Mpa) }\end{array}$ \\
\hline Touchstone Cfoam 17 & 0.27 & 6.2 & 550 \\
\hline Pitch Foam Sample 1 & $\mathbf{0 . 3 8}$ & $\mathbf{0 . 2}$ & $\mathbf{8}$ \\
\hline Koppers Carbon Foam Grade L1a & 0.39 & 1.1 & 119 \\
\hline Touchstone Cfoam 25 & 0.40 & $>15$ & 830 \\
\hline Koppers Carbon Foam Grade D1 & 0.46 & 2.5 & 396 \\
\hline Koppers Carbon Foam Grade L1 & 0.49 & 3.4 & 307 \\
\hline Pitch Foam Sample 2 & $\mathbf{0 . 5 2}$ & $\mathbf{0 . 5}$ & $\mathbf{3 8}$ \\
\hline Pitch Foam Sample 3 & $\mathbf{0 . 7 7}$ & $\mathbf{1 . 4}$ & $\mathbf{2 4 0}$ \\
\hline Pitch Foam Sample 4 & $\mathbf{0 . 8 0}$ & $<\mathbf{1 . 6}$ & $<\mathbf{1 6 0}$ \\
\hline
\end{tabular}

\subsection{Foam Examination: Extruded}

Using the experimental apparatus shown in Figure 3.8, extrusion of pitch foam was attempted with the $110^{\circ} \mathrm{C}$ softening point pitch. Higher temperatures and gas pressures were used in the extrusion process than in the batch process in order to force the pitch melt through the 
valve. The process was successful in producing an extruded pitch foam as can be seen in Figure 4.20. It can also be seen from Figure 4.21 that the pitch experiences significant swelling through the extrusion valve. Supercritical $\mathrm{CO}_{2}$ conditions were also achieved in the apparatus by adding dry ice during loading. Under supercritical conditions, pitch was successfully extruded at a significantly lower temperature $\left(70^{\circ} \mathrm{C}\right)$ than the $110^{\circ} \mathrm{C}$ softening point of the pitch, though little cell expansion was achieved. Little qualitative data could be gleaned from these experiments other than an upper range of foam melt stability beyond which the foam collapses due to the variability of flow and pressure-drop rate between runs. The upper temperature limit of melt stability for the $110^{\circ} \mathrm{C}$ softening point pitch was $\sim 130^{\circ} \mathrm{C}$ which corresponds to an undiluted viscosity of approximately 250Poise via the WFL equation. Further work was pursued on the extrusion process, but discontinued due to time constraints. The feasibility of making foam by this method though, was demonstrated. 


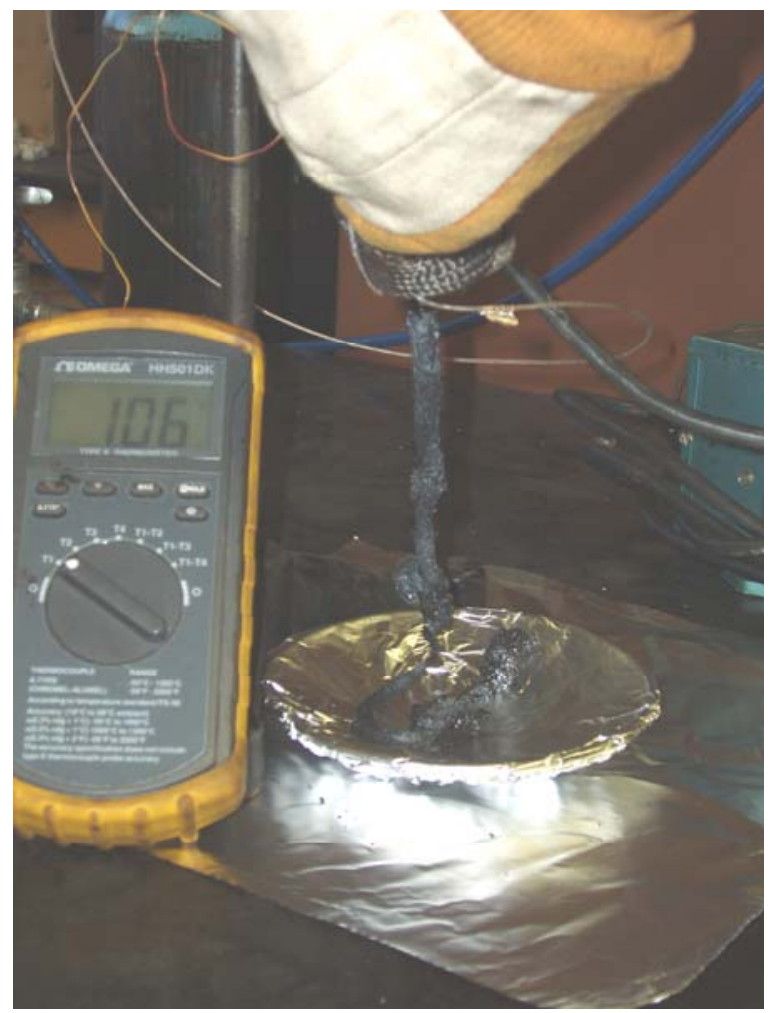

Figure 4.20: Extrusion test with a $110^{\circ} \mathrm{C}$ softening point pitch extruded at approximately $106^{\circ} \mathrm{C}$. 


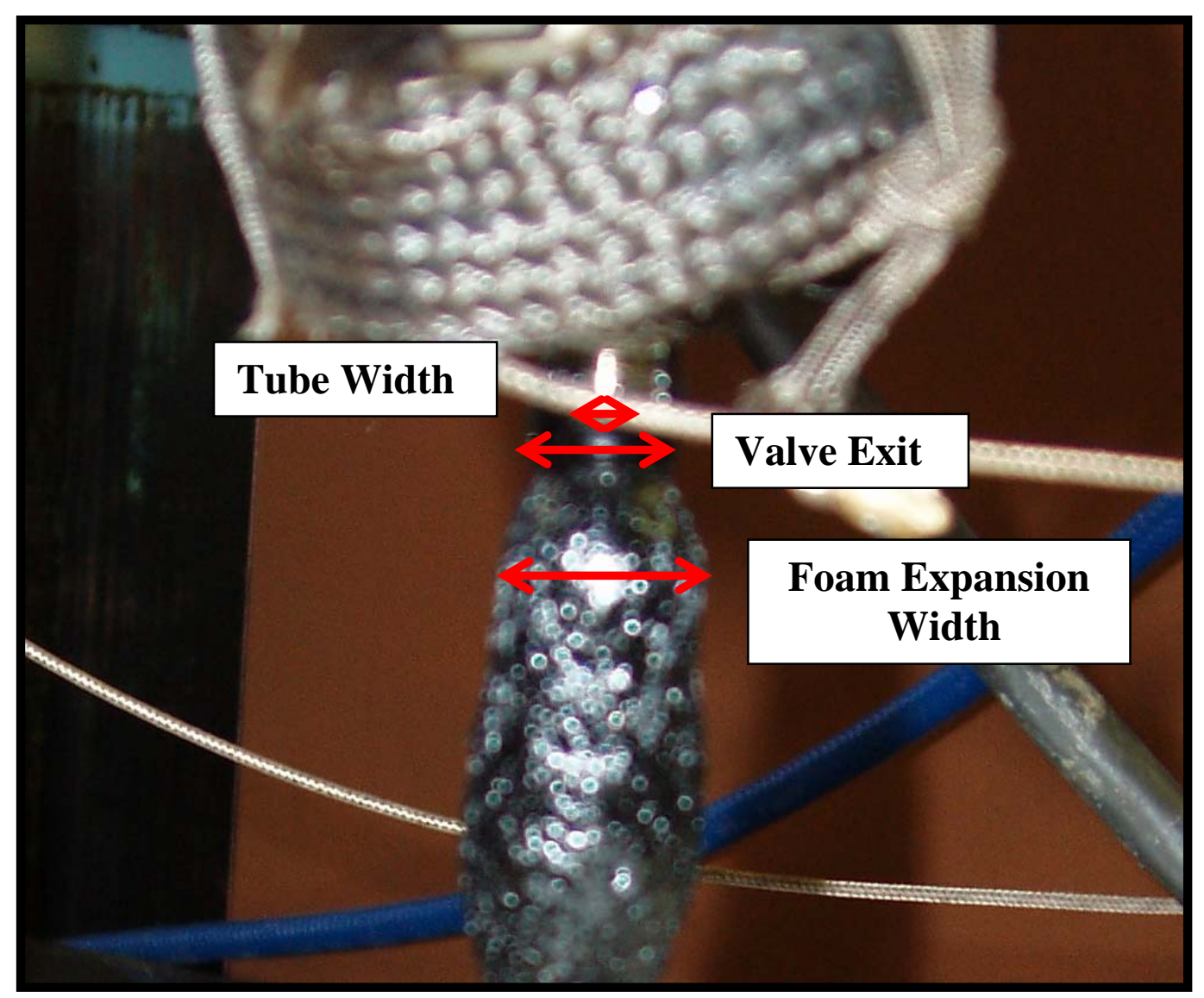

Figure 4.21: Foam expansion upon exiting the experimental extrusion apparatus at 106C and 540psig of $\mathrm{N}_{2}$ on a $110^{\circ} \mathrm{C}$ softening point pitch.

\subsection{Stabilization}

Stabilization was attempted only for the foam made from the $180^{\circ} \mathrm{C}$ softening point pitch due to the higher $\mathrm{T}_{\mathrm{g}}$ in comparison to the $110^{\circ} \mathrm{C}$ pitch. The samples were heated in air at a rate of $5^{\circ} \mathrm{C} / \mathrm{min}$ to only $6^{\circ} \mathrm{C}$ above the $\mathrm{T}_{\mathrm{g}}$ as calculated from the Barr et al. correlation, but the foam unfortunately experienced relaxation of the bulk foam matrix. From this it was concluded that heating above the $\mathrm{T}_{\mathrm{g}}$ allows relaxation of the foam matrix leading to cell collapse. The $180^{\circ} \mathrm{C}$ pitch experienced noticeable relaxation of the bulk structure prior to significant cross-linking of the volatile content that would solidify the structure. Higher softening point pitch or an alternative method of stabilization or slower heating rate is needed to stabilize the $180^{\circ} \mathrm{C}$ pitch without loss of foam structure than the one used in this work. Further work is needed to deduce an optimum strategy for stabilization of the foam. 


\section{Chapter V. \\ Conclusions}

In review, the objectives of this work were to:

1. Verify if pitch foam can be produced with physical blowing agents

2. Examine current polymer foaming theory and practice

3. Compare properties of select polymers and pitches

4. Test applicability by subjecting pitch to foaming processes variables

5. Evaluate pitch foam samples

6. Suggest further refinement in theoretical understanding of foaming pitch with physical blowing agents

7. Recommend methods for further applicability to foaming pitch

The results of this research indicated that:

1. Cells could be formed from pressure drop with saturated gas in a pitch melt

2. Key variables of polymer melt foaming were identified which were temperature, pressure and pressure release rate

3. The physical properties of pitch melts were found to be comparable to that of polymer melts

4. Key process variables were tested in a batch method

5. The produced foams were evaluated by SEM, optical microscopy, and mechanical compression testing

6. It was found that the use of physical blowing agents follow similar thermodynamic mechanisms as polymers

7. Further research recommendations are given in the next chapter 
The characteristics of coal tar and petroleum-based pitch melts mimic those of thermoplastic polymer melts as shown from previous research and tests preformed in this work. Similar characteristics between the two include: phase transition, heat capacity, density, surface tension, and viscoelastic melt behavior. This similar behavior extends to cell formation in the melts using physical blowing agents. Experiments in this work with a $110^{\circ} \mathrm{C}$ and $180^{\circ} \mathrm{C}$ softening point pitch showed that batch and extrusion methods of pitch foam production are possible with the use of $\mathrm{CO}_{2}, \mathrm{~N}_{2}$, and water as physical blowing agents. The solubility of $\mathrm{CO}_{2}$ and $\mathrm{N}_{2}$, coupled with moisture either present in or added to the pitch, at elevated pressures in coal tar pitch melts was sufficient at experimental conditions to reach the critical radius of bubble formation and resulted in cell formation upon thermodynamic instability (sudden pressure release). The use of water as a physical blowing agent was also shown to be feasible as a "phasechange" physical blowing agent. It is somewhat surprising that ambient moisture present in the pitch would be in sufficient quantities for foaming of pitch melts.

In retrospect, the effectiveness of phase-change physical blowing agents should not have been surprising considering that the volume change of water going from the liquid to the gas phase can be upwards of 1000 times. Despite the probable interaction between $\mathrm{CO}_{2}$ or $\mathrm{N}_{2}$ with moisture present in the pitch, the selection of blowing agent affects the resulting cell structure of the foam. The addition of talc up to $4 \mathrm{wt} \%$ did not detectably change the cell density or size in the final foam due to the presence of particulate ash naturally present in the pitch. Cell formation and growth in pitch melts follow the same theory as polymeric melts for the variables of viscosity, blowing agent concentration, and pressure release rate. This is to say that cell size is proportional to and cell density is inversely proportional to: decreased viscosity, blowing agent concentration and pressure release rate. The main dependence of these variables on the foam production is 
summarized in Table 5.1. The uses of physical blowing agents is a viable alternative rout for producing pitch foam that can be further processed into carbon foam through additional heat treatments. The mechanical properties at room temperature for the unoptimized cell structure pitch foams were lower than those for similar bulk density carbon and graphite foams.

Table 5.1: Qualitative relationships between experimental variables and how each effects foam structure.

\begin{tabular}{|l|c|c|}
\cline { 2 - 3 } \multicolumn{1}{c|}{} & Cell Density & Cell Size \\
\hline Viscosity & Proportional & Inverse \\
\hline Blowing Agent Conc. & Proportional & Inverse \\
\hline Pressure Drop Rate & Proportional & Inverse \\
\hline
\end{tabular}




\section{Chapter VI}

\section{Recommendations and Further Research}

It has been shown from this study that pitch foam can be produced in a manner similar to other thermoplastics. Areas of further interest include: possible modification to current polymer foam models to model pitch foam, investigation into the composition of pitch and how it effects foaming characteristics, the solubility and diffusion of gases in pitch for superior blowing agent selection, the use of additives and fillers to modify the pitch properties and foaming characteristics, the development of continuous foam production, and cost analysis in comparison to current carbon foam production methods. Each of these is discussed below.

\subsection{Polymer Foam Model Adjustments}

Cell formation, mass, and momentum theory are fairly well developed for foaming viscous fluids. However, spontaneous cell formation and growth in a continuous dynamic process, as in extrusion, is far less developed. The work presented herein showed that the control variables which influence the foam characteristics in the batch process follow the general trend predicted by the polymer foaming models. More strenuous control of experimental variables is needed to extend polymer foaming models to pitch beyond a qualitative analysis.

\subsection{Pitch Composition}

Little is known about how the composition of pitch affects the character of pitch foams. Additional study is needed to compare the characteristics of foam produced from various pitch sources (coal and petroleum) with a range of blowing agents.

\subsection{Solubility and Diffusivity}

There are limited data available for the solubility of gases in pitch. The limited amount of solubility information extends to other heavy petroleum and bitumens to a lesser degree. In this investigation, the solubility of $\mathrm{CO}_{2}$ was assumed to be approximately equivalent to heavy 
petroleum fractions and bitumens. Additional data on the solubility and diffusivity of $\mathrm{CO}_{2}$ and other blowing agents would aid in the selection of process conditions and blowing agent.

\subsection{Other Physical Blowing Agents}

This study primarily used $\mathrm{CO}_{2}$ as the blowing agent, though the presence of moisture in the pitch may have contributed to cell formation and growth with a synergistic interaction. Further investigation is needed to separate the effects that each is generating. Both water and $\mathrm{N}_{2}$ were tried as blowing agents and were shown to successfully produce foam. Other soluble gases and phase-changing liquids may be better suited for cell formation in pitch. Some gases that may be of interest for further investigation include light hydrocarbons and hydrofluorocarbons ${ }^{4}$.

\subsection{Additives to Pitch Foam}

As with polymers, the incorporation of additives can significantly alter the properties of the foam. Three areas of additives of interest are fillers, surfactants, and stabilizers which are disused below.

\subsubsection{Fillers}

A common practice with polymers and cement is to add fillers. The addition of fillers is often done for one of two reasons: first to reduce the quantity of matrix material needed, and second to modify the matrix properties. Some fillers of possible interest in pitch foam are: carbon black, refractory metals, carbon fibers and nanotubes. Using carbon black could be of interest in modifying the electrical characteristics of the foam. The addition of refractory metals by themselves is not of much interest, but with appropriate processing it may be possible to form carbides within the foam. The addition of carbon fibers and nanotubes may possibly modify the mechanical and conductivity characteristics of the foam. With the addition of any filler the 
surface interactions and wetting characteristics of the filler with the pitch need to be considered. Achieving complete uniform dispersion of the filler in the pitch is also of critical importance.

\subsubsection{Surfactants}

It is known from polymer foam theory that the surface tension of the melt performs a significant role in cell formation, growth and melt stability. Adding surfactants might be a way of improving the foaming characteristics of the pitch. Numerous surfactants have been developed for various petroleum products to reduce surface tension. Incorporating some of them into a pitch melt may result in improved foaming characteristics. Moreover, a much slower heating rate may be required to allow for the diffusion and reaction of oxygen with the pitch.

\subsubsection{Stabilizers}

One of the difficulties encountered in this examination was the air stabilization of the pitch foam. Because of the low softening point of the pitch, the foam structure would collapse when reheated above the $T_{\mathrm{g}}$. Normally, in air stabilization the material being treated is heated to $135^{\circ} \mathrm{C}$ or more and slowly increased. To attempt this, a pitch would need a softening point approximately $210^{\circ} \mathrm{C}$ to be above the $\mathrm{T}_{\mathrm{g}}$. The addition of cross-linking agents to the pitch may be a way to lower the temperature of stabilization for pitch foams. An experimental technique for evaluating possible cross-linkers in polymers is DSC since often the cross-linking process in polymers is exothermic. The resulting variations in heat flow are readily detected by $\mathrm{DSC}^{52-54}$.

\subsection{Continuous Extrusion Process}

This study showed that pitch foam can be extruded. The logical next step would be to attempt production of pitch foam in a continuous extrusion process. Melt processing techniques currently used with pitch fiber production would aid in identifying areas of divergence between handling of pitch and polymer melts in a continuous extrusion processing. Additionally, the use 
of a heat transfer medium may be useful in preventing cell collapse allowing operation at higher temperatures.

\subsection{Cost Analysis}

The ultimate test of the proposed production method is the economic feasibility of commercial production. The ability to use commercially available processing equipment designed for polymers to produce pitch foam would be advantageous. The additional requirement of heat treatment for pitch foam may reduce the economic benefit of producing carbon foam by this technique. 


\section{References}

1. Spradling, Drew M., R. Andrew Guth, "Carbon Foams", Advanced Materials \& Processes, vol. 161 issue 11 2003, 29-31.

2. Touchstone Research Laboratory Ltd. http://www.cfoam.com/index.htm. Accessed January 2006.

3. Gallego, Nidia C., James W. Klett, "Carbon Foams for thermal management", Carbon, vol.41, 2003, 14611466.

4. Evans, David editor, Handbook of Polymer Foams, Rapra Technology Limited, Shawbury, UK, 2004.

5. Gibson, Lorna J., Micheal E. Ashby, Cellular Solids: Structure and Properties, 2 Edition, Cambridge University Press, Cambridge, UK, 1997.

6. Choi, S., B.V. Sankar, "Fracture Toughness of Carbon Foam”, Journal of Composite Materials, vol.37, no.23, 2003, 2101-2116.

7. Sihn, Sangwook, Ajit K. Roy, "Modeling and prediction of bulk properties of open-cell carbon foam", Journal of the Mechanics and Physics of Solids, vol.52, 2004, 167-191.

8. Frisch, Kurt C., James H. Saunders, Plastic Foams Vol. 1 \& 2, Marcel Dekker Inc., New York, USA, 1972.

9. Suh, Kyung W., Chung P Park, Myron J. Naurer, Martin H. Tusim, Ricardo De Genova, René Broos, Daniel P. Sophiea, "Lightweight Cellular Plastics", Advanced Materials, vol.23 issue 12 (2000), 1779-1789.

10. Tomasko, David L., Hongbo Li, Dehua Liu, Xiangmin Han, Maxwell J. Wingert, L. James Lee, Kurt W. Koelling, "A Review of CO2 Applications in the Processing of Polymers", Industrial Engineering Chemical Research, vol.42, 2003, 6431-6456.

11. Lee, S. T. editor, Foam Extrusion: Principles and Practice, Technomic Pub. Comp., Pennsylvania, USA, 2000.

12. Latartech Holdings LTD, http://www.latartech.com/page7.phtml, Accessed: April 2006.

13. Maio, E. Di, G. Mensitieri, G., S. Iannace, L. Nicolais, W. Li, R.W. Flumerfelt, "Structure Optimization of Polycaprolactone Foams by Using Mixtures of $\mathrm{CO}_{2}$ and $\mathrm{N}_{2}$ as Blowing Agents", Polymer Engineering and Science, vol.45, 2005, 432-441.

14. Beechem, Thomas, Khalid Lafdi, Ahmed Elgafy, "Bubble Growth Mechanism in Carbon Foams", Carbon, vol. 43, 2005, 1055-1064.

15. Pop-Iliev, Remon, Fangyi Liu, Guobin Liu, Chul B. Park, "Rotational Foam Molding of Polypropylene with Control of Melt Strength", Advances in Polymer Technology, vol. 22, 2003, 280-296.

16. Bonzom; Albert (Sausset-les-Pins, FR); Crepaux; Alain P. (Lavera, FR); Moutard; AnneMarie E. J., French Patent \# 77 37747, 1977.

17. Kearns; Kristen M., United States Patent 5,961,814, Oct. 51999. 
18. Rogers, Derren, Kenneth, World Intellectual Property Organization, WO 03/072348 A1, 2003.

19. Campbell, D., R.A. Pethrick, J.R. White, Polymer Characterization: Physical Techniques, $2^{\text {nd }}$ Edition, Stanley Thornes Pub. Ltd., Cheltenham, UK, 2000.

20. Rand, B., "Pitch precursors for advanced carbon materials - Rheological aspects", Fuel vol.66, 1987, 1491-1503.

21. American National Standards Institute, ASTM D3104-99 (2005).

22. Khandare, Pravin M. Characterization of Mesophase Pitch Materials from Petroleum and Coal-Derived Precursors: Kinetics and Rheology at Elevated Temperatures. Ph.D. Dissertation, West Virginia University, 1995.

23. Rosato, Dominick V., Plastics Processing Data Handbook, Chapman \& Hall, London, UK, 1997.

24. Scanchez, Isaac C., 'Statistical Thermodynamics of Polymer Solutions", Macromolecules, vol 11, issue 6, 1978, 1145-1156.

25. Garg, Ashok, Esin Gulari, Charles W. Manke. "Thermodynamics of Polymer Melts Swollen with Supercritical Gases", Macromolecules, vol. 27, 1994, 5643-5653.

26. Royer, Joseph R, Joseph M. DeSimone, Saad A. Khan, "High-Pressure Rheology and Viscoelastic Scaling Predictions of Polymer Melts Containing Liquid and Supercritical Carbon Dioxide", Journal of Polymer Science, vol. 39, 2001, 3055-3066.

27. Danner, Ronald P., Martin S. High, Handbook of Polymer Solution Thermodynamics, American Institute of Chemical Engineers, New York, 1993.

28. Gerhardt, Linda J., Ashok Garg, Charles W. Manke, Esin Gulari, “ConcentrationDependent Visoelastic Scaling Models for Polydimethylsiloxane Melts with Dissolved Carbon Dioxide", Journal of Polymer Science: Part B: Polymer Physics, vol.35, 1998, 1911-1918.

29. Flory, P. J., "Principles of Polymer Chemistry”, Cornell University Press, Ithaca, N.Y., 1953, Chapter 12.

30. William, M. L., R.F. Landel, J.D. Ferry, "The Temperature dependence of relaxation mechanisms in amorphous polymers and other glass-forming liquids", Journal of the American Chemical Society, vol.77, 1955, 3701-3707.

31. Doolittle, A. K., "studies in Newtonian Flow. II. The Dependence of the Viscosity on Freespace", Journal of Applied Physics, vol.22, 1951, 147.

32. Chow, T.S., "Molecular Interpretation of the Glass Transition Temperature of PolymerDiluent Systems", Macromolecules, vol.13, 1980, 362-364.

33. Kwag, Choongyong, Charles W. Manke, Esin Gulari, "Effects of Dissolved Gas on Viscoelastic Scaling and Glass Transition Temperature of Polystyrene Melts", Industrial Engineering Chemical Research, vol.40, 2001, 3048-3052.

34. Royer, Joseph R., Yvon J. Gay, Joseph M. Desimone, Saad A. Khan, "High-Pressure Rheology of Polystyrene Melts Plasticized with CO2: Experimental Measurement and 
Predictive Scaling Relationship", Journal of Polymer Science: Part B: Polymer Physics, vol.28, 2000, 3168-3180.

35. Garland, Carl W., Joseph W. Nibler, David P. Shoemaker, Experiments in Physical Chemistry 7ed, McGraw-Hill Comp., New York, 1996.

36. Rand, B., "The Thermal Processing and Rheological Behavior of Pitch", Design and Control of Structure of Advanced Carbon Materials for Enhanced Performance. Kluwer Academic Publishers, Netherlands, 2001, 135-150.

37. Pierson, H.O, Handbook of Carbon, Graphite, Diamond and Fullerenes - Properties, Processing and Applications, William Andrew Publishing, Noyes, New Jersey, 1993.

38. Lewis, Richard J., Sr, Hawley's Condensed Chemical Dictionary, 14th Ed., Wiley \& Sons, 2002

39. Fair, W.F. Jr., "The Asphalt Symposium Part I", Industrial Engineering \& Chemistry, vol.55, 1966, 26-27.

40. Traceski, Frank T., "Assessing Industrial Capabilities for Carbon Fiber Production", Acquisition Review Quarterly, Spr. 1999, 179-194.

41. Speight, James G., Handbook of Petroleum Product Analysis, Wiley \& Sons, Inc., Hoboken, New Jersey, 2002.

42. Tadmor, Zehev, and Costas G. Gogos, Principles of Polymer Processing, John Wiley \& Sons, Inc., New York, 1979.

43. Hegde, Raghavendra R., Atul Dahiya, M. G. Kamath, Carbon Fibers, http://www.engr.utk.edu/mse/pages/Textiles/CARBON\%20FIBERS.htm, updated Apr. 2004, accessed Feb. 2006.

44. Briggs, D.K.H., "The Surface Tension of Coal Tar Pitch", Fuel, vol.43, 1964, 439-43.

45. Schwarz, Barry J., John M Prausnitz, "Solubilities of Methane, Ethane, and Carbon Dioxie in Heavy Fossil-Fuel Fractions", Industrial Engineering and Chemical Research, vol. 26, 1987, 2360-2366.

46. NIST Standard Reference Database 69, June 2005 Release: NIST Chemistry WebBook. http://webbook.nist.gov/chemistry/.

47. Deo, Milind D., Chia J. Wang, and Francis V. Hanson, "Solubility of Carbon Dioxide in Tar Sand Bitumen: Experimental Determination and Modeling", Industrial Engineering and Chemical Research, vol.30, 1991, 532-536.

48. Riazi, M.R., and J.H. Vera, "Method to Calculated the Solubilities of Light Gases in Petroleum and Coal Liquid Fractions on the Basis of their P/N/A Composition", Industrial Engineering and Chemical Research, vol.44, 2005, 186-192.

49. Carpenter, Stephen P., Development of a Constrained Piston Method for Compression Testing of Carbon Foams. Masters Thesis, West Virginia University 2005.

50. Lide, David R., editor, CRC Handbook of Chemistry and Physics 1997ed, 1997.

51. Park, Chul B., Lewis K Cheung, "A Study of Cell Nucleation in the Extrusion of Polypropylene Foams", Polymer Engineering and Science, vol.31, no.1, 1997, 1-10. 
52. Dean, John A., The Analytical Chemistry Handbook, New York, McGraw Hill, Inc., 1995, 15.1-15.5.

53. Pungor, Erno, A Practical Guide to Instrumental Analysis, Boca Raton, Florida, 1995, 181-191.

54. Skoog, Douglas A., F. James Holler and Timothy Nieman, Principles of Instrumental Analysis, Fifth Edition. New York, 1998, 905-908.

55. Berins, Micheal L. editor, SPI Plastics Engineering Handbook of the Society of the Plastics Industry, Inc. 5th Ed., Kluwer Academic Publishers, Boston, USA, 1991.

56. Landrock, A.H. editor, Handbook of Plastic Foams, William Andrew Publishing/Noyes, 1995.

57. Evans, David editor, Handbook of Polymer Foams, Rapra Technology Limited, Shawbury, UK, 2004.

58. American Petroleum Institute Technical Data Book: Petroleum Refining, Port City Press, Baltimore, Md, 1966. 


\section{Appendix A: Glossary}

As cellular materials developed, general terminology evolved, but in many cases it was poorly defined. Precise terminology was needed to describe the characteristics and processes for foaming. Much of the terminology for foam was barrowed from the polymers industry while that of heat treating carbon came from the ceramics industry. Below are listed some of the words and terms that need to be clearly defined as they are used in this document. Definitions are used directly from the reference noted.

\section{Air Stabilization}

Air stabilization is a process of heating pitch fiber and foam in the presences of oxygen to promote crosslinking and to remove volatiles present in the pitch, thereby increasing the softening point to above the carbonization point.

\section{Calcination}

Heating process from $600^{\circ} \mathrm{C}$ to $1600^{\circ} \mathrm{C}$ under an inert atmosphere.

Cell

A single bubble in a foam matrix, which can be open or closed in nature.

\section{Cellular Solid}

An assembly of cells with solid edges or faces, packed together so that they fill space ${ }^{5}$.

Chemical Blowing Agent (CBA)

Chemical blowing agents are compounds that liberate gas(es) under the foam processing conditions, either due to thermal decomposition or chemical reaction ${ }^{57}$.

\section{Closed-cell Foam}

Individual cells are noninterconnecting. The cells have no access to the surrounding air or fluids; cells are not communicating ${ }^{23}$.

\section{Foam}

Foam, also referred to as expanded or sponge plastics, generally consist of a minimum of two phases, a solid-polymer matrix and a gaseous phase derived from a blowing agent. The solid phase may be inorganic, organic or organometallic ${ }^{56}$.

\section{Foamed collapse}

Inadvertent densification of foam or cellular plastic during fabrication; it is caused by the breakdown of cell structure ${ }^{23}$.

Glass Transition Temperature $\left(T_{g}\right)$

The point at which an amorphous glassy state transitions to a mobile rubbery state ${ }^{19}$ 
Green Foam

A carbon foam that made from pitch which has net been stabilized.

Mettler Softening Point

Mettler softening point was adopted as a standard test method for the determination of the softening point of pitches, ASTM D3104-99 (2005). This test method covers the determination of the softening point of pitches in the range of 50 to $180 \mathrm{C}$, and gives results comparable to those obtained by Test Method D 2319 (80C).1.2 above 176F. The values stated in SI units are to be regarded as the standard ${ }^{21}$.

Open-cell Foam

Individual cells are generally interconnected; pores are accessible to surrounding air or fluids. This construction is called reticulated or web-like ${ }^{23}$.

Physical Blowing Agent (PBA)

Physical blowing agents provide gas for the expansion of polymers by undergoing a change in physical state. The change may involve volatilization (boiling) of a liquid or the release of a compressed gas to atmospheric pressure after it has been incorporated into a polymer, generally at elevated temperature and/or pressure ${ }^{57}$.

Pitch

A highly viscous organic liquid that appears solid at room temperature and is composed of numerous macro-organic molecules that are cyclic and/or aromatic in nature.

Softening Point (SP)

In document, used to refer to the Mettler Softening Point. See Metler Softening Point. 


\section{Appendix B: Sample Calculations}

Mettler Glass Transition Correlation for a $111^{\circ} \mathrm{C} \mathrm{SP}$ pitch:

$$
T_{g}=x T_{M S}=(0.84 \pm 0.02)\left(111^{\circ} \mathrm{C}+273\right)=322.6 \pm 6.5^{\circ} \mathrm{K}=49.6 \pm 6.5^{\circ} \mathrm{C}
$$

William-Ferry-Landle Equation for a $180^{\circ} \mathrm{C} \mathrm{SP}$ pitch at $180^{\circ} \mathrm{C}$ with reference viscosity at $170^{\circ} \mathrm{C}$ :

$$
\begin{aligned}
& \eta(T)=\eta_{s} 10^{\left(-\frac{c_{1}\left(T-T_{s}\right)}{c_{2}+T-T_{s}}\right)} \Rightarrow \eta\left(180^{\circ} \mathrm{C}\right)=(2275 \mathrm{~Pa}-\mathrm{sec})^{*} 10^{\left(-\frac{2.54(180-170)}{93.3+180-170}\right)}=986 \mathrm{~Pa}-\mathrm{sec} \\
& \text { Actual } \eta\left(180^{\circ} \mathrm{C}\right)=937 \mathrm{~Pa}-\mathrm{sec}
\end{aligned}
$$

Chow Equation for $\mathrm{Tg}$ of $49.7^{\circ} \mathrm{C}$ and with mass percent of $1 \% \mathrm{CO}_{2}$ diluent:

$$
\begin{gathered}
\theta=\frac{M_{p}}{z M_{d}} \frac{\omega}{1-\omega}=\frac{81 \mathrm{~g} / \mathrm{mol}}{1 * 44 \mathrm{~g} / \mathrm{mol} \operatorname{l}-0.01} \frac{0.01}{1-0.0186} \\
\Psi=\frac{z R_{g}}{M_{p} \Delta C_{p}}=\frac{1 * 8.314 \mathrm{~J} / \mathrm{mol}-\mathrm{K}}{81 \mathrm{~g} / \mathrm{mol} * 0.088 \mathrm{~J} / \mathrm{gK}}=1.02 \\
T_{g}=T_{g o} \exp \Psi[(1-\theta) \ln (1-\theta)+\theta \ln (\theta)]=49.7^{\circ} \mathrm{C} \exp 1.02[(1-0.0186) \ln (1-0.0186)+0.0186 \ln (0.0186)] \Rightarrow \\
T_{g}=38^{\circ} \mathrm{C}
\end{gathered}
$$

Surface Tension from Briggs correlation for a $180^{\circ} \mathrm{C}$ SP pitch with a density of $10.32 \mathrm{~g} / \mathrm{cm}^{3}$ :

$$
\gamma=18.4 \rho^{4}=18.4 *(1.32)^{4}=55.9 \text { Dynes } / \mathrm{cm}
$$




\section{Appendix C: Raw Viscosity Data}

\begin{tabular}{|c|c|c|c|c|c|c|c|c|c|c|c|}
\hline & Name & $\begin{array}{c}\text { Position } \\
(\mathrm{mm})\end{array}$ & $\begin{array}{c}\text { Speed } \\
(\mathrm{mm} / \mathrm{min})\end{array}$ & $\begin{array}{c}\text { Pressure } \\
(\mathrm{MPa})\end{array}$ & $\begin{array}{c}\text { Shear rate } \\
(/ \mathrm{s})\end{array}$ & $\begin{array}{c}\mathrm{L} / \mathrm{D} \\
\text { (Left) } \\
\end{array}$ & $\begin{array}{l}\mathrm{D} \text { (Left) } \\
(\mathrm{mm})\end{array}$ & $\begin{array}{c}\text { Shear stress } \\
(\mathrm{kPa})\end{array}$ & $\begin{array}{c}\text { Shear viscosity } \\
(\text { Pa.s })\end{array}$ & $\begin{array}{l}\text { TDie } \\
\left({ }^{\circ} \mathrm{C}\right) \\
\end{array}$ & $\mathrm{n}$ \\
\hline \multicolumn{12}{|c|}{$160^{\circ} \mathrm{C}$} \\
\hline 1 & Run 1 & 198.04 & 0.33 & 5.68 & 10.04 & 16 & 1 & 88.75 & 8633.98 & 159.99 & 0.91 \\
\hline 2 & Run 1 & 195.76 & 0.75 & 11.33 & 22.62 & 16 & 1 & 177.05 & 7645.41 & 159.94 & 0.91 \\
\hline 3 & Run 1 & 193.27 & 1.71 & 24.04 & 51.28 & 16 & 1 & 375.62 & 7155.21 & 160.03 & 0.91 \\
\hline 4 & Run 1 & 190.32 & 3.87 & 46.16 & 115.97 & 16 & 1 & 721.21 & 6074.52 & 160.05 & 0.91 \\
\hline 5 & Run 1 & 189.71 & -104.89 & 65.3 & -3146.71 & 16 & 1 & 1020.36 & -324.26 & 160.05 & 1 \\
\hline 6 & Run 1 & 189.49 & -147.82 & 65.24 & -4434.45 & 16 & 1 & 1019.43 & -229.89 & 160.05 & 1 \\
\hline 7 & Run 1 & 188.81 & -208.06 & 65.2 & -6241.89 & 16 & 1 & 1018.7 & -163.2 & 160.05 & 1 \\
\hline 8 & Run 1 & 185.94 & 3.86 & 58.23 & 115.94 & 16 & 1 & 909.91 & 7665.87 & 160.02 & 0.91 \\
\hline 9 & Run 1 & 183.43 & 1.71 & 42.78 & 51.22 & 16 & 1 & 668.51 & 12749.35 & 160.02 & 0.91 \\
\hline 10 & Run 1 & 181.13 & 0.75 & 15.87 & 22.56 & 16 & 1 & 247.91 & 10733.31 & 160 & 0.91 \\
\hline 11 & Run 1 & 179.3 & 0.33 & 5.85 & 9.98 & 16 & 1 & 91.47 & 8952.04 & 159.97 & 0.91 \\
\hline \multicolumn{12}{|c|}{$170^{\circ} \mathrm{C}$} \\
\hline 12 & Run 2 & 215.31 & 0.33 & 1.51 & 9.92 & 16 & 1 & 23.56 & 2275.98 & 170.19 & 0.85 \\
\hline 13 & Run 2 & 213.12 & 0.76 & 3.12 & 22.65 & 16 & 1 & 48.77 & 2063 & 170.17 & 0.85 \\
\hline 14 & Run 2 & 210.64 & 1.71 & 6.15 & 51.28 & 16 & 1 & 96.09 & 1795.68 & 170.17 & 0.85 \\
\hline 15 & Run 2 & 207.7 & 3.86 & 13.1 & 115.82 & 16 & 1 & 204.66 & 1693.18 & 170.17 & 0.85 \\
\hline 16 & Run 2 & 203.53 & 8.83 & 26.24 & 264.76 & 16 & 1 & 410.01 & 1483.92 & 170.19 & 0.85 \\
\hline 17 & Run 2 & 196.32 & 20.06 & 41.77 & 601.71 & 16 & 1 & 652.65 & 1039.34 & 170.17 & 0.85 \\
\hline 18 & Run 2 & 192.07 & 8.83 & 29.46 & 264.76 & 16 & 1 & 460.35 & 1666.1 & 170.19 & 0.85 \\
\hline 19 & Run 2 & 189.1 & 3.87 & 14.79 & 115.97 & 16 & 1 & 231.16 & 1909.97 & 170.14 & 0.85 \\
\hline 20 & Run 2 & 186.55 & 1.71 & 6.69 & 51.25 & 16 & 1 & 104.47 & 1953.32 & 170.03 & 0.85 \\
\hline 21 & Run 2 & 184.25 & 0.76 & 3.17 & 22.65 & 16 & 1 & 49.53 & 2095.29 & 170.06 & 0.85 \\
\hline 22 & Run 2 & 182.05 & 0.33 & 1.53 & 10.01 & 16 & 1 & 23.85 & 2283.13 & 170.09 & 0.85 \\
\hline
\end{tabular}




\begin{tabular}{|c|c|c|c|c|c|c|c|c|c|c|c|}
\hline & Name & $\begin{array}{l}\text { Position } \\
(\mathrm{mm})\end{array}$ & $\begin{array}{c}\text { Speed } \\
(\mathrm{mm} / \mathrm{min})\end{array}$ & $\begin{array}{c}\text { Pressure } \\
(\mathrm{MPa})\end{array}$ & $\begin{array}{c}\text { Shear rate } \\
(/ \mathrm{s})\end{array}$ & $\begin{array}{c}\mathrm{L} / \mathrm{D} \\
(\mathrm{Left})\end{array}$ & $\begin{array}{l}\mathrm{D}(\mathrm{Left}) \\
(\mathrm{mm})\end{array}$ & $\begin{array}{c}\text { Shear stress } \\
(\mathrm{kPa})\end{array}$ & $\begin{array}{c}\text { Shear viscosity } \\
\text { (Pa.s) }\end{array}$ & $\begin{array}{l}\text { TDie } \\
\left({ }^{\circ} \mathrm{C}\right) \\
\end{array}$ & $\mathrm{n}$ \\
\hline \multicolumn{12}{|l|}{$180^{\circ} \mathrm{C}$} \\
\hline 23 & Run 3 & 177.65 & 0.33 & 0.64 & 9.98 & 16 & 1 & 10.01 & 924.66 & 180.14 & 0.75 \\
\hline 24 & Run 3 & 175.37 & 0.76 & 2.26 & 22.65 & 16 & 1 & 35.32 & 1438.3 & 180.03 & 0.75 \\
\hline 25 & Run 3 & 172.88 & 1.71 & 4.69 & 51.28 & 16 & 1 & 73.25 & 1317.43 & 180.06 & 0.75 \\
\hline 26 & Run 3 & 170.45 & 3.86 & 4.09 & 115.91 & 16 & 1 & 63.87 & 508.16 & 180.06 & 0.75 \\
\hline 27 & Run 3 & 167.26 & 8.82 & 8.39 & 264.61 & 16 & 1 & 131.11 & 456.99 & 180.05 & 0.75 \\
\hline 28 & Run 3 & 161.06 & 20.06 & 16.45 & 601.86 & 16 & 1 & 257.01 & 393.84 & 180.05 & 0.75 \\
\hline 29 & Run 3 & 158.26 & 8.83 & 8.55 & 264.76 & 16 & 1 & 133.52 & 465.11 & 180.05 & 0.75 \\
\hline 30 & Run 3 & 155.33 & 3.86 & 4 & 115.94 & 16 & 1 & 62.55 & 497.56 & 180.03 & 0.75 \\
\hline 31 & Run 3 & 153.91 & 1.71 & 2.06 & 51.34 & 16 & 1 & 32.24 & 579.15 & 180.03 & 0.75 \\
\hline 32 & Run 3 & 151.61 & 0.75 & 1.07 & 22.59 & 16 & 1 & 16.71 & 681.99 & 180 & 0.75 \\
\hline 33 & Run 3 & 150.67 & 0.33 & 0.66 & 10.01 & 16 & 1 & 10.31 & 949.42 & 179.98 & 0.75 \\
\hline \multicolumn{12}{|l|}{$190^{\circ} \mathrm{C}$} \\
\hline 34 & Run 4 & 146.67 & 0.33 & 0.43 & 9.95 & 16 & 1 & 6.67 & 585.22 & 190.1 & 0.63 \\
\hline 35 & Run 4 & 144.4 & 0.76 & 0.57 & 22.65 & 16 & 1 & 8.91 & 343.43 & 190.12 & 0.63 \\
\hline 36 & Run 4 & 141.93 & 1.71 & 0.88 & 51.28 & 16 & 1 & 13.81 & 235.04 & 190.12 & 0.63 \\
\hline 37 & Run 4 & 139.04 & 3.87 & 1.57 & 115.97 & 16 & 1 & 24.54 & 184.74 & 190.12 & 0.63 \\
\hline 38 & Run 4 & 136.44 & 8.82 & 3 & 264.61 & 16 & 1 & 46.81 & 154.44 & 190.12 & 0.63 \\
\hline 39 & Run 4 & 129.2 & 20.06 & 6.04 & 601.83 & 16 & 1 & 94.37 & 136.88 & 190.12 & 0.63 \\
\hline 40 & Run 4 & 126.07 & 8.82 & 2.99 & 264.67 & 16 & 1 & 46.79 & 154.33 & 190.14 & 0.63 \\
\hline 41 & Run 4 & 123.06 & 3.87 & 1.57 & 115.97 & 16 & 1 & 24.56 & 184.87 & 190.14 & 0.63 \\
\hline 42 & Run 4 & 120.56 & 1.71 & 0.89 & 51.25 & 16 & 1 & 13.95 & 237.63 & 190.04 & 0.63 \\
\hline 43 & Run 4 & 118.58 & 0.76 & 0.58 & 22.65 & 16 & 1 & 9.11 & 351.11 & 190.02 & 0.63 \\
\hline 44 & Run 4 & 117.51 & 0.33 & 0.45 & 10.01 & 16 & 1 & 6.95 & 606.33 & 190.04 & 0.63 \\
\hline
\end{tabular}


Appendix D: Proximate Analysis Raw Data

\begin{tabular}{|c|c|c|c|c|c|c|c|c|c|c|c|}
\hline Name & $\begin{array}{c}\text { Crucible } \\
\text { Mass }\end{array}$ & $\begin{array}{l}\text { Initial } \\
\text { Mass }\end{array}$ & Location & Method & Analysis Date & $\begin{array}{c}\text { Moisture } \\
\text { Mass }\end{array}$ & $\begin{array}{c}\text { Volatile } \\
\text { Mass }\end{array}$ & $\begin{array}{c}\text { Ash } \\
\text { Mass }\end{array}$ & Moisture & Volatile & Ash \\
\hline $110^{\circ} \mathrm{C} \mathrm{S} \mathrm{P} \mathrm{Pitch} 1$ & 15.502 & 1.0093 & 1 & htv & $\begin{array}{c}3 / 21 / 2006 \\
15: 58\end{array}$ & 1.0026 & 0.5465 & -0.0003 & 0.66 & 45.19 & -0.03 \\
\hline $110^{\circ} \mathrm{C} \mathrm{S} \mathrm{P} \mathrm{Pitch} 2$ & 13.646 & 1.0703 & 2 & htv & $\begin{array}{c}3 / 21 / 2006 \\
15: 58\end{array}$ & 1.0639 & 0.5819 & 0.0011 & 0.60 & 45.04 & 0.10 \\
\hline $110^{\circ} \mathrm{C} \mathrm{S} \mathrm{P} \mathrm{Pitch} 3$ & 14.304 & 1.0793 & 3 & htv & $\begin{array}{c}3 / 21 / 2006 \\
15: 58\end{array}$ & 1.0787 & 0.5880 & 0.0006 & 0.06 & 45.46 & 0.06 \\
\hline & & & & & Average & 1.0484 & 0.5721 & 0.0005 & 0.44 & 45.23 & 0.04 \\
\hline & & & & & STD & 0.0403 & 0.0224 & 0.0007 & 0.33 & 0.21 & $\mathbf{0 . 0 7}$ \\
\hline
\end{tabular}

\begin{tabular}{|c|c|c|c|c|c|c|c|c|c|c|c|}
\hline $180^{\circ} \mathrm{C} \mathrm{S}$ P Pitch 1 & 15.652 & 1.1839 & 4 & htv & $\begin{array}{c}3 / 21 / 2006 \\
15: 58 \\
\end{array}$ & 1.1783 & 0.8038 & 0.0019 & 0.48 & 31.63 & 0.16 \\
\hline $180^{\circ} \mathrm{C} \mathrm{S}$ P Pitch 2 & 13.724 & 1.1647 & 5 & htv & $\begin{array}{c}3 / 21 / 2006 \\
15: 58\end{array}$ & 1.1646 & 0.7928 & 0.0021 & 0.00 & 31.92 & 0.18 \\
\hline $180^{\circ} \mathrm{C}$ S P Pitch 3 & 14.045 & 1.0843 & 6 & htv & $\begin{array}{c}3 / 21 / 2006 \\
15: 58\end{array}$ & 1.0833 & 0.7380 & 0.0020 & 0.09 & 31.85 & 0.18 \\
\hline & & & & & Average & 1.1421 & 0.7782 & 0.0020 & 0.19 & 31.80 & 0.17 \\
\hline & & & & & STD & 0.0514 & 0.0352 & 0.0001 & 0.26 & 0.15 & 0.01 \\
\hline
\end{tabular}

